\title{
2. Topographie und Architektur der Theodosianischen Landmauer
}

\author{
2.1. Zur Frage des Theodosianischen Baukonzepts
}

\subsubsection{Der nördliche Verlauf der Theodosianischen Mauer und die Mauer der sog. XIV. Region}

Der nördliche Verlauf der Theodosianischen Mauer bzw. ihr Anschluß an die Blachernen-Mauer beschäftigt die Forschung seit dem 19. Jahrhundert. ${ }^{39}$ Es wird heute allgemein angenommen, daß die Theodosianische Landmauer in Höhe von Tekfur Sarayı mit einer früheren Mauer, die bereits im 4. Jahrhundert existierte, zusammentraf. ${ }^{40}$ Man verbindet nämlich einige Mauerreste, die von Tekfur Sarayı ausgehen, mit einer Mitteilung der Notitia urbis Constantinopolitanae, wonach die außerhalb der Stadt gelegene XIV. Region eine eigene Unfassungsmauer besaß. ${ }^{41}$ Diese Nachricht wurde bereits von Petrus Gyllius auf

39 Paspatis, Meletai, 92, nahm an, daß die Theodosianische Mauer ab Tekfur Sarayı nach Norden umbiegend in Richtung Balat verlaufen sei. Nach Mordtmann, Esquisse, 11, verzweigte sich die Mauer ab Tekfur Sarayı einmal in Richtung Nordwesten und zum anderen in Richtung Nordosten, wofür unhaltbare Datierungen vorgeschlagen wurden. Für eine Diskussionen siehe zunächst Meyer-Plath/Schneider, Landmauer, 100-102 (Schneider), und Dirimtekin, İstanbul'un Fethi, 143-146. Weitere diesbezügliche Ansichten werden unten behandelt.

40 Van Millingen, Walls, 115; Meyer-Plath/Schneider, Landmauer, 3, 100-104 (Schneider); vgl. Schneider, Regionen, 158. - Müller-Wiener, Topographie, 301: „das bereits in der Antike selbständige und auch in konstantinischer Zeit noch weit vor der neugegründeten Stadt liegende Siedlungsgebiet Blachernai besitzt bereits im A. 4. Jh. einen eigenen Befestigungsring, dessen Verlauf mit Ausnahme kurzer Stücke im Hof des Tekfur Sarayı, bei Mumhane sowie im sog. Anemas-Gefängnis und vielleicht bei Hag. Deme-

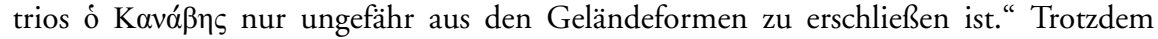
bezeichnete Müller-Wiener, ebd., 244, Abb. 275, durch schwarze Schraffur die Reste am Tekfur Sarayı als theodosianisch. Siehe dazu die kritischen Bemerkungen von Mango, Fourteenth Region, 3, Anm. 11; ders., Mystère, 451.

41 Notitia, 240-241: „Regio sane licet in urbis quartadecima numeretur parte, tamen quia spatio interiecto diuisa est, muro proprio uallata alterius quodammodo speciem ciuitatis ostendit. Est uero progressis a porta modicum situ planum, dextro autem latere in cliuum surgente usque ad medium fere plateae spatium nimis pronum; unde mare usque mediocris haec, quae ciuitatis continet partem, explicatur aequalitas. Continet in se: Ecclesiam. Palatium. Nympheum. Thermas. Theatrum. Lusorium. Pontem sublicium sive ligneum ..." (deutsche Übersetzung bei Berger, Regionen, 374). - Zur Datierung der Notitia siehe Anm. 129, 130, 143, 204. 
die Blachernen bezogen. ${ }^{42}$ Der überwiegend akzeptierte Verlauf und die Bauphasen der Blachernen-Mauer stellen sich folgenderweise dar (Abb. 33-35): ${ }^{43}$

1. Die teilweise erhaltene Mauer verlief von Tekfur Sarayı über Mumhane und den hinteren (östlichen) Teil der Blachernen-Substruktionen (sog. AnemasGefängnis). Dort bog sie oberhalb des Quartiers Lonca in Höhe der Emir Buhari Tekkesi nach Südosten ab und traf auf eine Mauer bei der DemetriosKirche ó Kavóß円 ऽ am Ufer des Goldenen Horns (Abb. 33). ${ }^{44}$ Dann richtete sie sich nach Südwesten und erreichte wieder Tekfur Sarayı. Der ummauerte Bezirk hatte demnach die Gestalt eines Dreiecks, dessen Spitze bei Tekfur Sarayı lag.

2. Dadurch verblieb aber zwischen den Blachernen-Substruktionen und dem Ufer des Goldenen Horns eine unbefestigte Zone, die wiederum durch einen zusätzlichen Mauerabschnitt in theodosianischer Zeit geschlossen wurde. Diese Mauer, die heute noch hinter den Theophilos-Türmen 16 bis 18 (Zweifronten-Wehrgang) zu erkennen ist und sowohl an der Stadt- als auch an der Feldseite Schießscharten aufwies, wird allgemein mit dem in den Schriftquellen erwähnten Pteron gleichgesetzt. ${ }^{45}$ Die durch das Kaiserpaar Markian (450-457) und Pulcheria errichtete und durch Justinian I. (527565) erneuerte Blachernen-Kirche ${ }^{46}$ lag demnach außerhalb des ummauerten Dreiecks an dessen Nordostseite, also zwischen dem sog. Pteron und dem genannten Mauerstück bei Hagios Demetrios ó Kaváß円s.

3. Unmittelbar nach der Awarenbelagerung (626) wurde die Uferzone zwischen Zweifronten-Wehrgang („Pteron“) und Demetrios-Kirche durch eine von Kaiser Herakleios (610-641) errichtete Ufermauer geschlossen, wodurch

42 Gyllius, Topographia, IV, 3, 196, und IV, 5, 203.

43 Siehe dazu im allgemeinen Meyer-Plath/Schneider, Landmauer, 100-104 (Schneider); Schneider, Blachernen, 81-120, bes.86-88; Dirimtekin, 14. Mıntıka, 197-210; Tsangadas, Fortifications, 22-32; Paribeni, Blacherne, 215-224. - Eine abweichende Rekonstruktion gab Speck, Bellum Avaricum, 37.

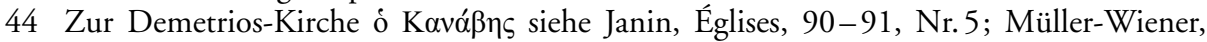
Topographie, 110.

45 Schneider/Meyer (= Meyer-Plath), Zweiter Vorbericht, 10 (Schneider); Meyer-Plath/

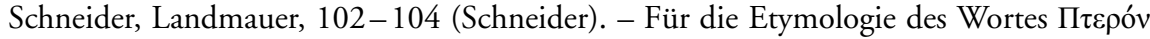
siehe Janin, Constantinople, 419, wo es mit „Aile“ = Flügel übersetzt wird. Tsangadas, Fortifications, 192, Anm. 80 notierte: „For our purposes Pteron-Ptera, is used to describe any enclosure that protects like wings. The term could easily apply to a two-sided fort, as we have here." Vgl. auch Procopius II 8, 8, 70/11-16, im Zusammenhang mit der

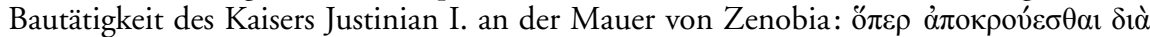

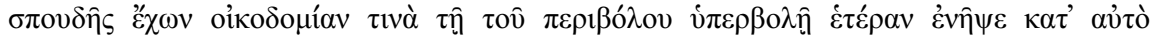

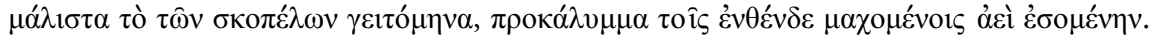

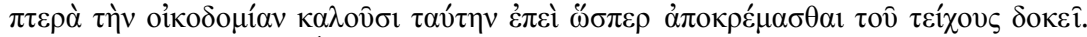

$46 \mathrm{Zu}$ dieser siehe Janin, Églises, 161-171, Nr. 17. 
nun auch die Blachernen-Kirche gesichert war. ${ }^{47} \mathrm{Im}$ Zusammenhang mit der Bulgarenbelagerung (813) wird von Kaiser Leon V. (813-820) ein Vorwerk errichtet (Abb. 35) ${ }^{48}$ welches das sog. Pteron schützt und auch die bis dahin außerhalb der Mauer gelegene Nikolaos-Kirche ${ }^{49}$ in die Befestigungsanlage einbezieht.

4. Durch Michael II. (820-829) und seinen Sohn Theophilos (829-842) werden das Leon-Vorwerk an der Südseite erweitert (Michael/Theophilos) und das sog. Pteron durch drei mächtige Türme verstärkt (Theophilos) sowie die Mauer renoviert. ${ }^{50}$

Der angenommene Verlauf der Mauer, vor allem des Abschnitts von den hin-

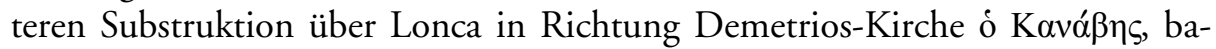
siert nicht auf gesicherten archäologischen Befunden, ${ }^{51}$ sondern vielmehr auf der schriftlich überlieferten Nachricht, wonach die Blachernen-Kirche noch im Jahre 626 außerhalb der Befestigung gestanden habe. Weiterhin setzt die heute überwiegend akzeptierte Entwicklung der Ummauerung des Blachernen-Gebiets voraus, daß die XIV. Region mit diesem identisch ist und die erhaltenen Mauerreste tatsächlich so alt sind, wie angenommen wird. Mango hat aber jüngst gezeigt, daß die XIV. Region nicht mit dem Blachernen-Viertel gleichgesetzt werden kann. ${ }^{52}$ Daher sollen folgende Fragen gestellt werden: 1.) Entstanden die im Blachernen-Gebiet zu beobachtenden Mauern (Reste im Hof von Tekfur Sarayl, Mumhane-Mauer, hintere Substruktionen, Abb. 33) bereits vor der Theodosianischen Landmauer? Und wenn nicht: Mit welcher Mauer trifft die Theodosianische Landmauer in Höhe von Tekfur Sarayı dann zusammen? - Die betreffenden Mauern sind heute zum Teil verschwunden oder unzugänglich, einige Teile wurden neuzeitlich intensiv restauriert. Obwohl etliche Probleme, welche die Blachernen-Mauer betreffen, nur durch archäologische Untersuchungen geklärt werden können, sollen im folgenden diese der vortheodosianischen Zeit zugewiesenen Mauerteile, die für die Frage des

47 Siehe Meyer-Plath/Schneider, Landmauer, 121-122 (Meyer-Plath).

48 Siehe Meyer-Plath/Schneider, Landmauer, 119 (Meyer-Plath).

$49 \mathrm{Zu}$ dieser siehe Janin, Églises, 369-371, Nr. 4.

50 Meyer-Plath/Schneider, Landmauer, 119-121 (Meyer-Plath); für die Inschriften ebd. 141, Nr. 64 a und b (Schneider).

51 Die heute noch an dieser Strecke aufragenden Mauerreste gehören zu den komnenischen Palast-Substruktionen, siehe Meyer-Plath/Schneider, Landmauer, 122-123 (MeyerPlath). - Siehe unten Abschnitt 3.1.

52 Mango, Fourteenth Region, 1-3, schlug zunächst eine Lage in der Nähe von Silahtarağa vor. Unlängst (Mango, Mystère, 449-455) lokalisierte er die XIV. Region mit überzeugenden Argumenten im heutigen Gebiet des Küçük Çekmece (Rhegion). - Bereits Verzone, Quartadecima, 174-177, äußerte Zweifel an der Gleichsetzung der Blachernen mit der XIV. Region und plazierte die XIV. Region im Hebdomon; dagegen jedoch Janin, Constantinople, 57-58; vgl. auch Mango, Addenda zu Study VIII, in: Studies, 6. 
nördlichen Verlaufs der Theodosianische Mauer von Bedeutung sind, zunächst in Augenschein genommen und anhand der Beschreibungen von Meyer-Plath/ Schneider überprüft werden.

Die von beiden Autoren beobachteten Reste der Mauer der sog. XIV. Region - hier also zunächst die Mauerreste, die vom Hof des Tekfur Sarayı ausgehen - liegen fast vollständig unter der Aufschüttung. Man ist bei ihrer Beurteilung überwiegend auf die Beschreibung von Meyer-Plath/Schneider und auf die alten Fotos angewiesen: ${ }^{53}$

Das ursprüngliche Mauerwerk besteht an der vorübergehend freigegrabenen Feldseite aus sorgfältig geschichteten $20-25 \mathrm{~cm}$ hohen Kalksteinquadern mit einem fünfschichtigen Ziegelband $(45 \mathrm{~cm})$. Von der an der Stadtseite freigelegten Nische unterhalb des Fußbodengewölbes des Wehrganges war an der Feldseite nichts zu bemerken. Der Mörtel hat trotz seiner ausreichenden Festigkeit ein sandiges Aussehen, da er wenig Ziegelbrocken und Kalk enthält (gleicher Mörtel findet sich auch in dem alten Teil des Anemas-Gefängnisses) ... Nahezu parallel mit dieser vortheodosischen Mauer ... läuft die über T. 96 hinaus verlängerte durch Schürfung erwiesene und nach Norden abbiegende theodosische Hauptmauer. Sie ist im oberen Teil durchweg erneuert. Unter dem Ostgiebel des Tekfur-Saray ist sie am besten erhalten. Hier weicht ihr $4,40 \mathrm{~m}$ breites Mauerwerk freilich durch breitere Fugen mit kleinen Auszwickungen etwas von dem sonstigen theodosischen Mauerwerk ab.

Die Autoren verglichen außerdem das Wehrgangsystem mit römischen Wehranlagen. ${ }^{54}$ Die von Turm 96 ausgehende Mauer ist bis zum Anschluß an die Südostecke von Tekfur Sarayı nicht mehr erhalten. Unterhalb des Ostgiebels ${ }^{55}$ lassen sich folgende Werte am Mauerwerk feststellen (Abb. 180): Unregelmäßige Quaderlagen (sechs bzw. elf bis zwanzig) mit breiten Fugen, fünfschichtige Ziegelbänder, Ziegelbandhöhe $53 \mathrm{~cm}$, Ziegelbreite 38 bis $40 \mathrm{~cm}$, Ziegelhöhe 4 bis $4,5 \mathrm{~cm}$, Mörtelhöhe 5,5 bis $6 \mathrm{~cm}$. Der Mörtel ist rötlich mit großen Ziegelbrocken. Meyer-Plath/Schneider haben darauf hingewiesen, daß die breiten Fugen vom theodosianischen Mauerwerk abweichen. Der gleiche Sachverhalt kann auch am Mörtel des Ziegelbands abgelesen werden, obwohl die Maße der Ziegel denen der theodosianischen fast entsprichen. ${ }^{56}$ Das Verhältnis von Ziegel-

53 Meyer-Plath/Schneider, Landmauer, 106 (Meyer-Plath).

54 Der über einer unteren Bogenreihe errichtete Wehrgang mit Bögen wird von Schneider/ Meyer, Zweiter Vorbericht, 4, vgl. Landmauer, 100 (Schneider), mit der Aurelianischen Mauer in Rom in Verbindung gebracht, doch kommen vergleichbare Bogenstellungen an den Kasematten der Vormauer vor. - Siehe meine Abb. 2.

55 Vgl. Meyer-Plath/Schneider, Landmauer, Taf. 44b und Faltplan 3. - Alle drei Faltpläne sind ohne Änderungen (aber verkleinert) diesem Buch als Beilagen beigefügt.

56 Vgl. Meyer-Plath/Schneider, Landmauer, 24 (Meyer-Plath). - Für eine Untersuchung der byzantinischen Ziegelmaße bzw. einen Vergleich mit den römischen Ziegeln siehe Ward-Perkins, Notes, 52-104; Deichmann, Bautechnik, 473-527; Mitchell/Aran/ Liggett, Construction, 467-487; Kâhya, Tuğla, 171-182; Ersen, Physical Evidence, 111; Bardill, Brickstamps, 27-28; vgl. auch Anm. 664. 
zu Mörtelhöhe beträgt am Mauerwerk der theodosianischen Zeit jedoch 1:1.57 Somit kann dieser Abschnitt nur unter Vorbehalt als theodosianisch gelten.

Mit der Mauer im Hof von Tekfur Sarayı fluchtet ein weiteres Mauerstück (die erwähnte Mumhane-Mauer), das über eine Länge von ca. $100 \mathrm{~m}$ erhalten ist und sich im Garten eines Privathauses in der Avcı Maslağı Sokak (Abb. 22, 33, 136, 137) befindet. Meyer-Plath/Schneider hatten zwischen den beiden halbrunden Bastionen noch die Flankenreste eines Turms an der Feldseite und einige Nischen an der Stadtseite registriert. Heute sind nur die nördliche Bastion und der Rest wohl eines Turmeingangs zu erkennen. Die übrigen Teile der Mauer, die stadtseitige Nischen aufwiesen, sind wegen der Überbauung bzw. der Aufschüttungen weder an der Stadt- noch an der Feldseite zugänglich. Die Autoren verbanden diese Mauer mit der zuvor erwähnten Mauer im Hof von Tekfur Sarayı und äußerten sich zum Mauerwerk wie folgt: ${ }^{58}$

Leider ist die Mauer an der Ostseite sehr verschüttet und an der Westseite ihrer Schale beraubt, so daß sich der ursprüngliche Mauercharakter kaum noch festzustellen läßt. Nach den wenigen erhaltenen Resten zu urteilen, bestand das Mauerwerk aus 25 bis $30 \mathrm{~cm}$ hohen Kalksteinquadern mit fünf- bis sechsschichtigen Ziegelbändern von 41 bis 63 bzw. 65 bis $70 \mathrm{~cm}$ Höhe.

Wie ebenfalls aus einer Abbildung ihres Buches hervorgeht, war die Schale an der Westseite zum Teil noch vorhanden und ist auch heute teilweise zu sehen (Abb. 22). ${ }^{59}$ Wenn man die Reste der Mauer mit dem von Meyer-Plath/ Schneider gezeichneten Mauerwerk des Mauerteils im Hof von Tekfur Sarayı vergleicht ${ }^{60}$ stellt man fest, daß in der Mumhane-Mauer weniger Quaderlagen vorkommen. Es muß natürlich immer im Auge behalten werden, daß wir die Mauer nur bruchstückhaft kennen, da unter den sichtbaren Teilen mehrere Meter im Schutt verborgen sind.

Die Mumhane-Mauer wurde von Meyer-Plath/Schneider in die vortheodosianische Zeit datiert. ${ }^{61}$ Am Mauerwerk lassen sich folgende Werte festgestellen: Im Bereich der nördlichen Bastion (unten) drei Quaderlagen (ca. $80 \mathrm{~cm}$ hoch) mit 25 bzw. $40 \mathrm{~cm}$ hohen Quadern und sechsschichtige Ziegelbänder, Ziegelbandhöhe 63 bzw. $70 \mathrm{~cm}$, Ziegelbreite $37-40 \mathrm{~cm}$, Ziegelhöhe ca. 5 bis $6,5 \mathrm{~cm}$, Mörtelhöhe 5 bis $7 \mathrm{~cm}$, heller Mörtel mit groben Ziegelbrocken (Abb. 137). Im Bereich der Turmflanke oben fünfschichtige Ziegelbänder, Ziegelbandhöhe 50 bzw. $53 \mathrm{~cm}$, Ziegelbreite 36 bzw. $38 \mathrm{~cm}$, Ziegelhöhe

57 Vgl. Meyer-Plath/Schneider, Landmauer, 24.

58 Meyer-Plath/Schneider, Landmauer, 108 (Meyer-Plath).

59 Meyer-Plath/Schneider, Landmauer, 109, Abb. 26, Taf. 50a und b.

60 Meyer-Plath/Schneider, Landmauer, 106 (Meyer-Plath), Abb. 24, Taf. 49a-c, Faltplan 3.

61 Meyer-Plath/Schneider, Landmauer, 100, Anm.3 (Schneider). 
$4,5 \mathrm{~cm}$, Mörtelhöhe 5 bis $6 \mathrm{~cm}^{62}$ Soweit sich erkennen läßt, scheinen die an der Mumhane-Mauer verwendeten Ziegel, die eine Breite bis zu $40 \mathrm{~cm}$ erreichen, größer als die spätrömischen Ziegel zu sein. ${ }^{63}$ Auch das bis zu $7 \mathrm{~cm}$ hohe Mörtelbett kann man nicht dem 4. Jahrhundert zuweisen. ${ }^{64}$ Schneider zufolge sei diese Mauer das älteste Beispiel mit Haustein und Ziegeldurchschuß in Konstantinopel. ${ }^{65}$ Die Tatsache, daß polychromes Sichtmauerwerk bzw. Schichtenmauerwerk an einer monumentalen Wehranlage erstmals an der Theodosianischen Landmauer begegnet ${ }^{66}$ läßt jedoch daran zweifeln, daß die Mumhane-Mauer der Theodosianischen Landmauer als Vorbild gedient haben soll. Mauerwerk und Baumaterial geben m. E. keine Anhaltspunkte, um die Mumhane-Mauer mit Sicherheit in die vortheodosianische Zeit bzw. in das 4. Jahrhundert datieren zu können, sondern diese weisen sie ganz im Gegenteil als nachtheodosianisch aus. Auch die beiden Bastionen wurden von MeyerPlath/Schneider mit römischen Wehranlagen verglichen, um damit die Früh-

62 Kâhya, Tuğla, 172, Tabelle 1, gibt die meistverwendete Ziegelhöhe mit $4,5 \mathrm{~cm}$ (Grenzwerte 3,9 bis 4,7 cm) und die Ziegelbreite mit 37,0 cm (Grenzwerte: 32,0 bis $39,0 \mathrm{~cm})$ an. Die Autorin nimmt an, daß die Mauer aus dem 4. Jahrhundert stammt.

63 An den datierbaren Teilen des Hippodroms kommen vergleichsweise schmalere Ziegel vor; siehe Bardill, Brickstamps, 118; vgl. auch Kâhya, Tuğla, 172, Tabelle 1.

64 Vgl. Mango, Byzanz, 12: „Während in den römischen Bauten der Kaiserzeit die Mörtelfugen schmäler als die Ziegel sind, verhält es sich bei den byzantinischen Gebäuden umgekehrt. Im 4. Jahrhundert ist das Verhältnis der Dicke von Ziegel und Mörtelfuge $1: 1 . “$

65 Schneider, Byzanz, 14: „Das älteste mir bekannte Beispiel, die vortheodosianische Mauer der 14. regio, zeigt abwechselnd 3 Steinlagen und 5 Ziegelbänder.“ Ebd., 2, nahm Schneider an, daß das Mauerwerk der Kirche von Karpos und Papylos mit Kalksteinblöcken und fünf Ziegelbändern (ebd., Taf. 2 und 3) einen etwas altertümlicheren Eindruck mache als die Landmauer von Konstantinopel und daher in das 4.15. Jahrhundert datiert werden sollte. Als Ziegelbreite gibt er in Anm. 1 ca. 0,37 m an. WardPerkins, Notes, 69: „The identification, though not implausible, is not certain, and there is no clear evidence of date other than that afforted by the surviving structures." Deichmann, Bautechnik, 525, setzte das Mauerwerk der Kirche in die erste Hälfte des 5. Jahrhunderts. - Die erste Bauphase der 1976/77 von Müller-Wiener im Beyazıt-Gebiet entdeckten Kirche zeigt ein Mauerwerk mit dreilagigem Ziegelband. Die Höhe des Ziegelbands beträgt $22 \mathrm{~cm}$, die Ziegelmaße sind $31 \times 31 \times 4 \mathrm{~cm}$. Der Autor datierte diese Bauphase in das 4. Jahrhundert und brachte die Reste mit der in den Quellen erwähnten Agathonikos-Kirche in Verbindung, jedoch mit Fragezeichen; siehe Müller-Wiener, Agathonikos, 13-20. Auch hier ist die Mörtelhöhe entschieden geringer als diejenige der Mumhane-Mauer. Die Identifikation dieses Befunds als Agathonikos-Kirche wurde von Berger, Untersuchungen, 584-586, 591-593, abgelehnt, der die Reste für die Homonoia-Kirche hält; vgl. auch Berger, Tauros, 24. Die Datierung des Schichtenmauerwerks an der vorjustinianischen Hagia Sophia schwankt zwischen dem 4. und 5. Jahrhundert und ist noch nicht abschließend geklärt, siehe Mathews, Churches, 14-15; zuletzt Bardill, Brickstamps, 55-56.

66 Siehe dazu Krischen, Landmauer, 5; Reusche, Sichtmauerwerk, 14; Deichmann, Wölbtechnik, 31. 
datierung der Mumhane-Mauer weiterhin zu begründen, ${ }^{67}$ doch kommen halbrunde Bastionen hier nicht zum ersten Mal in Konstantinopel vor. Sowohl die Landmauer als auch die Marmara-Seemauer besitzen solche Verstärkungen, wobei erstere von Meyer-Plath/Schneider selbst erwähnt wurden. ${ }^{68}$ Insofern entfällt auch dieses Argument für eine Frühdatierung.

Weitere Mauerteile, die sich hinter den großen Blachernen-Substruktionen befinden (Abb. 33-35), sind nicht zugänglich. ${ }^{69}$ Meyer-Plath/Schneider zufolge besteht das Mauerwerk der hinteren Substruktionen ebenfalls aus 25 bzw. $40 \mathrm{~cm}$ hohen Kalksteinquadern, die in der Regel dreilagig angeordnet sind. Die Höhe der fünfschichtigen Ziegelbänder beträgt $51 \mathrm{~cm} .{ }^{70}$ Soweit man der Beschreibung entnehmen kann, bestand eine gewisse Ähnlichkeit zwischen dem Mauerwerk der Mumhane-Mauer und dem der hinteren Substruktionen, wobei an der Mumhane-Mauer auch sechsschichtige Ziegelbänder nachweisbar sind.

Zwischen den Substruktionen und Turm 15 (südlicher Theophilos-Turm) erstreckt sich ein Mauerstück mit der ungewöhnlichen Stärke von maximal $14 \mathrm{~m}$, deren Stadt- und Feldseite unterschiedliches Mauerwerk aufweisen (Abb. 35, 138, 169). In ihrem zweiten Vorbericht waren Schneider/Meyer noch der Meinung, daß sich an der Stelle der 14-Meter-Mauer ursprünglich die südliche Fortsetzung des Zweifronten-Wehrgangs (sog. Pteron) befand: $:^{71}$ „Von der Treppe bis zum Anemas-Gefängnis (d.h. den Substruktionen) ist die alte Pteronmauer offenbar gestört und vom Turm $15 \mathrm{ab}$ in unbestimmbarer Zeit durch eine breitere Anlage ersetzt worden. ${ }^{\text {" } 72}$

67 Meyer-Plath/Schneider, Landmauer, 100, Anm.3 (Schneider).

68 Meyer-Plath/Schneider, Landmauer, 80 (Meyer-Plath). - Die Kurtine mitsamt der Bastion wurde beim Bau der Fevzi Paşa Caddesi abgerissen. Meyer-Plath, ebd., bemerkte dazu, daß die Bastion späteres Mauerwerk aufweise; für eine Abbildung siehe Krischen, Landmauer, Taf. 24, unteres Foto. - Die Reste der Bastion an der Marmara-Seemauer befinden sich an Kurtine 23/24 (nach Dirimtekin, Marmara, numeriert) kurz vor Ahırkapı (von der Serailspitze aus).

69 Detailplan des gesamten Abschnitts zwischen Blachernen-Substruktionen und Goldenem Horn bei Müller-Wiener, Topographie, 304, Abb. 347 (meine Abb. 35).

70 Meyer-Plath/Schneider, Landmauer, Taf.58. - Im September 2006 fand im Bereich dieser Mauer eine Ausgrabung durch die İstanbuler Archäologischen Museen statt. Es wurden die Gewölbe des obersten Wehrgangs, vermutlich in Höhe der siebten Kammer, geöffnet. Hier konnte man einen Teil der Tonnengewölbe und der Westmauer (mit vier Ziegelschichten) sowie der nach Osten weiterlaufenden Substruktionen beobachten.

71 Von Schneider/Meyer, Zweiter Vorbericht, Taf.2, wurde die Mauer, besonders die Rückseite etwa von Turm 15 bis zum Begin des Zweifronten-Wehrganges, dem 7. Jahrhundert zugeschrieben. Für die Feldseite wurde „unbestimmte Zeit“ notiert. Müller-Wiener, Topographie, 304, Abb. 347 (meine Abb. 35), datierte die Mauer in das 9. Jahrhundert.

72 Schneider/Meyer, Zweiter Vorbericht, 11, Anm 2. (Schneider). - Bei Meyer-Plath/ Schneider, Landmauer, 118 (Meyer-Plath) lautet die Aussage: „Die verwickelte Baubeschreibung der Mauern in Bereich der Türme Bl. 15-20 geschieht am besten in der 
Die 14-Meter-Mauer soll hier kurz in Augenschein genommen werden. An der südlichsten Partie der oberen Plattform ist ein abgebrochener Gewölberest zu erkennen (Abb. 139), der mit den hinteren Substruktionen in Verbindung steht. ${ }^{73}$ An dem Gewölberest ist heller Mörtel verwendet. Die Ziegelhöhe beträgt hier 3,5 cm, der Mörtel ist $5 \mathrm{~cm}$ dick. Die 14-Meter-Mauer muß an der Feldseite nachträglich verstärkt worden sein, da die Mauer der südlichen Erweiterung des Leon-Vorwerks, die auf Michael II. und Theophilos zurückgeht, hinter der feldseitigen Verstärkung verschwindet (Abb. 140) ${ }^{74}$ Beide Mauerteile wurden im oberen Bereich später einheitlich repariert (Abb. 138, 169). An der Mauerecke zwischen Turm 15 und 14-Meter-Mauer (Feldseite) erfolgte ebenfalls eine Verstärkung (Abb. 35). Obwohl die Feldseite der 14-Meter-Mauer mehrere Reparaturen aufweist, sind fünfschichtige Ziegelbänder noch erkennbar (Abb. 138). Die Werte sind wie folgt: Ziegelbandhöhe, $58 \mathrm{~cm}$, Ziegelbreite 33 bis $37 \mathrm{~cm}$, Ziegelhöhe 4 bis $5 \mathrm{~cm}$, Mörtelhöhe ca. 5 bis $7 \mathrm{~cm}$. In den untersten Partien wurden große Blöcke verwendet.

Die stadtseitige Schale der 14-Meter-Mauer verläuft hinter den TheophilosTürmen 15 und 16 und schließt an den Zweifronten-Wehrgang an (Abb. 35). Sie zeigt in den unteren Bereichen (südlich von Turm 15) nebeneinander angeordnete und später zugemauerte Nischen, wie sie auch an der MumhaneMauer vorkommen. Eine weitere Nische der unteren Reihe diente später als Eingang zu Turm 15. ${ }^{75}$ Etwas südlich von Turm 15 an der Stadtseite oberhalb der unteren Nische befindet sich noch eine zweite und etwas schmalere, die nicht näher untersucht werden konnte (Abb. 141). Die Werte dieser Mauer sind

ungefähren Reihenfolge ihrer Entstehung. Am ältesten ist vermutlich die unterste Hälfte des Mauerstücks hinter den Türmen Bl. 15-16.“ Von der alten „Pteronmauer“ ist aber keine Rede mehr.

73 Meyer-Plath/Schneider, Landmauer, 117 (Meyer-Plath) registrierten im Schnittpunkt der Kammerachse 2 mit den hinteren Substruktionen einen brunnenartigen Schacht, wodurch man in die Substruktionen gelangte.

74 Der Befund wurde von Meyer-Plath/Schneider, Landmauer, hinsichtlich der zeitlichen Einordnung gegensätzlich beurteilt. Schneider, 104: „Die Leomauer, deren ursprüngliche Gestalt indessen ohne größere Grabung nicht völlig zu klären ist, wurde unter Michael nach Süden etwas erweitert, sei es, daß die Mauer dort während der Belagerung durch den Gegenprätendenten Thomas beschädigt und während der Ruhepause 821/22 (Inschrift Nr. 64b) erneuert wurde, sei es, daß man bereits die Türme 15-18 zu bauen beabsichtigte und die Mauer nur deshalb verschob, weil man dazu Platz brauchte." Meyer-Plath, 121: „Nach der Erbauung der drei großen Türme [Türme 15-18] wurde im Zusammenhang mit der sich nach Westen vorschiebenden Mauerverbreiterung zwischen Bl. 15 und Anemasgefängnis, die vermutlich durch eine Palasterweiterung verursacht wurde, eine neue Südfront des Leovorwerks errichtet. Sie war im unteren Teil voll gemauert, darüber folgte eine überwölbte Schartenzone, die zugleich den Fußboden des Zinnenwehrgangs bildete. An der schmalen Westfront mit den Inschriften Nr. 64a und 64b ist eine Scharte mit kreuzgeschmücktem Deckstein erhalten."

75 Für die stadtseitigen Nischen siehe Meyer-Plath/Schneider, Landmauer, Taf. 61b. 
wie folgt (aufgenommen an der Stadtseite nördlich der hinteren Substruktionen und hinter Turm 16, Abb. 27b): Fünfschichtige Ziegelbänder, Ziegelbandhöhe $52 \mathrm{~cm}$, Ziegelbreite 32 bis $37 \mathrm{~cm}$, Ziegelhöhe 2,5 bis 3,5 cm, Mörtelhöhe 4 bis $6 \mathrm{~cm}$. Der Mörtel ist zum Teil rötlich mit großen Ziegelbrocken, wobei hier mehrere Reparaturen zu erkennen sind. An der Feldseite zwischen Turm 15 und 16 konnte ich folgende Werte aufnehmen: Ziegelbandhöhe $54 \mathrm{~cm}$, Ziegelbreite 31 bis $37 \mathrm{~cm}$, Ziegelhöhe 3,5 bis $5 \mathrm{~cm}$, Mörtelhöhe 4 bis $6 \mathrm{~cm}$ (dieser Teil wurde kürzlich intensiv renoviert). Die unterschiedlichen Ziegelmaße lassen vermuten, daß zahlreiche Ziegel als Spolienmaterial wiederverwendet worden sind.

Van Millingen hat auf seinem Sketch Plan (Abb. 34) eine Quermauer eingezeichnet, die von der 14-Meter-Mauer stadteinwärts verläuft (auf gleicher Flucht mit der Substruktions-Mauer vor der Emir Buhari Tekkesi) und die nördliche Grenze der hinteren Substruktionen markiert. Die heute im Garten eines Privathauses befindliche Mauer (Abb. 165) weist ebenfalls einen später zugemauerten Bogendurchgang auf, der in die hinteren Substruktionen führte. ${ }^{76}$ Während die obere Partie der Mauer auch hier mehrfach renoviert wurde und in schlechtem Zustand ist, sind in den unteren Bereichen fünfschichtige Ziegelbänder mit folgenden Werten noch teilweise zu sehen: Ziegelbreite $47 \mathrm{~cm}$, Ziegelhöhe 4 bis $6 \mathrm{~cm}$, Mörtelhöhe $6 \mathrm{~cm}$. An verschiedenen Stellen der Stadtseite der 14-Meter-Mauer kommen riesige Ziegel $(44 \times 70 \times 6$ bzw. $6,5 \mathrm{~cm})$ vor, die wahrscheinlich wiederverwendet sind. ${ }^{77}$ Diese Quermauer mit ihrem Zugang markiert die Nordgrenze der Substruktionen und scheint nichts mit der Mauer der sog. XIV. Region zu tun zu haben. Die Substruktionen erstrecken sich stadteinwärts und wurden, wie oben erwähnt, später, vor allem in komnenischer Zeit, erweitert. ${ }^{78}$

Meyer-Plath/Schneider bestimmten den Zweifronten-Wehrgang zwischen den Theophilos-Türmen 16 und 18 (Abb. 35) als ,nach seinem Mauerwerk aus theodosischer Zeit" stammend. ${ }^{79}$ An der Stadtseite sind die Mauern sehr ver-

76 Van Millingen, Walls, Sketch Plan of the Blachernae Quarter, gegenüber 115 (meine Abb. 34), siehe ebd. 117; vgl. Paspatis, Meletai, 92; Meyer-Plath/Schneider, Landmauer, Taf. 40; Müller-Wiener, Topographie, 304, Abb.347 (meine Abb. 35).

77 Deichmann, Bautechnik, 479, gibt Beispiele für römische Ziegelbauten, wo die Ziegel eine Seitenlänge von $64 \mathrm{~cm}$ und eine Höhe von $4-5 \mathrm{~cm}$ erreichen, wobei die Mörtelhöhe nur 3 bis $4 \mathrm{~cm}$ beträgt. Hingegen ist an der 14-Meter-Mauer ein hohes Mörtelbett zu erkennen.

78 Vgl. Van Millingen, Walls, 117; Meyer-Plath/Schneider, Landmauer, 122-123 (MeyerPlath).

79 Meyer-Plath/Schneider, Landmauer, 118 (Meyer-Plath); vgl. Foss, Fortifications, 66. Auch Müller-Wiener, Topographie, 304, Abb.347 (meine Abb. 35), markierte die betreffenden Teile als Mauerwerk des 5. Jahrhunderts. 
wittert „bis auf die hinter der späten Treppe geschützt liegenden Teile. “80 Unter dem großen Treppenbogen (Abb. 145) „werden scharf geschnittene Quadern mit 1-2 cm breiten Fugen in weißlichem Mörtel mit grobem Ziegelzuschlag und fünfschichtigen Ziegelbändern $(48 \mathrm{~cm})$ sichtbar. Ein vierschichtiges Ziegelband liegt in mittlerer Mauerhöhe." Das Mauerstück zwischen den Türmen 16 und 17, das auf ihrer Taf. 62b abgebildet ist, läßt an der Feldseite noch die gemauerten Bögen dreier zugesetzter Scharten erkennen. Hier sei „das Mauerwerk in der unteren Hälfte trotz teilweiser Verwitterung und Ausbesserungen noch im ursprünglichen Zustand zu erkennen. Die Quadern können theodosisch sein.“ Das Mauerwerk wird folgenderweise beschrieben: „Scharfkantige Quadern von 5-17 cm Schichthöhe und engen Fugen werden von fünfschichtigen Ziegelbändern $(41-53 \mathrm{~cm})$ gebunden." Die Formulierung, die Quader „können theodosisch sein“ läßt offen, ob Meyer-Plath/Schneider damit den betreffenden Mauerabschnitt oder nur das verwendete Steinmaterial in die theodosianische Zeit datieren wollten, obwohl sie zuvor den ZweifrontenWehrgang insgesamt als „theodosisch“ bezeichnet hatten.

Ich habe an der Stadtseite (Abb. 144) folgende Werte aufgenommen: Dreibis sechslagige Quader, fünfschichtige Ziegelbänder, Ziegelbandhöhe 47 bzw. $54 \mathrm{~cm}$, Ziegelbreite 32 bis $38 \mathrm{~cm}$, Ziegelhöhe 3 bis $4 \mathrm{~cm}$, Mörtelhöhe 5 bis $6 \mathrm{~cm}$ (auch die innerhalb einer Nische aufgenommene Ziegelbreite beträgt $35 \mathrm{~cm}$ ). Unterhalb des erwähnten Treppenbogens an der Stadtseite (Abb. 145) stellt man folgende Werte fest: Scharf geschnittene Quader, fünfschichtige Ziegelbänder, Ziegelbreite 35 bis $38 \mathrm{~cm}$, Ziegelhöhe 4 bis $5 \mathrm{~cm}$, Mörtelhöhe 5,5 bis $6 \mathrm{~cm}$. Ein breiteres Mörtelbett und kleinere Ziegel sind hier ebenfalls zu beobachten. Das von Meyer-Plath/Schneider registrierte vierschichtige Ziegelband in halber Mauerhöhe ist nicht mehr nachweisbar, auch die Baufuge ist nicht zu erkennen. ${ }^{81}$

Es ist also festzuhalten, daß innerhalb der langen Strecke zwischen Tekfur Sarayı bis zum Goldenen Horn kein einziges Mauerstück mit Sicherheit in die theodosianische oder vortheodosianische Zeit datiert werden kann. Die einzelnen Mauerteile weisen in vielerlei Hinsicht Gemeinsamkeiten auf. Um einer Datierung dieser Mauerabschnitte näher kommen zu können, soll zunächst auf die Frage eingegangen werden, ob der Zweifronten-Wehrgang mit dem in den Quellen erwähnten Pteron identisch sein kann, da nämlich die meisten Interpretationen auf dieser Annahme beruhen und sie als gesichert voraussetzen. Auch die Bestimmung der Ufermauer am Goldenen Horn zwischen Theophi-

80 Eine Detailaufnahme des stadtseitigen Mauerabschnitts zwischen dem Treppenrest und Theophilos-Turm 18 fehlt leider. Aus der Zeichnung gehen keine Details hervor, siehe Meyer-Plath/Schneider, Landmauer, Taf. 42.

81 Meyer-Plath/Schneider, Landmauer, 118 (Meyer-Plath). 
los-Turm 18 und Demetrios-Kirche ó Kaváßฺ (Abb. 33) als Herakleios-Mauer stützt sich auf die Gleichsetzung von Zweifronten-Wehrgang und Pteron.

Wäre das Pteron von Theodosius II. errichtet worden, müßte die von Markian und Pulcheria erbaute Blachernen-Kirche zur Zeit des Herakleios (610-641) an der Rückseite des Zweifronten-Wehrgangs gestanden haben. Das Chronicon Paschale berichtet jedoch zum Jahr 626, daß die Blachernen-Kirche bis dahin außerhalb des Pteron lag: ${ }^{82}$

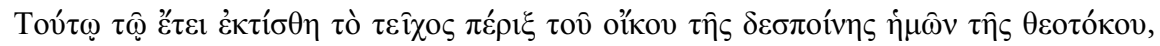

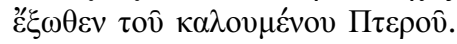

In diesem Jahre [626] wurde die Mauer um das Haus unserer Herrin, der Gottesmutter erbaut, außerhalb des sogenannten Pteron.

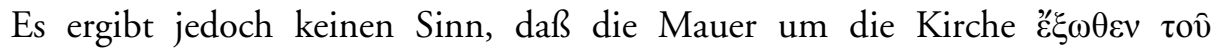
$\kappa \alpha \lambda o v \mu \varepsilon ́ v o v ~ П \tau \varepsilon \rho \circ \hat{v}$ errichtet worden sein soll, wenn mit dem Pteron der Zweifronten-Wehrgang gemeint gewesen wäre. Demnach hat man unter dem Pteron nicht das Mauerstück mit dem Zweifronten-Wehrgang verstanden, sondern vielmehr eine flügelartige Mauer, die sich an einer anderen Stelle befand. Eine Bestätigung für die Lage der Blachernen-Kirche vor der Stadtmauer also außerhalb des Pteron - geht aus Prokopios hervor ${ }^{83}$

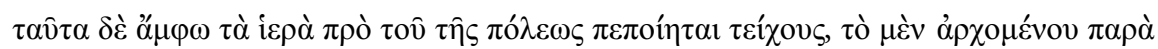

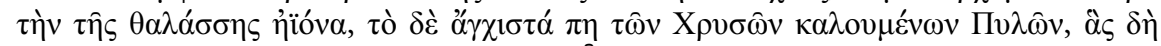

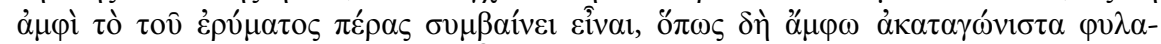

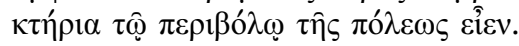

Diese zwei Kirchen [Blachernen und Pege] liegen vor der Stadtbefestigung, die eine bei deren Anfang am Meeresstrand, die andere unmittelbar beim sog. Goldenen Tor,

82 Chron. Pasch. ad ann.626, 726/14-15; englische Übersetzung: Whitby/Whitby, Chronicon, 181. - Eine Randnotiz im gleichen Werk datiert den Mauerbau bereits in

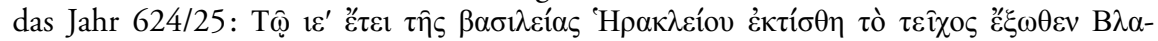

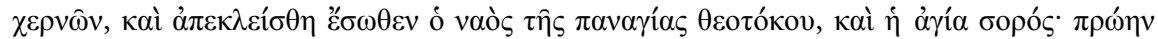

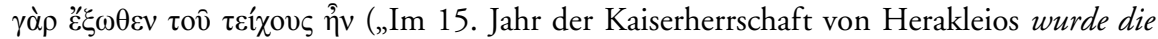
Mauer außerhalb der Blachernen erbaut, und es wurde die Kirche der Allerheiligsten Gottesmutter und die Heilige Soros nach innen einbezogen, denn vorher stand sie auBerhalb der Mauer") (kursive Hervorhebungen: Verfn.). Siehe dazu Chron. Pasch.726, apparatus criticus; englische Übersetzung: Whitby/Whitby, Chronicon, 182, Anm. 481. - Ausgehend von dieser Randnotiz bzw. der Notiz in einer Kleinchronik (zu dieser siehe Schreiner, Kleinchroniken, I, 44, Nr.1, \$14; II, 80; III, 14, \$14) und von einem Text des Georgios Pisides ist in der Sekundärliteratur von unterschiedlichen Bauzeiten der Herakleios-Mauer die Rede, worauf hier nicht eingegangen werden soll; vgl. die Diskussion der divergierenden Zeitangaben bei Speck, Bellum Avaricum, 39, 102, Anm. 167; siehe auch Whitby/Whitby, Chronicon, 182, Anm. 627.

83 Procopius I 3, 21/9-14; deutsche Übersetzung: Prokop, Bauten, 41 (kursive Hervorhebungen: Verfn.); vgl. Van Millingen, Walls, 116, Anm. 4; Mango, Fourteenth Region, 3 . 
das sich an ihrem Ende befindet. Beide sollen ja unbezwingliche Bollwerke für die Stadtmauer sein.

Prokopios beschreibt die Situation des 6. Jahrhunderts, also vor der Bautätigkeit des Kaisers Herakleios. Nach der bisher angenommenen Datierung der Mauer der sog. XIV. Region sowie des Zweifronten-Wehrgangs müßte die BlachernenKirche innerhalb dieser Mauerlinie gestanden haben. Prokopios spricht aber eindeutig davon, daß die Kirche vor der Stadtbefestigung lag und die Mauer vom Goldenen Horn bis zum Goldenen Tor reichte. Die Frage, weshalb gerade die mit kostbaren Marienreliquien ausgestattete Blachernen-Kirche vor der

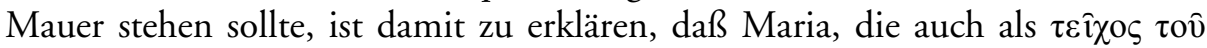

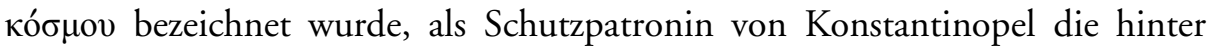
ihrer Kirche gelegene Stadt bzw. die Stadtmauer überwachen und ihr somit einen zusätzlichen Schutz bieten sollte. ${ }^{84}$ Demnach hat es im 6. Jahrhundert vor der Blachernen-Kirche noch keine Mauer gegeben. Meyer-Plath/Schneider waren aber anderer Ansicht, weswegen sie die mit 12 Türmen besetzte Mauer

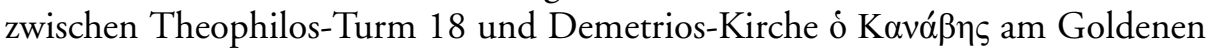
Horn (Abb. 33) Kaiser Herakleios zugeschrieben haben: ${ }^{85}$

Die vielberufene Bautätigkeit des Heraclius nach Abwehr dieses Angriffes [AvarenAngriff] beschränkte sich dem Text nach nur auf weniges: Es wurde lediglich eine Mauer um die Blachernenkirche gelegt, $\left.{ }^{86}\right]$ um sie in Zukunft vor Raub zu schützen, was ja trotz Pteronmauer durchaus möglich war. Nikephorus Cpl. (21B) berichtet nämlich, man habe die „Mauer um das Heiligtum“ gebaut und es so zu einer Festung ( $\varphi$ poúpiov) gemacht, $\left[{ }^{87}\right]$ ebenso spricht Chronicon Pasch. von der „Mauer rings um das Heiligtum " (

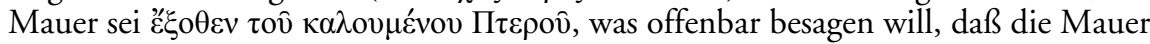
das Pteron miteinschloß. Wenn wir nun die Seemauer von Turm 18 ab bis zum Ajos Dimitrios als Heracliusmauer ansprechen, was berechtigt ist, da sie sich technisch von der Theophilos unterscheidet, so paßt das ausgezeichnet zu unserem Text und wir dürfen die Heracliusmauer dann nicht weiter landeinwärts suchen, wie es im Vorbericht geschah.

Bei der im Vorbericht erwähnten Mauer ${ }^{88}$ handelt es sich um einen noch von Van Millingen registrierten und auf seinem Plan eingetragenen Mauerrest. Dieser verlief nördlich der Blachernen-Kirche und wurde von dem Autor als „wall with windows" bezeichnet (Abb. 34). ${ }^{89}$ Er war bereits zur Zeit von Meyer-

84 Siehe dazu Cameron, Virgin's Robe, 42-56, bes. 55-56, Anm. 56.

85 Meyer-Plath/Schneider, Landmauer, 103-104 (Schneider):

86 So auch Van Millingen, Walls, 116. - Anm. in [] von Vfn.

87 Siehe Nikephoros 18/27-19/2; englische Übersetzung: Mango, Nikephoros, 60/1342. - Anm. in [] von Vfn.

88 Bei Schneider/Meyer, Zweiter Vorbericht, 11, Taf. I, Buchstabe D (Schneider), noch wiedergegeben; in den späteren Plänen der beiden Autoren nicht mehr eingetragen.

89 Van Millingen, Walls, Sketch Plan of the Blachernae Quarter, gegenüber 115 (meine Abb. 34). 
Plath/Schneider nicht mehr vorhanden und blieb in den späteren Diskussionen unberücksichtigt. Mauerwerk und Architektur sind also heute unbekannt. Doch geht aus der Bezeichnung „wall with windows“ sowie aus dem Eintrag von Van Millingen hervor, daß dieser Mauerabschnitt möglicherweise einen ähnlichen Wehrgang wie die Mauer der sog. XIV. Region aufwies. Abgesehen davon lief die Mauer in direkter Richtung auf den Mauerabschnitt hinter TheophilosTurm 16 zu (wo der Zweifronten-Wehrgang anschließt) und bildete mit diesem anscheinend eine Ecke. Stadteinwärts verlief sie in Richtung des Mauerstücks bei der Demetrios-Kirche. Nach dem Mauerwerk und den architektonischen Merkmalen - soweit bekannt - gehören die Teile, die vom Hof des Tekfur Sarayı über die Mumhane-Mauer und die hinteren Substruktionen verlaufen, zur selben Anlage. Wenn man den „wall with windows“ diesem Ensemble ebenfalls zurechnet, käme man auf einen Mauerzug, der in Höhe der Rückseite von Turm 16 nach Osten abbog und dadurch auch die Blachernen-Kirche

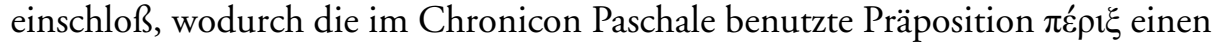
Sinn ergeben würde. ${ }^{90}$ Auf die allgemein als Herakleios-Mauer akzeptierte Mauerlinie am Ufer des Goldenen Horns träfe diese Kennzeichnung nicht zu, da sich diese Mauer nur vor der Nordseite der Kirche hinzieht. Es sprechen also mehr Argumente dafür, in der gesamten Mauer der sog. XIV. Region einschließlich dem „wall with windows" die eigentliche Herakleios-Mauer zu erkennen, die demnach bald nach 626 errichtet worden sein müßte.

Der Zweifronten-Wehrgang (Abb. 35), der erst an der nördlichen Mauerecke von Turm 16 beginnt und in Richtung Norden verläuft, wäre in zeitlicher Hinsicht zwischen der Herakleios zuzuschreibenden Mauerlinie und der Erbauung des Leon-Vorwerks einzuordnen. Verlauf und Architektur des Zweifronten-Wehrgangs können mit der geologischen Situation in diesem Gebiet erklärt werden. Wie man den eingesunkenen Türmen der bisher Kaiser Herakleios zugeschriebenen Ufermauer ablesen kann, stehen sie nicht auf festem Grund, sondern auf einer Auffüllung, ${ }^{91}$ zumal dieser Teil sumpfig war und sich hier wahrscheinlich eine Bucht befand. ${ }^{92}$ Der Zweifronten-Wehrgang bot eine ideale Verteidigungslinie, wodurch die Uferzone nach beiden Seiten geschützt werden konnte.

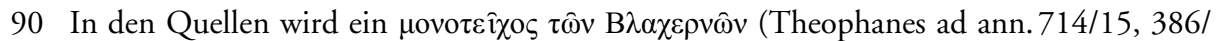

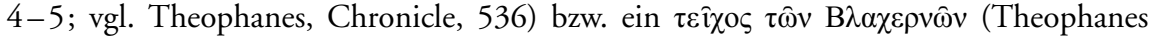
Cont., 618/2) erwähnt. Van Millingen, Walls, 166, verstand darunter den ZweifrontenWehrgang. Schneider/Meyer, Zweiter Vorbericht, 11, Anm. 1 (Schneider) zufolge sei dies die alte Blachernen-Mauer (Diskussion weiterer unterschiedlicher Anschichten bei Tsangadas, Fortifications, 99).

91 Vgl. Dirimtekin, Haliç, 7-8.

92 Schneider/Meyer, Zweiter Vorbericht, 10 (Schneider); vgl. Meyer-Plath/Schneider, Landmauer, 102 (Schneider). 
Doch die Frage, wo sich der nördliche Abschluß der theodosianischen Mauer befand, ist damit noch immer offen. Daher soll der Mauerrest an der

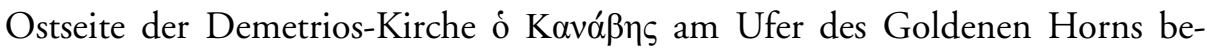
rücksichtigt werden, da dieser mit der angeblich alten Blachernen-Ummauerung in Verbindung gebracht wird (Abb. 33, 146). Das Mauerstück ist bis zu einer Höhe von ca. $5 \mathrm{~m}$ erhalten. Seine Länge beträgt noch ca. $3 \mathrm{~m}$. Das Mauerwerk weicht von allen bisher betrachteten Mauern ab und ist augenscheinlich älter. Die Quader haben eine Länge von ca. $1 \mathrm{~m}$ Meter und eine Höhe von ca. $40 \mathrm{~cm}$. Die oberen Teile sind heute zerstört. Früher waren noch siebenschichtige Ziegelbänder sichtbar, ${ }^{93}$ von denen jedoch nicht bekannt ist, ob sie zum Bestand gehörten. Die ursprüngliche Funktion dieser Mauer ist ungeklärt. ${ }^{94}$ Speck nahm an, daß der Mauerrest bei der Demetrios-Kirche das in den Quellen erwähnten Pteron gewesen sein müsse. ${ }^{95}$ Die von ihm herangezogene Quelle, wonach die Prozession zur Erinnerung an die überstandene Awarengefahr von der Hagia Sophia kommend durch das Tor im Pteron zur Blachernen-Kirche verlief, bietet hierfür ein überzeugendes Argument. ${ }^{96} \mathrm{Da}$ aber auch Speck von der Existenz einer geschlossenen Blachernen-Ummauerung ausging, hat er eine reichlich phantasievolle Rekonstruktion vorgeschlagen. ${ }^{97}$

Wenn das Mauerstück bei der Demetrios-Kirche mit dem in den Schriftquellen erwähnten Pteron identifiziert werden darf, dann würde das erklären,

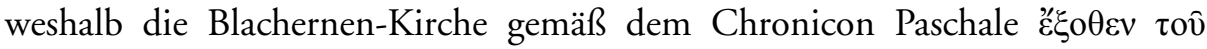

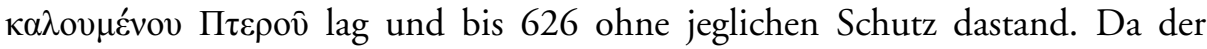
„wall with windows“ direkt auf das Mauerstück bei der Demetrios-Kirche zuläuft, gewinnen wir ein weiteres Argument, um in der gesamten Mauerlinie, die von Tekfur Sarayı ausgeht und vor dem Zweifronten-Wehrgang stadteinwärts abbiegt, die eigentliche Herakleios-Mauer zu vermuten. Diese Mauerlinie muß nicht nur mit Bastionen, sondern auch mit Türmen ausgestattet gewesen sein. Neben dem von Meyer-Plath/Schneider registrierten Turmeingang an der Mumhane-Mauer werden Türme auch durch schriftliche Quellen belegt, worin

93 Dirimtekin, Haliç, Abb. 15, läßt noch die oberen Ziegelreihen erkennen; bei MüllerWiener, Topographie, 110, Abb. 92, nicht mehr zu sehen.

94 Zur möglichen Funktion dieser Mauer äußerte Schneider, Blachernen, 88, Anm. 2: „das kurze ostwestlich verlaufende alte Mauerstück beim Hag. Dimitrios könnte zu einer Ufersperrmauer ähnlich dem Pteron gehört haben." Vgl. Mango, Fourteenth Region, 3; ders., Shoreline, 25: "Its function is unknown, but it seems to have had originally nothing to do with Golden Horn fortifications."

95 Speck, Bellum Avaricum, 53.

96 Mateos, Typicon I, 362/25-26; vgl. Speck, Bellum Avaricum, 53. - Nach der üblichen Lokalisierung des Pteron müßte die Prozession zuerst ganz weit nach Norden über den Zweifronten-Wehrgang hinaus und dann wieder zurück zur Blachernen-Kirche geführt haben, was nicht logisch erscheint.

97 Speck, Bellum Avaricum, 37 (Lageskizze). 
ausdrücklich von „Blachernen-Türmen“ die Rede ist. So berichtet die Chronik des Ioannes Skylitzes über den Aufstand des Thomas im Jahre 821/22: ${ }^{98}$

Er [Thomas] führte die starken Belagerungsmaschinen mit sich und versuchte den Angriff an den Blachernentürmen, indem er entsprechend hohe Leitern an die Mauer anlehnen ließ und hier Schirmdächer („Schildkröten“), dort Mauerbrecher („Widder") ansetzte ... Die restlichen Mauern hatte er mit seiner Seestreitsmacht umzingelt; mit Feuer und Pfeilschüssen verbreitete er Schrecken.

Die hier erwähnten Türme können weder die erst zur Zeit des Theophilos errichteten „Pteron-Türme“ 15, 16 und 18 noch die Türme am Ufer des Goldenen Horns gewesen sein. Sie lassen sich daher nur mit der oben beschriebenen Mauerlinie in Verbindung bringen. ${ }^{99}$

Zusammenfassend kann festgehalten werden: Solange die schriftlichen Quellen und die archäologischen Belege keine eindeutigen Hinweise geben, wird die angebliche Existenz einer alten Ummauerung des Blachernen-Gebiets nur Hypothese bleiben. Darüber hinaus sprechen viele Argumente dafür, die Mauer zwischen Tekfur Sarayı bis zum Beginn des Zweifronten-Wehrgangs bei Turm 16 und einschließlich dem „wall with windows" als die eigentliche Herakleios-Mauer von 626 anzusehen und die nördliche Fortsetzung der theodosianischen Mauer von Tekfur Sarayı bis zum Mauerrest bei der DemetriosKirche zu ziehen. ${ }^{100}$ Wie diese Verbindung beschaffen war und ob auf dieser Strecke Türme bzw. Bastionen lagen, kann nur anhand einer Ausgrabung festgestellt bzw. ausgeschlossen werden. Die bislang als Herakleios-Mauer bezeichnete Ufermauer muß m. E. neu definiert werden.

\subsubsection{Die Zahl der theodosianischen Türme}

Keine einzige byzantinische Quelle informiert uns über die ursprüngliche Anzahl der Türme der Theodosianischen Landmauer. Heute werden zwischen Marmarameer und Tekfur Sarayı jeweils 96 Haupt- und Vortürme bzw. ihre Reste angenommen. ${ }^{101}$ Diese Zahl entspricht der Aussage des Florentiner Reisenden Cristoforo Buondelmonti, der im Konstantinopel-Kapitel seines Liber

98 Thurn, Weltreich, 65. - Ich gebe hier nur die Übersetzung wieder.

99 Auch der unzugängliche Turm 17 kann dieser Zeit angehören.

100 In Verbindung mit den Blachernen-Mauern äußerte Schneider, Blachernen, 88, bereits: „Der Verlauf von hier [Mauer bei der Demetrios-Kirche] bis zurück zum Tekfur Sarayı ist wohl am Hang, ein wenig unterhalb der Straße Şeyh Ali Tekke - Molla Aşki - Odun Yarıc1, anzunehmen."

101 Meyer-Plath/Schneider, Landmauer, Faltpläne 1-3 - Mamboury, Karte, zeigt nur 75 Türme; in späteren Arbeiten ist im allgemeinen von 96 Türmen die Rede. Foss, Fortifications, 45, spricht von 95 Türmen. 
insularum archipelagi $(1420 / 22)$ vermerkte: ${ }^{102}$ „a dicta Vlacherna usque Criseam portam ... sunt turres nonaginta sex."

Die Türme und die benachbarten Kurtinen wurden erst durch Meyer-Plath/ Schneider systematisch numeriert, wobei sie die Ziffer 80 jeweils zwei benachbarten Türmen vergeben ${ }^{103}$ und im sogenannten Sigma ${ }^{104}$ einen Turm mit der Nummer 41 eingetragen haben. Damit kamen auch sie auf die Gesamtzahl von 96. Die Kurtinenlängen betragen an der Landmauer in der Regel ca. 40 bis ca. $70 \mathrm{~m}$, wodurch nach Meyer-Plath/Schneider ein sicherer Pfeilschuß gegen Angreifer ermöglicht wurde. ${ }^{105}$ Doch begegnet man hin und wieder Kurtinenlängen, die weit unter $40 \mathrm{~m}$ liegen. Im folgenden soll zunächst ein Überblick über die Turmabstände in verschiedenen Etappen der Landmauer gegebenen werden (siehe Faltpläne 1-3):

1. Etappe/Zwischen Turm 1 und Goldenem Tor: Kurtinenlängen zwischen ca. 45 und ca. $60 \mathrm{~m}$.

2. Etappe/Zwischen Goldenem Tor und Belgratkapı: Kurtinenlängen zwischen ca. 45 und ca. $60 \mathrm{~m}$.

3. Etappe/Zwischen Belgratkapı und Silivrikapı: Kurtinenlängen zwischen ca. 40 und ca. $50 \mathrm{~m}$.

4. Etappe/Zwischen Silivrikapı und sog. 3. Nebentor: Kurtinenlängen ca. $50 \mathrm{~m}$.

5. Etappe/Zwischen Silivrikapı und Mevlevihanekapı: Kurtinenlängen zwischen ca. 50 und ca. $60 \mathrm{~m}$.

102 Gerola, Vedute, 271. - Obwohl Buondelmonti von der Strecke zwischen Blachernen und Goldenem Tor spricht, ist offensichtlich, daß er die Mauer zwischen Goldenem Tor und Tekfur Sarayı gemeint hat. Gyllius, Topographia, I, 19, 53, gibt (1544/50) die Zahl der Türme folgenderweise an: ,in quo ex continenti sunt plus ducentae quinquaginta turres, in quas gradibus lapideis ascenditur." Es ist zu vermuten, daß er die Haupt- und Vortürme sowie die Türme der Blachernen-Mauer mitgezählt hat. In einigen Reiseberichten findet sich gelegentlich die phantastische Zahl von tausend Türmen, z. B. bei Saurau, Beschreybung, 82.

103 Für den doppelt gezählten Turm 80 siehe Meyer-Plath/Schneider, Landmauer, 79 (Meyer-Plath) und Faltplan 3; Van Millingen, Walls, Plan 2, zufolge befand sich in der Mitte des sog. Sigma ebenfalls ein Turm. Auch auf der MISN-Karte I ist hier ein Turm eingezeichnet. Meyer-Plath/Schneider, Landmauer, 76 (Meyer-Plath), lehnten dies zwar $\mathrm{ab}$, behielten ihn aber in ihrer Numerierung bei. Die einst zwischen den Türmen 89 und 90 befindliche Bastion wurde (ebd. 80) ebenfalls als Turm 89 numeriert,

104 Das in den Schriftquellen erwähnte Sigma westlich vom Exakionion (siehe dazu Janin, Constantinople, 424-26; Berger, Patria, 360-362; ders., Tauros, 17-28; MundellMango, Street, 37; weitere Literatur bei Bauer, Denkmal, 212-213 und 418) hat mit diesem Abschnitt der Mauer nichts zu tun. - Auf den MISN-Karten I und II ist das Mauerstück als Sigma bezeichnet. Meyer-Plath/Schneider, Landmauer, 18, zufolge sei das Sigma „in keiner Weise durch das Gelände gefordert und nur als Reminiszenz an ältere Technik zu verstehen" (Schneider); siehe auch Anm. 121.

105 Meyer-Plath/Schneider, Landmauer, 27 (Meyer-Plath). 
6. Etappe/Zwischen Mevlevihanekapı und sog. 4 . Nebentor: Kurtinenlängen zwischen ca. 50 und einmal ca. $75 \mathrm{~m}$, letztere Entfernung kommt allerdings nur zwischen den Türmen 55 und 56 vor.

7. Etappe/Zwischen dem sog. 4. Nebentor und Topkap1: Kurtinenlängen zwischen den Türmen 60/61, 61/62 und 62/63 betragen jeweils ca. $50 \mathrm{~m}$. Die Abstände erreichen zwischen den Türmen 63 und 64, ca. $60 \mathrm{~m}$, wobei die Entfernung zwischen den Türmen 64 und 65 (südlicher Torturm von Topkapı) nur ca. $30 \mathrm{~m}$ beträgt.

8. Etappe/Zwischen Topkapı und Sulukulekapı: Kurtinenlängen zwischen ca. 50 und ca. $65 \mathrm{~m}$.

9. Etappe/Zwischen Sulukulekapı und Edirnekapı: Zwischen den Türmen 78 und 82 betragen die Kurtinenlängen ca. 50 bis ca. 55 m. Ab Turm 82 bis zum südlichen Torturm von Edirnekapı stehen die Türme nur ca. 19 bis ca. $22 \mathrm{~m}$ von einander entfernt.

10. Etappe/Zwischen Edirnekapı und Turm 96: Zwischen nördlichem Torturm vor Edirnekapı (Turm 87) bis Turm 89 beträgt der Abstand zwischen den Türmen nur ca. 19 bzw. ca. $21 \mathrm{~m}$. Ab Turm 89 stehen die Türme ca. 50 bzw. ca. $55 \mathrm{~m}$ von einander entfernt.

Soweit man feststellen kann, schwanken die Kurtinenlängen an der Südseite des Lykos-Bachs (dieser tritt unter Turm 75 in die Stadt ein) in der Regel zwischen ca. 40 bis ca. $60 \mathrm{~m}$. Nur in einem Ausnahmefall (Kurtine 55/56) beträgt die Entfernung ca. $75 \mathrm{~m}$. Der schon von Meyer-Plath/Schneider erwähnte Abstand von ca. $30 \mathrm{~m}$ kommt ebenfalls nur ein einziges Mal vor, und zwar zwischen den Türmen 64 und $65 .{ }^{106}$ Eine von allen Regeln abweichende Kurtinenlänge mit sehr geringem Abstand zwischen den Türmen begegnet nur im Bereich von Edirnekapı, besonders zwischen den Türmen 82 und 89, und zwar ca. 19 bzw. ca. $21 \mathrm{~m}$.

Dieser Sachverhalt war bereits Hanak aufgefallen, der jedoch nicht näher darauf einging und es bei der Feststellung beließ: ${ }^{107}$ „This peculiar spacing and design of the inner land walls cannot be explained in terms of the gradient of the terrain nor simply of the strategic needs of the area." Obwohl Meyer-Plath/ Schneider deutlich gemacht haben, daß das Abstecken der Turmabstände nach einem gewissen Augenmaß erfolgte, ${ }^{108}$ läßt der abweichende Rhythmus der Türme an einigen Stellen überlegen, ob alles auf das ursprüngliche theodosianische Konzept zurückgehen muß. Der Rhythmus verläuft an der Nordseite des Lykos bis zu Turm 82 entsprechend der Regel. Turm 83 markiert den ersten Turm, der den theodosianischen Rhythmus durchbricht (Abb. 109). Neben der

106 Meyer-Plath/Schneider, Landmauer, 27 (Meyer-Plath), Faltplan 2.

107 Hanak, Mesoteikhion, 76.

108 Meyer-Plath/Schneider, Landmauer, 27 (Meyer-Plath). 
engen Stellung der Türme sind die Kurtinen ab Turm 82 fast zweifach stärker, da sie ihr jetziges Aussehen später angebrachten feldseitigen Schalen verdanken (Abb. 104). ${ }^{109}$ Turm 82 ist nicht mehr erhalten, nur der stadtseitige Eingang ist heute noch zu erkennen (Abb. 104, 105). ${ }^{110}$ Während der Abstand zu dem südlich benachbarten Turm 81 mit ca. $50 \mathrm{~m}$ dem theodosianischen Konzept entspricht, beträgt die Entfernung zu dem im Norden benachbarten Turm 83 nur ca. $21 \mathrm{~m}$.

Die Kurtine zwischen den Türmen 81 und 82 ist mehrfach repariert (Abb. 104, 105). Unmittelbar südlich von Turm 82 beobachtet man Schichtenmauerwerk mit unregelmäßigen Quadern in sechs Lagen und fünfschichtige Ziegelbänder. Die Werte an der Feldseite betragen (Abb. 104): Ziegelbandhöhe $55 \mathrm{~cm}$, Ziegelbreite 32 bis $35 \mathrm{~cm}$, Ziegelhöhe 3 bis $4 \mathrm{~cm}$, Mörtelhöhe 6,5 bis $8 \mathrm{~cm}$. An der Stadtseite begegnen folgende Werte (Abb. 105): Siebenlagige wiederverwendete Quader und fünfschichtige Ziegelbänder, Ziegelbandhöhe 48 bis $54 \mathrm{~cm}$, Ziegelbreite $35 \mathrm{~cm}$, Ziegelhöhe 3 bis $4 \mathrm{~cm}$, Mörtelhöhe 6,5 bis $9 \mathrm{~cm}$. Nördlich von Turm 82 beginnt an der Stadtseite ein anderes Mauerwerk bzw. eine andere Architektur (Abb. 106). Der hier durch Nischen bzw. durch Strebepfeiler gegliederte Mauerabschnitt zeigt wiederverwendete Quader mit fünfschichtigen Ziegelbändern und folgenden Werten: Ziegelbandhöhe 51 bzw. $62 \mathrm{~cm}$, Ziegelbreite 31 bis $42 \mathrm{~cm}$, Ziegelhöhe 2,5 bis $6 \mathrm{~cm}$, Mörtelhöhe 6 bis $10 \mathrm{~cm}$. Fast alles Baumaterial ist wiederverwendet. Doch die Feldseite dieses Bereichs (bis Turm 84) weist besonders in den unteren Partien das gleiche Mauerwerk wie die stadtseitige Kurtine südlich von Turm 82 auf. Dieses Mauerwerk besteht aus acht bis zwölf Quaderlagen (wiederverwendete Quader) und fünfschichtigen Ziegelbändern: Ziegelbandhöhe 44 bzw. $55 \mathrm{~cm}$, Ziegelbreite 32 bis $35 \mathrm{~cm}$, Ziegelhöhe 3 bis $4 \mathrm{~cm}$, Mörtelhöhe 6 bis $7,5 \mathrm{~cm}$.

Turm 83 zeigt eine jüngere Mauertechnik, indem die hier wiederverwendeten Kleinquader sorglos und zum Teil ohne Ziegeldurchschuß eingefügt worden sind (Abb. 109). Auch die wiederverwendeten skulptierten Spolienstücke wurden ohne Rücksicht auf ihren Schmuck gelegentlich umgekehrt eingemauert (Abb. 195, 196). Die kurzen Flanken unterscheiden sich ebenfalls von den theodosianischen Türmen. Die theodosianischen bzw. die später nach dem theodosianischen Konzept wiederhergestellten Türme haben eine Flankenlänge von 9,50 bzw. 10,15 m, wohingegen bei Turm 83 die Flankenlänge nur wenige Meter beträgt. Darüber hinaus hat der Turm weder Schieß- noch Lichtscharten. Meyer-Plath/Schneider vertraten die Meinung, daß der Turm in einer sehr raschen Arbeitsphase in palaiologischer Zeit errichtet worden sei und erklärten die kürzeren Flanken mit dem wiederbenutzten theodosianischen

109 Meyer-Plath/Schneider, Landmauer, 83 (Meyer-Plath), Faltplan 3.

110 Meyer-Plath/Schneider, Landmauer, 83 (Meyer-Plath) sahen damals noch die Reste eines Halbbogens an der Südflanke. 
Fundament sowie mit der Verstärkung der Kurtine bzw. der zusätzlichen feldseitigen Mauerschale. ${ }^{111}$ Eine nähere Betrachtung des Mauerwerks zeigt jedoch, $\mathrm{da} ß$ die rasche Arbeitsphase nur von sekundärer Bedeutung für die Beurteilung sein dürfte, da Reste des ursprünglichen Schichtenmauerwerks mit gleichen Werten wie an der feldseitigen Kurtine 82/83 sowie an einigen Stellen die saubere Verbindung mit dieser Kurtine bzw. Schale zu erkennen sind. Es läßt sich daher vermuten, daß die gesamte Partie zunächst wie die stadtseitigen Kurtinen zwischen den Türmen 82 bis 84 errichtet war, wobei etwas später die Kurtine 81/82 mit einem anderen Mauerwerk repariert und gleichzeitig die vordere Schale zwischen den Türmen 82 und 84 einschließlich Turm 83 aufgeführt wurden. Das hohe Mörtelbett und die hier feststellbaren Ziegelmaße (32 bis $35 \mathrm{~cm}$ ) weisen den Turm und die mit ihm im Verband stehende benachbarte Kurtine als mittelbyzantinisch, womöglich als Erneuerung des 10. Jahrhunderts aus (Abb. 107, 108) (siehe Abschnitt 4.2.). Bei Turm 83 handelt es sich demnach um die spätbyzantinische Reparatur eines mittelbyzantinischen Turms. Die kurzen Flanken allein weisen m.E. nicht unbedingt auf einen theodosianischen Vorgängerturm hin. Die umgekehrte Einsetzung des Spolienbands erfolgte wahrscheinlich in palaiologischer Zeit, wobei eine Erstverwendung im 10. Jahrhundert wahrscheinlich ist.

Das Mauerwerk der stadtseitigen Kurtine zwischen den Türmen 82 und 84, die sicherlich älter ist (älter auch als der nördliche Teil von Kurtine 81/82 und der stadtseitigen Verstärkung), unterscheidet sich mit ihrem über $60 \mathrm{~cm}$ hohen Ziegelband sowohl von dem in das 8. als auch dem in das 10. Jahrhundert datierbaren Mauerwerk und läßt sich mit einem bestimmten Abschnitt des Leon-Vorwerks vergleichen, und zwar mit dem an der Südseite des zugemauerten Tors gelegenen Abschnitt (nördlich der Bastion von Michael und Theophilos). ${ }^{12}$ Die stadtseitigen Kurtinen 82 bis 84 (Abb. 106) können daher mit gewisser Vorsicht in das frühe 9. Jahrhundert gesetzt werden.

Zwischen den Türmen 83 und 84 beträgt die Kurtinenlänge nur ca. $19 \mathrm{~m}$. Auch in diesem Bereich sind intensive mittel- und spätbyzantinische Reparaturen sowie eine feldseitige Verstärkung zu erkennen. Obwohl Turm 84 (Abb. 110, 111) ebenfalls keinen theodosianischen Mauerverband aufweist, harmoniert er nicht nur mit dem theodosianischen Konzept, ${ }^{113}$ sondern besitzt auch einen stadtseitigen Eingang. ${ }^{114}$ Daher ist anzunehmen, daß Turm 84 bzw. sein Vorgänger bereits in der theodosianischen Bauphase hier stand, wenn er

111 Meyer-Plath/Schneider, Landmauer, 79 (Meyer-Plath).

$112 \mathrm{Zu} \mathrm{dem} \mathrm{zugemauerten} \mathrm{Tor} \mathrm{siehe} \mathrm{Meyer-Plath/Schneider,} \mathrm{Landmauer,} 119$ (MeyerPlath).

113 Meyer-Plath/Schneider, Landmauer, 79 (Meyer-Plath), registrierten im heute verschütteten Untergeschoß altes, aber nachtheodosianisches Mauerwerk.

114 Meyer-Plath/Schneider, Landmauer, 79 (Meyer-Plath). 
auch später - dem Mauerwerk nach zu urteilen, erstmals in mittelbyzantinischer Zeit - gründlich repariert wurde. Zieht man jetzt Turm 83 ab, beträgt die Kurtinenlänge zwischen den Türmen 82 und $84 \mathrm{ca} .50 \mathrm{~m}$ und entspricht den an mehreren Abschnitten der theodosianischen Anlage zu beobachtenden Maßen. Turm 85 ist nicht erhalten. Er befand sich nur ca. $21 \mathrm{~m}$ nördlich von Turm 84 . Nach Norden war er dem südlichen Torturm von Edirnekapı benachbart, wobei wiederum eine sehr geringe Kurtinenlänge von ca. $21 \mathrm{~m} \mathrm{zu}$ beobachten ist. Turm 85 hatte anscheinend keinen ursprünglichen stadtseitigen Eingang. ${ }^{115}$ Wenn wir diesen jüngeren Turm ausklammern, bleibt zwischen den Türmen 84 und 86 ein Abstand von ca. 69 m, der sich ebenfalls innerhalb der theodosianischen Kurtinenlängen bewegt. Soweit man also erkennen kann, gehörten die beiden Türme 83 und 85 an der Südseite von Edirnekapı nicht zum theodosianischen Konzept.

Der gleiche Sachverhalt begegnet an der Nordseite von Edirnekapı. Unmittelbar nördlich des Torturms 87 steht Turm 88 in einer Entfernung von ca. $19 \mathrm{~m}$ (Abb. 56, 102). Nicht nur die geringe Kurtinenlänge, sondern auch weitere Indizien weisen darauf hin, daß sich an dieser Stelle kein theodosianischer Turm befand. Erstens steht vor dem Turm ein in mittelbyzantinischer Zeit wiederhergestellter Vorturm (Abb. 56), der dem theodosianischen Rhythmus folgt. Vortürme fluchten normalerweise niemals mit den Haupttürmen, sondern wurden immer zwischen zwei Haupttürmen errichtet. Ein Vorturm, der direkt vor einem Hauptturm plaziert ist, beeinträchtigt den ganzen Abschnitt in strategischer Hinsicht, weshalb dieser Umstand ein zusätzliches Indiz für eine spätere Errichtung von Turm 88 liefert. Zweitens hat der Turm weder einen stadtseitigen Eingang noch Schießscharten. Seinem Mauerwerk nach scheint er gleichzeitig mit der feldseitigen Schale der Kurtine in diesem Bereich errichtet worden zu sein. Das Mauerwerk der feldseitigen Kurtinen 84/85 (Abb. 111), 85/86 (Abb. 103), 87/88 (Abb. 102), 88/89 (Abb. 56) und von Turm 88 (Abb. 56) unterscheiden sich nämlich von allen anderen Mauerabschnitten der Landmauer. Hier wurden in den unteren Bereichen - soweit noch sichtbar große, regelmäßig geschnittene Quader verwendet (ca. $140 \times 60 \mathrm{~cm}$ und etwas kleiner). Darüber befinden sich sechs bzw. sieben Ziegelschichten. Die oberen Bereiche bestehen nur aus Ziegeln. Dieses Mauerwerk weist eine augenscheinliche Ähnlichkeit mit den datierten Theophilos-Türmen vor dem ZweifrontenWehrgang auf (Abb. 143). Darüber hinaus läßt ein in diesem Abschnitt der Mauer registrierter Inschriftrest mit der Jahresangabe 826/27 $7^{116}$ keinen Zweifel daran, daß der Bereich nördlich von Turm 84 bereits kurz vor der Regierungszeit des Kaisers Theophilos (829-842) durch seinen Vater Michael II.

115 Meyer-Plath/Schneider, Landmauer, 80 (Meyer-Plath).

116 Foss, Fortifications, 55; für den Inschriftrest siehe Meyer-Plath/Schneider, Landmauer, 144, Nr. 81 (Schneider). 
(820-829) intensiv, aber vom theodosianischen Konzept abweichend, restauriert wurde. Es scheint, daß eine lange Strecke zwischen Kurtine 81/82 und Edirnekapı zunächst im früheren 9. Jahrhundert intensiv repariert worden war. Kurz danach (zur Zeit Michael II.) und auch im 10. Jahrhundert müssen die feldseitigen Schalen sowie einige zusätzliche Türme angebracht worden sein. Die Türme 83, 85 und 88 sind also von der herkömmlichen Zählung abzuziehen.

Ein weiteres Problem bildet der „Sigma“ genannten Mauerabschnitt an der Südseite des Lykos, nördlich von Silivrikapı, der ebenfalls kurz betrachtet werden soll (Abb. 36). Zwischen den Türmen 40 und 42 befindet sich ein ca. $30 \mathrm{~m}$ tiefer Rücksprung mit einer hinteren Länge von ca. $90 \mathrm{~m}$ und einer vorderen Länge von ca. $130 \mathrm{~m}$. Am südlichen Einsprung steht Turm 40 (der nördliche Torturm des sog. 3. Nebentors unmittelbar nördlich von Silivrikapı, Abb. 36), an der nördlichen Ecke erhebt sich Turm 42. In der Mitte der Rückwand wird - wie oben erwähnt - bei der Zählung gelegentlich ein Turm 41 angenommen. Die Plazierung der Vortürme in diesem Bereich nimmt keinerlei Rücksicht auf die Haupttürme, denn fast direkt vor Turm 42 (etwas südlich) ist ein großer, seinem Mauerwerk sowie der Inschrift zufolge spätbyzantinischer Vorturm (Vorturm 41a) gesetzt (Abb. 53) ${ }^{117}$ Ein weiterer, von der Größe her ebenfalls von den anderen Vortürmen der Stadtmauer leicht abweichender und heute ziemlich beschädigter Vorturm (40a) befindet sich in der Mitte des Sigma. Turm 42 zeigt zwar Schichtenmauwerk, doch lassen ihn die registrierten Werte (Ziegelbandhöhe $58 \mathrm{~cm}$, Ziegelbreite $35 \mathrm{~cm}$, Ziegelhöhe $4,5 \mathrm{~m}$, Mörtelhöhe $6 \mathrm{~cm}$, größere Stoßfugen) in mittelbyzantinische Zeit datieren. Seine Entfernung zu dem nach Norden benachbarten Turm 43 (Abb. 53) beträgt ca. $60 \mathrm{~m}$ und weist darauf hin, daß es sich hier möglicherweise um die Wiederherstellung eines theodosianischen Turms handelt. Turm 40 (Abb. 77) an der Südecke des Sigma wurde nach Meyer-Plath/Schneider im Jahr 685 erbaut, wie das an der Südflanke eingemauerte Inschriftstück angibt (Abb. 199). ${ }^{118}$ Das Mauerwerk dieses Turms besteht aus neun Quader- und fünf Ziegelschichten, deren Werte (Ziegelbandhöhe $49 \mathrm{~cm}$, Ziegelbreite $38 \mathrm{~cm}$, Ziegelhöhe $4 \mathrm{~cm}$, Mörtelhöhe 5 bis $6,5 \mathrm{~cm}$ ) früheren Werten recht nahekommen. Sowohl wegen der Datierung als auch wegen seines älteren Mauerwerks wird zumeist angenommen, daß der Turm an der Stelle eines theodosianischen Vorgängers errichtet wurde. ${ }^{119}$ Es muß hier jedoch angemerkt werden, daß dieser Turm größer als der benachbarte

117 Meyer-Plath/Schneider, Landmauer, 130, Nr. 27 (Schneider); vgl. auch Anm. 713.

118 Meyer-Plath/Schneider, Landmauer, 66; 130, Nr. 26 (Schneider). Dem Autor zufolge handelt es sich dabei um eine bauzeitliche Inschrift.

119 Meyer-Plath/Schneider, Landmauer, 65-66. 
Torturm 39 ist. ${ }^{120}$ Der palaiologische Vorturm 41a (Abb. 53) müßte eigentlich aus strategischen Gründen nicht so nahe zum Hauptturm 42 gestanden haben. Es ist offensichtlich, daß Turm 41a keine Wiederherstellung eines theodosianischen Turms ist. Die Kurtine zwischen den Vortürmen ist völlig verschwunden.

Das an der südlichen Hälfte der Kurtine des Sigma nur noch in Resten erhaltene Mauerwerk zeigt mehrere Reparaturen, wobei die Schale zum größten Teil verloren ist. Soweit erhalten, sind die Stadt- und Feldseite mit Quadern mit Ziegeldurchschuß repariert und lassen sich als palaiologischen bestimmen (siehe Abschnitt 4.2.). Dieses Mauerwerk erstreckt sich nach Süden bis zum hinteren Teil von Turm 39 (Abb. 76). Die nördliche Schrägwand zeigt Reste des Schichtenmauerwerks mit elf Quaderreihen und fünfschichtigen Ziegelbänder auf (Ziegelbandhöhe $49 \mathrm{~cm}$, Ziegelbreite 35 bis $37 \mathrm{~cm}$, Ziegelhöhe $4,5 \mathrm{~cm}$, Mörtelhöhe 4,5 bis $7 \mathrm{~cm}$ ). Dieser Teil scheint in mittelbyzantinischer Zeit repariert zu sein. Das theodosianische Konzept bevorzugt für die Knickpunkte der Mauer polygonale Türme, wie z. B. Turm 4, 13, 46 und 90 (siehe Beilagen). Sowohl Turm 40 als auch Turm 42 befinden sich an Knickpunkten. Man würde hier eigentlich polygonale Türme erwarten, wenn das Sigma tatsächlich zum theodosianischen Bauprogramm gehört hätte. Die Türme 40 und 42 folgen dem theodosianischen Rhythmus, weshalb ich der Meinung bin, daß auch die Vorgängertürme rechteckig waren. Zwischen beiden wird in theodosianischer Zeit eine gerade Wand verlaufen sein, wobei anstelle des Vorturms 40a ein normaler theodosianischer Turm (41) gestanden haben müßte. ${ }^{121}$ Diese Überlegung bleibt natürlich Hypothese, da sie nur durch eine archäologische Grabung bewiesen werden könnte.

Zusammenfassend läßt sich sagen: Der Standort einiger Türme sowie ihre geringe Distanz können nicht unbedingt mit fortifikatorischen Überlegungen erklärt werden, da ein direkt vor einem Hauptturm - wie im Falle von Turm 42 und 88 (Abb. 56) - angeordneter Vorturm für die Bestreichung des Vorgeländes eher hinderlich ist. Darüber hinaus ist das Fehlen wichtiger Bestandteile der Türme wie Schieß- und Lichtscharten oder teilweise auch stadtseitiger Eingänge nur dadurch zu erklären, daß es sich dabei um spätere Scheintürme handelt, die mit dem theodosianischen Konzept nicht in Verbindung gebracht werden können. Ich ziehe zunächst die Türme 83,85 und 88 von der bislang angenommen 96 theodosianischen Türmen ab, woraus sich die Zahl von 93 Türmen

120 Das kann auch der Zeichnung Meyer-Plath/Schneider, Landmauer, 38, Abb. 5, entnommen werden; vgl. auch Beilage 2.

121 Nach Mordtmann, Esquisse, 14-15, standen im sog. Sigma die kaiserlichen Truppen,

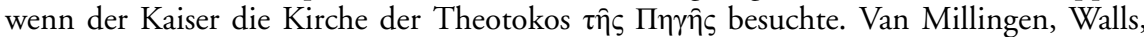
78, machte zu Recht darauf aufmerksam, daß während des Baus der Theodosianischen Landmauer diese Kirche noch nicht existierte. 
ergibt. Doch kommt dazu ein doppelt gezählter Turm 80, womit sich die Zahl auf 94 erhöht. Wenn meine Überlegungen richtig sind und an der Stelle von Turm 40a ein Hauptturm gestanden hat, ergäbe sich die Gesamtzahl von 95 Türmen. Auf die beiden Türme 39 (Abb. 76) und 40 (Abb. 77) an der Südecke des Sigma wird im Zusammenhang mit den Stadttoren nochmals eingegangen (Abschnitt 2.2.2.), da auch hier möglicherweise ein weiterer Turm abgezogen werden muß, so daß am Ende die Zahl von mindestens 94 und höchstens 95 Türmen stünde.

\subsubsection{Die Entstehungszeit der Vormauer}

Die bereits von Meyer-Plath/Schneider abgelehnte Annahme früherer Forscher, wonach - ausgehend von einer Inschrift am Mevlevihanekapı - die Vormauer erst im Jahre 447 errichtet worden sei, ${ }^{122}$ wurde kürzlich wieder aufgegriffen und durch eine neue Interpretation der Schriftquellen untermauert, die jedoch nicht überzeugt. ${ }^{123}$ Daher soll im folgenden auf die Errichtungszeit der Vormauer anhand der schriftlichen Überlieferung und der archäologischen Befunde nochmals eingegangen werden.

\subsubsection{Die schriftlichen Zeugnisse}

Die erwähnte Inschrift ist noch heute am Vortor des Mevlevihanekapı (Abb. 14) an der Feldseite zu sehen (Abb. 42, 79). Sie befindet sich auf der oberen Profilleiste des Türsturzes und lautet: ${ }^{124}$

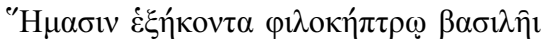

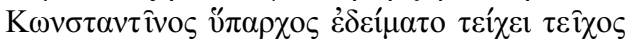

In sechzig Tagen baute der Präfekt Konstantinos dem szepterliebenden Kaiser zum Schutz der Mauer eine Mauer/oder: Mauer an Mauer

122 Dethier, Bosphor, 12; vgl. auch Strzygowski, Goldenes Thor, 18; Van Millingen, Walls, 45-46; Bury, Date, 442; Lietzmann, Vorbericht, 4-5; vgl. Anm. 130.

123 Lebek, Bauepigramm, 107-154. Zustimmend Berger, Regionen, 351, Anm. 5; siehe auch die kürzlich dagegen vertretene, jedoch nicht begründete Meinung von Bardill, Brickstamps, 122: „In the period 405-13, both the inner and outer walls would have been erected."

124 Meyer-Plath/Schneider, Landmauer, 66, 132, Nr.33b (Schneider); Lebek, Bauepi-

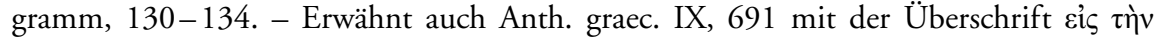

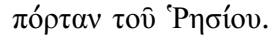


Eine weitere, in lateinischer Sprache verfaßte Inschrift auf der Konsole desselben Tors gibt die gleiche Auskunft: ${ }^{125}$

Theodosii iussis gemino nec mense peracto

Constantinus ovans haec moenia firma locavit

tam cito tam stabilem Pallas vix conderet arcem.

Auf Theodosius' Befehl und, nachdem noch keine zwei Monate vergangen waren, stellte Constantinus triumphierend die hier stehende feste Mauer hin. So schnell würde eine so standfeste Burg kaum Pallas Athene erbauen.

Eine ähnliche Inschrift befand sich einst am Xylokerkos-Tor, das mit Belgratkap1 (Abb. 11) identifiziert werden kann. ${ }^{126}$ Sie ist inzwischen verschollen und nur in der Anthologia graeca überliefert. Es ist unbekannt, ob sie am Vor- oder am Haupttor angebracht war. Sie lautet: ${ }^{127}$

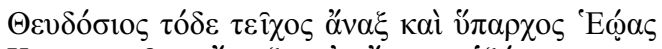

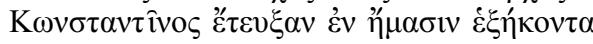

Theodosius, der Herrscher, und sein Praefekt des Ostens Konstantinos bauten diese Mauer hier in sechzig Tagen.

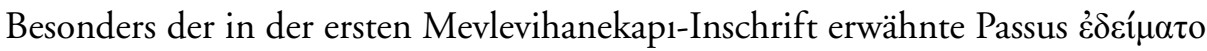
$\tau \varepsilon i ́ \chi \varepsilon 1 ~ \tau \varepsilon i ̄ \chi o \varsigma$ wurde früher im Sinne einer zusätzlichen Mauer für eine schon bestehende Mauer interpretiert, was zur Folge hatte, daß auch die Notitia urbis Constantinopolitanae, worin die Theodosianische Mauer als „Doppelmauer“ bezeichnet wird, ${ }^{128}$ der Zeit zwischen 447 und 450 zugeschrieben wurde. ${ }^{129}$ Meyer-Plath/Schneider machten aber - trotz voneinander abweichender Aussagen - darauf aufmerksam, daß zwischen der Errichtung der Haupt- und der Vormauer keine große zeitliche Distanz gelegen haben kann, da die Hauptmauer ohne eine Vormauer in strategischer Hinsicht nicht brauchbar gewesen

125 CIL III, 734; vgl. Meyer-Plath/Schneider, Landmauer, 133, Nr. 35 (Schneider); Lebek, Bauepigramm, 134-135 (danach die Übersetzung).

126 Meyer-Plath/Schneider, Landmauer, 63.

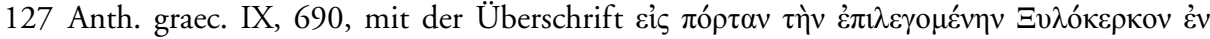

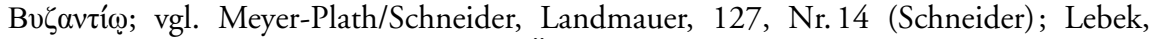
Bauepigramm, 135 (danach Text und Übersetzung). - Die Inschrift hat Gyllius, Topographia I, 3, 19, noch gesehen.

128 Notitia, 242/14; Berger, Regionen, 375 (Übersetzung), dort 350-351 auch die Datierungsproblematik diskutiert.

129 So Strzygowski, Goldenes Thor, 18; Bury, Date, 442-443; zuletzt wieder Lebek, Bauepigramm, 150-153, hier 153: „Erst vom Jahre 447 existierte die Theodosianische Landmauer als Doppelmauer. Die Notitia erwähnt nun aber gerade den duplex murus. Folglich kann die vorliegende Fassung dieser Beschreibung Konstantinopels nur in den Jahren 447 bis 450 entstanden sein." 
wäre. ${ }^{130}$ Den Autoren zufolge sei der in der Inschrift vorkommende Satzteil

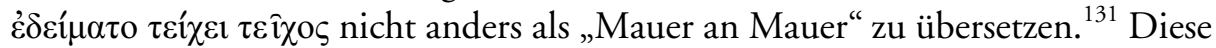
Interpretation fand nachdrückliche Zustimmung von Speck. ${ }^{132}$ Eine weitere beschädigte Inschrift, die sich heute im Depot der Archäologischen Museen von İstanbul befindet, ordnete Speck zu Recht der gleichen Serie zu. Die Inschrift ist nach Lebek folgenderweise zu lesen: ${ }^{133}$

$\Theta \varepsilon v \delta o \sigma[i ́ \omega$

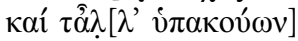

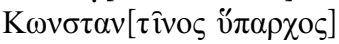

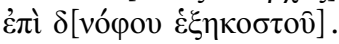

Für Theodosius vollendete die Mauer er, der ihm auch in allem übrigen gehorsam ist, der Präfekt Konstantinos am sechzigsten Abend.

Doch auf Grund einer im Jahre 1994 von Kalkan und Şahin ${ }^{134}$ in der Nähe des Belgratkapı entdeckten und von ihnen veröffentlichten Inschrifttafel brachte Lebek die Frage über die Bauzeit der Vormauer wieder in die Diskussion. ${ }^{135}$ Der

130 Meyer-Plath/Schneider, Landmauer, 17 (Schneider): „Es erhebt sich nun eine prinzipielle Frage, die bisher auf Grund einer falsch interpretierten Inschrift (Nr. 33) allgemein im gegenteiligen Sinne gelöst wurde. Man ist nämlich der Ansicht, daß Vormauer und Graben erst 447 vor die längst vollendete Hauptmauer gelegt worden seien. Bei näherer Betrachtung ergibt sich jedoch, daß beide gleichzeitig geplant gewesen sein müssen. Alle sonstigen Anlagen, die nur aus einer Mauer (evtl. mit Graben) bestehen, sind meist bedeutend niedriger ... oder haben wenigstens immer in geringer Höhe bereits Schießscharten. Der Grund ist einleuchtend: sitzen die Schießscharten zu hoch, so wird der nicht übersehbare tote Winkel zu groß und man kann den Feind nicht mehr stören, wenn er nahe genug gekommen ist ... Überdies steht noch in der Notitia urbis Constantinopolitanae, die nach 425, aber sicher vor 444 anzusetzen ist, klipp und klar: ,Auch die Strecke, die als offenes Land das Band des Meeres nicht umschließt, beschützt eine doppelte turmbewehrte Mauer“"; (18): „Zuerst wird man die Hauptmauer errichtet haben und zwar rasch, da ja Gefahr im Verzuge war, und danach gleich die Vormauer." (Meyer-Plath, 24): „Die bestimmt nicht nach 440 errichtete Vormauer..."; hingegen (33): „Zunächst fällt auf, daß ihre Mauertechnik an keiner einzigen Stelle auch nur annähernd mit unserer Hauptmauer übereinstimmt. Das führt zu der Annahme, daß die Vormauer nicht gleichzeitig mit der Hauptmauer, sondern erst gegen Ende der theodosischen Regierung errichtet wurde."

131 Meyer-Plath/Schneider, Landmauer, 17 und 132 (Schneider). - Croke, Earthquakes,

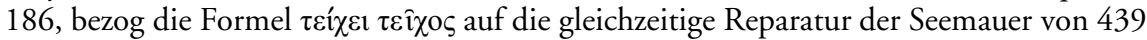
und der Landmauer, veranlaßt durch das Beben des Jahres 447.

132 Speck, Mauerbau, 135-178, bes.161-162, Anm.44; vgl. auch Müller-Wiener, Topographie, 287-288.

133 Kalkan/Şahin, Bauepigramm, 150; Lebek, Bauepigramm, 135-136 (danach die Übersetzung).

134 İstanbul, Arkeoloji Müzeleri, Inv.-Nr. 94.53; siehe dazu Kalkan/Şahin, Bauepigramm, 145-155, Taf. 15.

135 Lebek, Bauepigramm, 107-154, bes. 137-146. 
Text der neunzeiligen Inschrift in Hexametern wird hier nach der Lesung von Feissel wiedergegeben: ${ }^{136}$

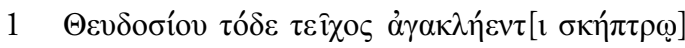

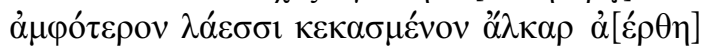

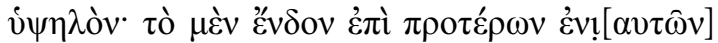

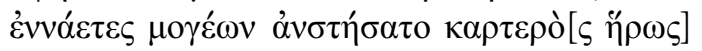

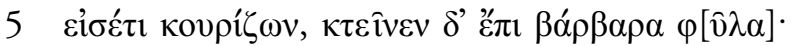

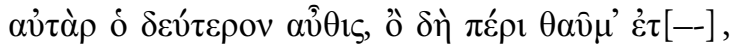

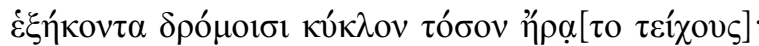

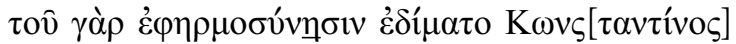

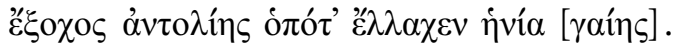

Feissel übersetzte:

De Théodose [sous le sceptre] glorieux, cette muraille, double défence excellemment faite de pierres, [fut érigée] bien haut. Celle de l'intérieur, au cours des années précédents, en neuf ans d'efforts l'a élevée le vaillant [héros], d'âge encore juvénile, et qui tuait en outre des races barbares. C'est à nouveau lui que, une seconde fois, et c'est de quoi l'on s'émerveille, érigea en soixante cours du jour un tel cercle [de muraille]. C'est en effet suivant ses ordres que l'édifia Kônstantinos, l'eminent, quand il eut pris les rênes de la terre d'Orient. ${ }^{137}$

136 Der textkritische Kommentar und die Übersetzung von Kalkan/Şahin sind durch Feissels Lesungsvorschlag hinfällig geworden, vgl. Feissel, Inscriptions, 566-568; Feissel, Chroniques, 57-58, Nr. 170. Allerdings wird die Lesung kontrovers diskutiert. Lebek, Bauepigramm, 138-146, setzt sich in seiner Textanalyse mit Feissel, Inscriptions, auseinander und gibt eine abweichende Lesung und Übersetzung. Feissel, Chroniques, 61, Nr. 186, bemerkt dazu: „Cette version nouvelle ... est loin de s'imposer, mais une critique détaillée serait ici trop longue."

137 Demnach müßte die deutsche Übersetzung lauten: „Von Theodosius, unter seinem hochgepriesenen Szepter, wurde diese doppelte Schutzwehr ausgezeichnet aus Stein hoch erbaut. Die innere in früheren Jahren, neun Jahre sich mühend, hat der tapfere Held, noch jugendlich, aufgeführt, gegen Barbarenstämme kämpfend. Indes ein weiteres Mal, weshalb man sich aufs höchste verwundert, fügte er in sechzig Tagesläufen diesen Mauerring an. Denn auf seinen Befehlt erbaute sie der hervorragende Konstantinos, als er die Zügel des Ostens innehatte." - Ich füge hier auch Lebeks Übersetzung an, weil dadurch die Tendenz seiner Interpretation deutlich wird: „Von Theodosius stammt diese Mauer hier [und] die hochberühmte [Vormauer], / beide durch Steinmaterial ausgezeichnet, (beide) ein Bollwerk [gegen den Krieg]. / Den inneren Hochbau erstellte in früheren Ja[hren], / neun Jahre sich abmühend, [der] gewaltige [Mann], / als er noch ein Jüngling war; außerdem war er damit beschäftigt, Barbaren[stämme] zu töten. / Jedoch ein zweites Mal fügte er wiederum - worüber wahrhaftig [noch größeres] Staunen herrscht - / in sechzig Umläufen (der Sonne) eine ebenso lange Mauer [außen] an. / Denn auf Grund seines Befehls erbaute sie Kons[tantinos], /die Eminenz, als er die Zügel des [gesamten] Ostens übertragen bekommen hatte." 
Aus dem Fundort der Inschrift („,ca. $140 \mathrm{~m}$ südlich von Belgrat-Kapi, vor dem 20. Turm ... in dem Stadtviertel Yedikule ${ }^{\text {“138) }}$ schlußfolgerte Lebek: ${ }^{139}$ „Da dieser Fundort auf der Stadtseite der Innenmauer liegt, wird die Inschrift ursprünglich eben an der Stadtseite der Innenmauer angebracht gewesen sein." Das ist jedoch ein Trugschluß, da Kalkan/Şahin ausdrücklich betont hatten, daß die fragmentierte Platte nur in zweiter Verwendung - als Bauspolie - eingesetzt war. ${ }^{140}$ Beide Autoren bezogen die Inschrift lediglich auf den Wiederaufbau der Hauptmauer durch Konstantios, ${ }^{141}$ veranlaßt durch das Erdbeben von 447.

Die Frage, ob die Vormauer zum ursprünglichen Konzept gehört hat, ist für die archäologische Beurteilung der gesamten Befestigungsanlage von entscheidender Bedeutung. Lebek vertrat nach eingehender Untersuchung der Reparaturinschriften - insbesondere der zuletzt erwähnten neuen - und unter Hinzuziehung weiterer Quellen die Meinung, daß die Hauptmauer gegen 405 unter Anthemios begonnen wurde und nach neunjähriger Bauzeit am 4. April 413 vollendet war. ${ }^{142}$ Die Vormauer sei hingegen durch Konstantinos 447 nach 60 Tagen Bauzeit hinzugefügt worden; erst seit diesem Zeitpunkt habe es die Doppelmauer gegeben. ${ }^{143}$ Die Möglichkeit, daß die Vormauer 447 nur repariert werden mußte, wurde in diesem Zusammenhang lediglich von Speck erwogen ${ }^{144}$ und von Croke mit weiteren Argumenten unterstützt. ${ }^{145}$

Ein Argument von Lebek kann bereits an dieser Stelle entkräftet werden: Die Tatsache, daß in den Reparaturinschriften ein Erdbeben als Auslöser der

138 Kalkan/Şahin, Bauepigramm, 150-151.

139 Lebek, Bauepigramm, 137.

$140 \mathrm{Kalkan} /$ Şahin, Bauepigramm, Taf. 14b (Fundstelle).

$141 \mathrm{Zu}$ Konstantinos siehe PLRE II, 317-318. (Fl. Constantinus 22).

142 Lebek, Bauepigramm, 112-117. - Lebek hat die Diskrepanz neun Jahre für die Hauptmauer / 60 Tage für die Reparatur 447 durchaus bemerkt und verfällt in die seltsame Ausflucht: „Solange an der Mauer gebaut wurde, dürfte die Präfektur für Anthemios sicher gewesen sein."

143 Lebek, Bauepigramm, 116-117 (diese Behauptung steht hier noch vor jeglicher Beweisführung); zustimmend Berger, Regionen, 350: „Neuerdings ist W. D. Lebek mit guten Gründen erneut für die zuerst von J. B. Bury aufgestellte These eingetreten, daß Haupt- und Vormauer dieser Befestigung nicht gemeinsam in den Jahren vor 413 errichtet wurden, sondern die Vormauer erst 447 hinzukam. “ Da Berger die Notitia, worin die Doppelmauer erwähnt wird, dem Jahr 425 zuschrieb, wie zumeist angenommen wird, führte er weiterhin aus (351): „Daß die neue Mauer nur am Schluß erwähnt wird, ist auch dann nicht erklärbar, wenn die Vormauer erst im Jahr 447 erbaut wurde, da sie als einfache Befestigung zur Zeit der Redaktion des Haupttextes schon bestand. Allerdings sollte man bedenken, daß der Raum zwischen ihr und der konstantinischen Befestigung noch lange Zeit nicht als eigentliches Stadtgebiet, sondern als befestigtes Vorland betrachtet wurde, wie u. a. die durchgehende Verwendung des Friedhofs bei der Mokioszisterne zeigt."

144 Speck, Mauerbau, 139-140.

145 Croke, Earthquakes, $122-147$. 
Arbeiten nicht erwähnt wird, ${ }^{146}$ besagt nichts, denn in keiner einzigen der zahlreich erhaltenen Reparaturinschriften ${ }^{147}$ wird die Ursache der Beschädigung mitgeteilt. Wir erfahren also niemals, ob ein Erdbeben oder ein feindlicher Angriff zu Zerstörungen an den Mauern geführt hatte, sondern können die Gründe bestenfalls aus der historischen Parallelüberlieferung erschließen.

Lebek hat sich bei der Interpretation der Reparaturinschriften auf das Jahr 447 festgelegt und den Grund für die Baumaßnamen in einem Erdbeben oder mehreren Erdbeben gesucht. Er befaßte sich in seiner Untersuchung zunächst mit den Quellen, die über diese Erdbeben und die dadurch veranlaßten Reparaturen berichten. Da er weder den Artikel von Downey zitierte ${ }^{148}$ noch den Aufsatz von Croke berücksichtigte, der die Beben von 438 und 447 im Zusammenhang mit den Baumaßnahmen des Konstantinos untersucht hat, ${ }^{149}$ ist ihm entgangen, daß die Hauptstadt - von früheren Beben abgesehen ${ }^{150}$ - bereits am 25. September 438 von einem Erdbeben heimgesucht worden war. Allerdings hatte schon Downey, der das Ereignis noch auf den 25. September 437 datierte, zur Quellenlage bemerkt, daß die Nachrichten zu den beiden Beben teilweise vermischt worden sind. ${ }^{151}$

Im folgenden sollen die von Lebek herangezogenen Quellen und seine Interpretationen kritisch geprüft werden, obwohl viele seiner Schlußfolgerungen durch die Untersuchung von Croke bereits hinfällig geworden waren. Dabei geht es mir nicht darum, grundsätzlich in Frage zu stellen, daß Konstantinos die Vormauer errichtet hatte, sondern vielmehr um den Nachweis, daß die Vormauer von Anfang an zum theodosianischen Konzept gehörte und durch Konstantinos nur neu aufgeführt wurde, weil sie vermutlich durch ein Erdbeben zerstört worden war. In den zitierten Textstellen habe ich bei den Übersetzungen die relevanten Zeit- und Sachangaben kursiv hervorgehoben.

146 Lebek, Bauepigramm, 116.

147 Siehe dazu Meyer-Plath/Schneider, Landmauer, 123-144 (Schneider); vgl auch Mango, Inscriptions, 53-54.

148 Downey, Earthquakes.

149 Croke, Earthquakes, 127 -131 (25. September 438), 131-140 (26. Januar 447).

150 Für die theodosianische Zeit siehe die Erdbebenlisten bei Downey, Earthquakes, 597 598, und Hermann, Erdbeben, 1104-1113, die jedoch vielfach der Korrektur bedürfen; vgl. Cameron, Earthquake, 343-360; Croke, Marcellinus, zu den Jahren 396, 400, 402, 403, 417, 423, 438 und 442; Guidoboni, Catalogue, unter den entsprechenden Jahren.

151 Downey, Earthquakes, 597: „Certain details of this earthquake [437] are mistakenly given by some sources as belonging to the earthquake of 447." Und zum Beben von 447 (ohne Tagesangabe): „Certain details of this disaster, as given in some accounts, belong to the earthquake of 437.“ - Einige von Downey für 437 (438) verzeichnete Quellen sowie weitere, die den Mauerbau in 60 Tagen mit dem Stadtpräfekten Kyros verbinden, hat schon Speck, Mauerbau, 139-140, kritisch bewertet. 
Theophanes (8. Jahrhundert) zum Jahr 438: ${ }^{152}$

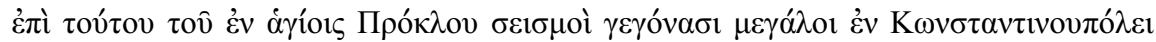

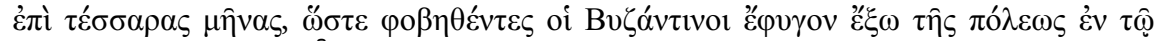

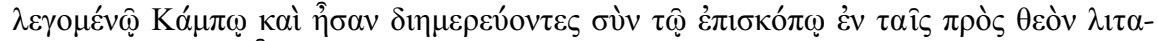

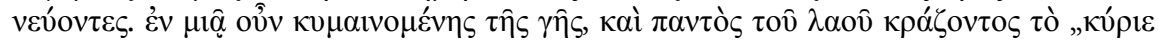

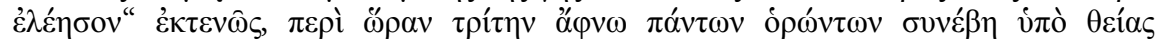

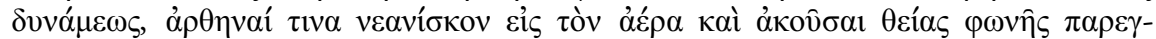

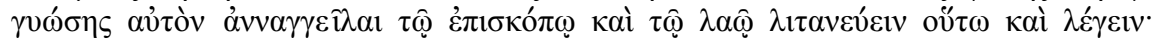
„ơ

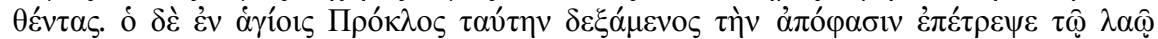

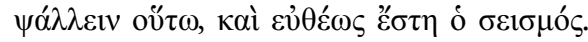

In der Zeit desselben heiligen Proklos ereigneten sich schwere Erdbeben in Konstantinopel, die vier Monate andauerten, weshalb die Byzantiner voller Furcht aus der Stadt auf den sogenannten Kampos flohen, und sie blieben dort viele Tage mit dem Bischof, indem sie Gott anflehten. Wie in einem nun die Erde erbebte und das ganze Volk inbrünstig das ,Kyrie eleison' anstimmte, etwa um die dritte Stunde, wurde vor aller Augen durch göttliche Kraft ein Jüngling zu den Lüften emporgehoben und hörte die Stimme Gottes, die ihn aufforderte, dem Bischof und dem Volk zu verkünden, ihn mit den folgenden Worten zu verehren: „Heiliger Gott, heiliger Allmächtiger, heiliger Unsterblicher, erbarme dich unser' und nichts weiter hinzuzufügen. Und der heilige Proklos vernahm die Rede und befahl dem Volk so zu singen, und sogleich hörte das Beben auf.

Theophanes nennt weder Tag noch Monat und berichtet auch nichts von Zerstörungen in Konstantinopel. Seiner Mitteilung ist lediglich zu entnehmen, daß das Erdbeben vier Monate dauerte und mit dem Trishagionwunder endete. Beben und Trishagionwunder werden jedoch im Synaxar unter dem 25. September erwähnt, wenn auch ohne Jahr, womit das Datum des Ausbruchs festgelegt ist. ${ }^{153}$ In einer Notiz der Patria (Ende 10. Jahrhundert) wird berichtet: ${ }^{154}$

Im fünften Regierungsjahr Theodosios des Jüngeren geschah ein Erdbeben, und die Stadtmauern fielen ein... Der Kaiser führte mit dem Patriarchen Proklos eine Bittprozession zum Feld des Tribunals durch...

Berger hat zwar drauf hingewiesen, daß die Zeitangabe sich auf das fünfte Amtsjahr des Proklos (438/39) bezieht, ${ }^{155}$ doch könnte die Aussage, daß in diesem Jahr die Stadtmauern beschädigt wurden, möglicherweise zutreffend

152 Theophanes ad. ann. 438, 93/5-17; vgl. Theophanes, Chronicle, 144-145. - Mango, ebd. 145, Anm.4, datiert das Beben auf September 438, da Theophanes das Ereignis nach der Beisetzung des Johannes Chrysostomus (28. Januar 438) und in das fünfte Jahr des Patriarchen Proklos (434-446), 438/39, setzt; siehe schon Speck, Mauerbau, 137 138; Croke, Earthquakes, 129; Guidoboni, Catalogue, 288-289, Nr. 176.

153 Synaxar, 79/18-80/21; vgl. Mateos, Typicon I, 44/24-45/18.

154 Patria, I 72, 150/5-16; Berger, Patria, 232-233 (danach die Übersetzung).

155 Berger, Patria, 233, jedoch ohne Erwähnung von Croke, Earthquakes. 
sein. In diesem Zusammenhang ist auch auf eine Mitteilung des Michael Glykas (12. Jahrhundert) hinzuweisen: ${ }^{156}$

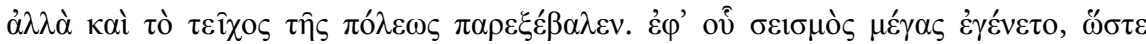

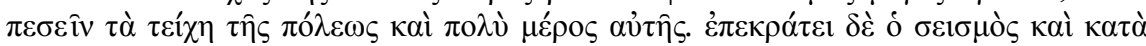

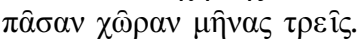

Aber auch die Mauer der Stadt schob er (Theodosius II.) vor, wonach ein großes Erdbeben geschah, so daß die Mauern der Stadt und ein großer Teil derselben einfielen.

Es dauerte das Erdbeben in der ganzen Umgegend drei Monate.

Der Patriarch Proklos, der Kaiser und der gesamte Hofstaat zogen hinaus und sangen das Trishagion. Der Bericht gleicht in manchem dem des Theophanes und der Patria, obwohl die Angabe der Dauer (drei Monate) besser zu 447 paßt (s. u.). Wenn die Nachricht auf 438 bezogen werden dürfte, hätten wir hier einen Beleg, daß bereits durch dieses frühere Erdbeben Teile der Mauer und der Stadt beschädigt wurden. Es würde dadurch zwar nicht erwiesen, daß schon 438 die Vormauer existierte, doch könnte die von Theodosius errichtete Landmauer von diesem Beben betroffen worden sein. Beiden Zeugnissen möchte ich aber kein allzu großes Gewicht beimessen. ${ }^{157}$

Marcellinus Comes (6. Jahrhundert) zum Jahr 447: ${ }^{158}$

Ich zitiere nur die für mein Thema relevanten $\$ \$ 1$ und 3 .

$\$ 1$ Ingenti terrae motu per loca varia inminente plurimi urbis augustae muri recenti adhuc reaedificatione constructi cum quinquaginta septem turribus corruerunt.

Infolge eines ungeheueren Erdbebens, das an verschiedenen Stellen losbrach, stürzten sehr viele Mauern der Kaiserstadt, die in noch unmittelbar vorangegangenem Wiederaufbau hergestellt worden waren, zusammen mit 57 Türmen ein. ${ }^{159}$

$\$ 3$ Eodem anno urbis augustae muri olim terrae motu conlapsi intra tres menses Constantino praefecto praetorio operam dante reaedificati sunt.

Im selben Jahr wurden die Mauern der Kaiserstadt, die vor Zeiten in einem Erdbeben zusammengefallen waren, innerhalb von nur drei Monaten durch die Anstrengung des Prätoriumspräfekten Konstantinos wiederaufgebaut.

Lebek untersuchte zunächst die unterschiedlichen Zeitbezüge in den beiden Paragraphen, da „mit einer Verschiebung der Nachrichten zu rechnen“ sei und

156 Glykas, 483/5-8.

157 Schon Croke, Earthquakes, 134, Anm. 50, vgl. 137, meinte: Glykas „conflate the quakes of 438 and $447 . "$

158 Marcellinus Comes ad ann.447, 82/9-19 und 24-27 (\$\$1-5); Croke, Marcellinus, 19, 88; vgl. Lebek, Bauepigramm, 121-123 (danach die Übersetzung); Guidoboni, Catalogue, 292-295, Nr. 180.

159 Es folgen Angaben über die Zerstörung, die das Beben am Forum Tauri angerichtet hatte; siehe dazu Croke, Earthquakes, 136-137. 
diskutierte zwei Möglichkeiten. - Erste Möglichkeit: Da in $\$ 1$ von einem unmittelbar vorangegangenem Wiederaufbau der 447 abermals eingestürzten Mauern und 57 Türme die Rede ist, erwog er als Ursache dafür ein früheres Erdbeben, weshalb die Reparatur nicht Konstantinos, sondern einem „früheren Verantwortlichen " zuzurechnen sei. ${ }^{160}$ - Zweite Möglichkeit: Das Erdbeben des $\$ 1$ müsse „in Wirklichkeit hinter die Wiederaufbaumaßnahmen des Konstantinos gerückt werden" ( $(\$ 3)$; der unmittelbar vorangegangene Wiederaufbau $(\$ 1)$ wäre dann die im $\$ 3$ genannte Leistung des Konstantinos im Jahre 447, während die Zerstörung der Mauern vor Zeiten (\$3) wieder auf ein viele Jahre zurückliegendes Ereignis zu beziehen sei, wobei dieses frühere Erdbeben bei Marcellinus Comes nicht erwähnt werde. ${ }^{161}$ Die Umstellung liest sich dann so:

(\$3) „Im selben Jahr wurden die Mauern der Kaiserstadt, die vor Zeiten in einem Erdbeben zusammen gefallen waren, innerhalb von nur drei Monaten durch die Anstrengung des Prätoriumspräfekten Konstantinos wiederaufgebaut."

$(\$ 1)$ „Infolge eines ungeheueren Erdbebens, das an verschiedenen Stellen losbrach, stürzten sehr viele Mauern der Kaiserstadt, die in noch unmittelbar vorangegangenem Wiederaufbau hergestellt worden waren, zusammen mit 57 Türmen ein."

Die Umstellung erscheint auf den ersten Blick einleuchtend, auch in den von Lebek vorgenommenen Verbindungen mit den anderen von Marcellinus Comes für das Jahr 447 berichteten historischen Ereignissen, doch wird dadurch der Anschein erweckt, als hätten in diesem Jahr zwei Beben stattgefunden, worauf Lebek schließlich hinaus will. ${ }^{162}$ Es muß aber die Frage gestellt werden, weshalb Marcellinus Comes nicht selbst bemerkt hat, daß die Zeitangaben in $\$ 1$ und $\$ 3$ in dieser Reihenfolge und bezogen auf das Jahr 447 in sich unstimmig sind. Man kann den beiden Aussagen auch in der bestehenden Abfolge einen logischen Sinn abgewinnen. Zum einen ist mit sehr viele Mauern, die in noch unmittelbar vorangegangenem Wiederaufbau hergestellt und nun wieder eingestürzt waren $(\$ 1)$, überhaupt nicht gesagt, um welche es sich dabei gehandelt hat. Es könnten damit die Haupt- oder die Vormauer bzw. die Seemauern gemeint sein. ${ }^{163}$ Fest steht nur, daß 1.) diese - anscheinend nicht lange vor 447 - reparierten Mauern 447 erneut zusammenbrachen $(\$ 1)$, und 2.) daß im selben Jahr 447 andere Mauern, die schon vor Zeiten bei einem Erdbeben zusammengefallenen waren, ebenfalls repariert werden mußten, und zwar durch

160 Lebek, Bauepigramm, 122.

161 Lebek, Bauepigramm, 122-123.

162 Lebek, Bauepigramm, 127-128.

163 Croke, Earthquakes, 135, bezieht die Reparatur von 447 sowohl auf die 439 errichtete Seemauer als auch auf die Landmauer. Da bei Marcellinus $(\$ 1)$ jedoch von „muri recenti adhuc reaedificatione constructi“ die Rede ist, können damit kaum die kürzlich neu errichteten Seemauern gemeint sein, abgesehen davon, daß deren Errichtung 439 überhaupt umstritten ist, vgl. Anm. 7 . 
Konstantinos in drei Monaten $(\$ 3)$. Daher ist es m. E. durchaus denkbar, daß mit den vor Zeiten $(\$ 3)$ eingefallenen Mauern die Vormauer gemeint sein könnte, die durch Konstantinos zusammen mit den schon früher hergestellten und nun wieder zerstörten repariert werden mußte. ${ }^{164}$ Offen ist nur das Datum des Erdbebens, das vor Zeiten (olim) stattfand und die früheren Reparaturen veranlaßt hatte. Darauf ist später noch einzugehen.

Was die widersprüchlichen Zeitangaben drei Monate / 60 Tage betrifft, so würde ich die authentische Auskunft der Reparaturinschriften hier höher bewerten als die späte des Marcellinus Comes, zumal die Angabe der 60 Tage innerhalb von drei Monaten nicht ganz falsch ist, wenn man die den Bau vorbereitenden Maßnahmen einkalkuliert. Die lateinische Inschrift am Mevlevihanekapı übertrieb die Kürze der Bauzeit noch mehr, indem sie „keine zwei Monate" dafür veranschlagte. ${ }^{165}$ Lebek kritisierte zwar die Harmonisierungsbemühungen früherer Forscher - Meyer-Plath/Schneider ${ }^{166}$ verbesserten bekanntlich intra (lies II) menses -, doch werde ich zeigen, daß Marcellinus Comes kein Fehler in der Zeitangabe unterlaufen ist. Auf keinen Fall kann mit Marcellinus Comes bewiesen werden, daß die Vormauer erst 447 durch Konstantinos errichtet wurde.

Johannes Malalas (6. Jahrhundert) zum 26. Januar ohne Jahr: ${ }^{167}$

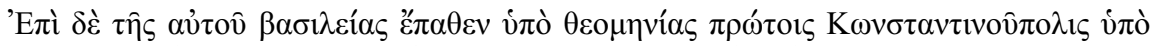

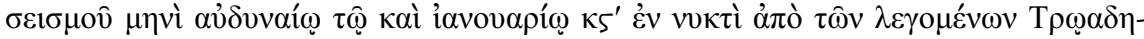

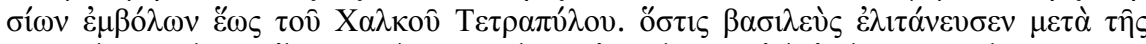

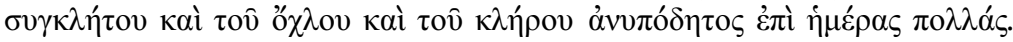

Lebek übersetzte: ${ }^{168}$

Unter seiner (des Theodosius) Herrschaft wurde durch einen Ausbruch göttlichen Zorns zum ersten Mal Konstantinopel von einem Erdbeben in Mitleidenschaft gezogen am 26. Januar in der Nacht, von den sogenannten Troadesischen Säulenhallen bis zum Bronzenen Viertor. Der König betete daher zusammen mit Senat, Volk und Klerus barfuß viele Tage hindurch.

Die korrekte Übersetzung müßte jedoch lauten: ${ }^{169}$

164 Feissel, Chronique, 61 zu Nr.186, ist, wie aus seiner Kritik an Lebeks Interpretation hervorgeht, anscheinend der Ansicht, daß Konstantinos 447 nur die Hauptmauer in drei Monaten repariert habe.

165 Lebek, Bauepigramm, 134.

166 Meyer-Plath/Schneider, Landmauer, 153 unter Nr.7 (Schneider).

167 Malalas, 284/60-285/64; Lebek, Bauepigramm, 124; Croke, Earthquakes, 132-133, $143-144$.

168 Lebek, Bauepigramm, 124.

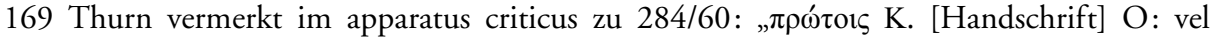

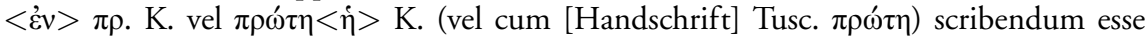
videtur." - Diesen wichtigen Hinweis verdanke ich Prof. Dr. Diether Roderich Reinsch. 
Unter seiner (des Theodosius) Herrschaft wurde durch einen Ausbruch göttlichen Zorns besonders Konstantinopel von einem Erdbeben in Mitleidenschaft gezogen am 26. Januar in der Nacht, von den sogenannten Troadensischen Säulenhallen bis zum Bronzenen Viertor. Der Kaiser betete daher zusammen mit Senat, Volk und Klerus barfuß viele Tage hindurch.

Zuvor hatte Malalas mitgeteilt, daß dieses Beben auch die bithynische Metropole Nikomedeia betroffen hatte, wodurch die Hervorhebung, daß besonders Konstantinopel in Mitleidenschaft gezogen wurde, einen Sinn ergibt. ${ }^{170}$

Euagrios Scholastikos (6. Jahrhundert): ${ }^{171}$

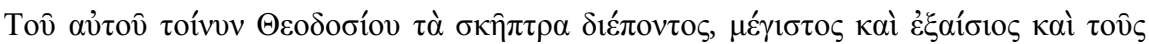

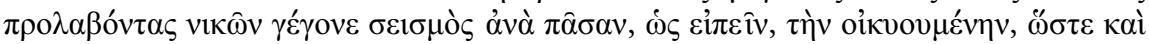

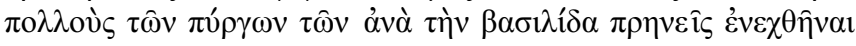

Als der jetzt regierende Theodosius [II.] das Szepter führte, geschah ein großes und gewaltiges und alle früheren übertreffendes Erdbeben sozusagen über die ganze Erde, so daß viele Türme der Kaiserstadt umgestürzt wurden.

Anschließend berichtet auch Euagrios, daß von diesem Bebeben Bithynien, der Hellespont und beiden Phrygien betroffen waren. Es handelt sich also um dasselbe schwere Beben von 447, das - ähnlich wie das letzte große Erdbeben vom 17. August 1999 - das östliche Marmara-Gebiet mit Teilen Bithyniens und Konstantinopel erfaßt hatte. ${ }^{172}$ Im Unterschied zu Euagrios vermeldet Malalas, der für den Beginn des Bebens den 26. Januar angibt, Schäden zwischen Troadensischen Hallen und Tetrapylon. ${ }^{173}$ Hier wäre die Frage zu stellen, aus welcher Quelle Malalas das Tagesdatum 26. Januar übernommen haben könnte. ${ }^{174}$

Chronicon Paschale (7. Jahrhundert) zum 6. November 447: ${ }^{175}$

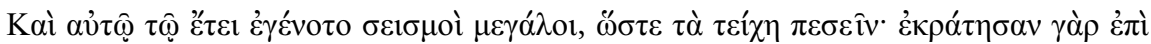

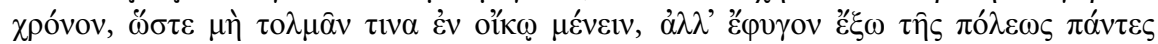

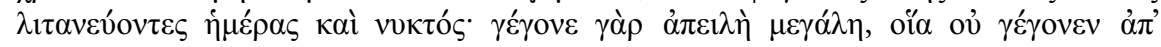

170 Malalas, 283/50-284/54; vgl. Guidoboni, Catalogue, 293.

171 Evagrius, I, 17, 26/32-27/3; englische Übersetzung: Whitby, Evagrius, 44; siehe dazu Guidoboni, Catalogue, 292-293.

172 Guidoboni, Catalogue, 292-295, Nr. 180.

173 Da Marcellinus Comes weiter von Schäden am Theodosius-Forum berichtet (siehe Anm. 163), wird das Tetrapylon an der Mese gemeint sein. Die Beschädigungen betrafen also das Gebiet zwischen dem konstantinischen Goldenen Tor am Exakionion bis zum Makros Embolos.

174 Zur Quelle des Malalas siehe Croke, Earthquakes, 133-134.

175 Chron. Pasch. ad ann. 447, 586/6-14; englische Übersetzung: Whitby/Whitby, Chronicon, 76; vgl. Croke, Earthquakes, 140-144; Lebek, Bauepigramm, 123 (danach die Übersetzung). 


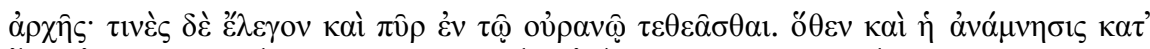

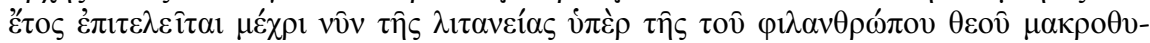

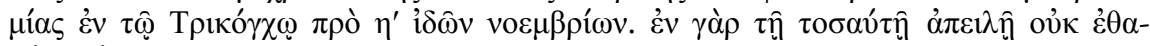

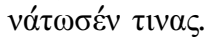

Und in eben dem Jahr gab es gewaltige Erdstöße, so daß die Mauern einstürzten. Sie dauerten nämlich längere Zeit, so daß niemand wagte, im Haus zu bleiben, sondern alle flohen aus der Stadt und beteten Tag und Nacht. Denn es war eine furchtbare Bedrohung, wie es sie von Anbeginn an nicht gab. Manche aber sagten, es sei sogar Feuer am Himmel gesehen worden. Daher wird auch die Erinnerung an das Gebet jährlich bis jetzt begangen wegen der Langmut des menschenfreundlichen Gottes, in dem Trikonchenraum am 6. November. Denn bei dieser gewaltigen Bedrohung ließ er niemanden umkommen.

Auch das Chronicon Paschale berichtet zum Jahr 447 von gewaltigen Erdstößen, die längere Zeit andauerten und die Mauern zum Einsturz brachten. Es nennt jedoch den 6. November als Datum für die jährlichen Gedächtnisfeiern zur Erinnerung an die von Gott erhörten Gebete. Zerstörungen werden nicht mitgeteilt. Nur die Bemerkung, daß niemand dabei umgekommen sei, widerspricht Marcellinus Comes, nach dessen Bericht viele Menschen durch Hungersnot und Pestgestank - zumindest in den mitbetroffenen Gebieten - gestorben seien. ${ }^{176}$ Lebek bemerkte dazu, daß die am 6. November begangene „Erinnerung nur am Tage der Rettung stattgefunden haben“ könne. Er übertrug dieses Datum als Tag des Ausbruchs auf das von Marcellinus Comes in $₫ 1$ erwähnte Erdbeben gemäß der von ihm konstruierten Reihenfolge der Ereignisse $(\$ 3, \S 1)$ mit dem Argument, daß Konstantinos nach dem 6 . November bis zum Ende seiner Amtszeit keine drei Monate mehr zum Wiederaufbau der Mauern zur Verfügung hatte. ${ }^{177}$ Die Diskussion erübrigt sich jedoch, da am 6. November 447 kein Beben stattfand, wie bereits Croke dargelegt hatte. ${ }^{178}$

Chronicon Paschale zum 26. Januar 450: ${ }^{179}$

Auf eine Wiedergabe von Text und Übersetzung kann hier verzichtet werden, da schon Meyer-Plath/Schneider erkannt hatten, daß es sich dabei um eine Doublette der Nachricht des Chronicon Paschale zum Jahr 447 handelt. ${ }^{180}$ Croke

176 Marc. Com. ad ann. 447, 82/17-19.

177 Lebek, Bauepigramm, 123-124.

178 Croke, Earthquakes, 142-143. - Das Synaxar, 197/7-199/12, vgl. Mateos, Typicon I, 90/22-23, berichtet zur Gedächtnisfeier am 6. November nichts von einem Erdbeben, wohl aber von einem Aschenregen. Speck, Mauerbau, 227 (Nachtrag zu Anm.42), hat vermutet, daß die Zeitangabe im Synaxar („im 18. Jahr Leons I.“) eine Kontamination mit dem letzten Jahr des Theodosius (450) sei, doch hatte schon Grumel, Chronologie, 478, darauf hingewiesen, daß dieser Aschenregen durch den Vesuv-Ausbruch des Jahres 472 hervorgerufen worden war; so auch Croke, Earthquakes, 142-143.

179 Chron. Pasch ad ann.450, 589/6-16; siehe dazu Croke, Earthquakes, 140-144.

180 Meyer-Plath/Schneider, Landmauer, 133, Nr. 9 (Schneider). 
hat darüber hinaus gezeigt, daß erst das Chronicon Paschale das Datum 26. Januar mit dem Jahr 450 verbunden und die betreffende Malalas-Stelle fast wortwörtlich übernommen sowie mit Passagen seines eigenen Berichts („selfplagiarism") über das angebliche Erdbeben vom 6. November 447 kombiniert hatte. ${ }^{181}$ Das Beben vom 26. Januar 450 muß demnach aus allen Listen gestrichen werden. ${ }^{182}$ Auch daß Konstantinopel unter Theodosius (II.) „zum ersten Mal“ von einem Erdbeben betroffen worden sei - ein entscheidender Punkt in Lebeks Argumentation ${ }^{183}$-, kann als erledigt gelten.

Synaxar zum 26. Januar: ${ }^{184}$

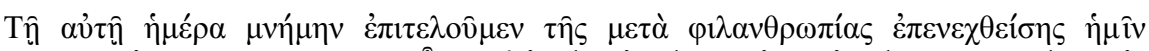


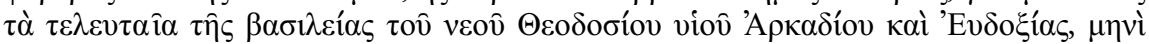

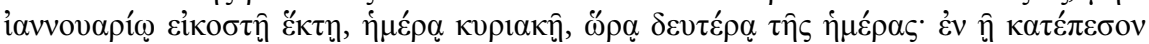

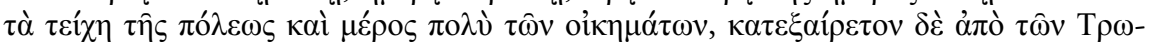

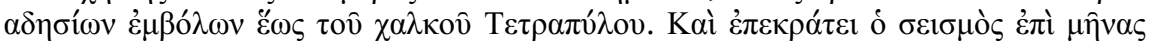
$\tau \rho \varepsilon i \bar{c}$.

An demselben Tag begehen wir die Erinnerung an die mit Menschenfreundlichkeit uns auferlegte furchtbare Bedrohung durch das Erdbeben, aus der uns wider Erwarten der Herr errettet hat. Es ereignete sich gegen Ende der Herrschaft des jüngeren Theodosius, ..., am 26. Januar, einem Sonntag, zur zweiten Tagesstunde. Bei dieser Bedrohung stürzten die Mauer der Stadt und ein großer Teil der Gebäude zusammen, besonders von den Troadesischen Säulenhallen bis zum Bronzenen Viertor. Und es dauerte das Erdbeben drei Monate lang.

Im Falle des 26. Januar ist der Tag des Ausbruchs als Erinnerungstag begangen worden. Das Synaxar sagt eindeutig, daß sich das Erdbeben gegen Ende der Herrschaft Theodosius' II. an einem 26. Januar und einem Sonntag ereignet habe. Malalas gibt nur das Tagesdatum 26. Januar an. Downey bezog zwar Malalas, Chronicon Paschale (zum Jahr 450) und Synaxarnotiz noch auf den 26. Januar 450, was viel besser zum „Ende der Herrschaft des jüngerem Theodosius" passen würde als jedes Datum vor 447, doch fiel der 26. Januar 450 nicht auf einen Sonntag, sondern auf einen Donnerstag. Die Kombination 26. Januar und Sonntag hatten bereits Meyer-Plath/Schneider mit den Jahren 441 und 447 verbunden, in denen der 26. Januar auf einen Sonntag fiel. ${ }^{185}$ Lebek argumentierte folgenderweise: ${ }^{186}$

181 Croke, Earthquake, 142-143. - Lebeck, Bauepigramm, 124-125, kam zwar zu ähnlichen Schlußfolgerungen, aber leider 14 Jahre zu spät.

182 Siehe auch Guidoboni, Catalogue, 294-295.

183 Lebek, Bauepigramm, 124-125.

184 Synaxar, 425/1-11; vgl. Mateos, Typicon I, 212/1-2; Lebek, Bauepigramm, 126 (danach die Übersetzung).

185 Meyer-Plath/Schneider, Landmauer, 153, unter Nr. 11 (Schneider); siehe auch Croke, Earthquakes, 144. 
Aber ein Beben am 26. Januar 447 wäre nicht mit der Aussage des Marcellinus Comes zu vereinbaren, der Prätoriumspräfekt habe in diesem Jahr die olim entstandenen Erdbebenschäden beseitigt. Also wird das Jahr 441 das Jahr sein, in dem

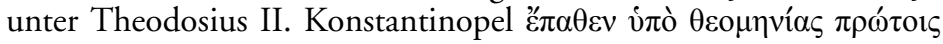

Ein Beben des Jahres 441 ist aber in keiner Liste zu finden. ${ }^{187}$ Allein Lebek behauptet, daß Malalas dieses Beben für 441 bezeuge. Viel näher hätte es gelegen, an das Beben von 438 zu denken, obwohl dafür Schäden nicht sicher belegt sind.

Seine Rekonstruktion der Ereignisse faßte Lebek wie folgt zusammen: $\left.{ }^{188} 1.\right)$ Erstes großes Erdbeben am Sonntag, dem 26. Januar 441 (Malalas und Synaxar). - 2.) Konstantinos beseitigt 447 in nur drei Monaten die Erdbebenschäden des Jahres 441 (Marcellinus Comes [\$3]). Anschließend errichtet er in 60 Tagen - Mai bis Juni - die Vormauer (Reparaturinschriften). - 3.) Am 6. November 447 erneut schweres Erdbeben (Chronicon Paschale zum Jahr 447, eventuell Marcellinus Comes [\$1]).

Hingegen hatte schon Croke die Abfolge der Ereignisse folgenderweise zusammengestellt: ${ }^{189}$

1. The quake in 438 (not 437) was the occasion for the origin of the Trisagion but had little damaging effect. It was celebrated annually at Constantinople with a procession to the Hebdomon on September 25.

2. The quake celebrated in the liturgical calendars on January 26 happened in 447. It was a very destructive quake and caused the emperor to appear barefoot with the people to pray for atonement. The land and sea walls were rebuilt within sixty days under the supervision of the Praetorian Prefect, Constantine. The quake was remembered annually at the Hebdomon, later at the Helenianai.

3. The entries for the quake of 447 in the Chronicon Paschale form a clear doublet. That under 450 describes the quake of 447 while that under 447 also describes the quake of that year but confuses its annual commemoration with the eruption of Mt. Vesuvius in 472.

4. The earthquake which appears in the standard catalogues under the year 450 must be deleted. It is simply that of 447 misplaced in the Chronicon Paschale.

Wir besitzen also verschiedene Daten für Ausbruch und Dauer der Erdbeben sowie die angerichteten Zerstörungen, wobei die Notiz in den Patria und die Mitteilung des Michael Glykas (s. o.) hier unberücksichtigt bleiben, da Ereignisse der Jahre 438 und 447 vermengt zu sein scheinen:

186 Lebek, Bauepigramm, 126.

187 Das sicher belegte Beben vom 17. April 442 (Theophanes ad, ann.442, 96/5-20; Theophanes, Chronicle, 150) fiel auf einen Freitag, könnte aber Konstantinopel betroffen haben, vgl. Guidoboni, Catalogue, 290, Nr. 177; über Schäden wird nichts mitgeteilt.

188 Lebek, Bauepigramm, 127-128.

189 Croke, Earthquakes, 145. 
1. 438, vier Monate, ohne Tages- und Monatsangabe (Theophanes); 25. September ohne Jahr (Synaxar): Trishagionwunder, keine Schäden mitgeteilt

2. vor Zeiten $=$ vor 447 (Marcellinus Comes [\$3]): die vor Zeiten zusammengefallenen Mauern durch Konstantinos 447 in drei Monaten wieder aufgebaut

3. 447, ohne Tages- und Monatsangabe (Marcellinus Comes [\$1]): die unmittelbar vorher $(=$ vor 447$)$ wieder aufgebauten Mauern und 57 Türme stürzen ein

4. „6. November“ 447, längere Zeit (Chronicon Paschale zum Jahr 447): Mauern beschädigt

5. Seit 26. Januar ohne Jahres- und Tagesangabe, viele Tage hindurch (Malalas): Schäden zwischen Troadensischen Hallen und Tetrapylon $(=447)$

6. 26. Januar, Sonntag, ohne Jahresangabe, „gegen Ende der Herrschaft des jüngeren Theodosius") drei Monate lang (Synaxar zum 26. Januar): Schäden an Mauern und Gebäuden zwischen Troadensischen Hallen und Tetrapylon $(=447)$

7. Ohne Datum, Zeit Theodosius' II. (Euagrios): viele Türme $(=447)$

Es ist klar, daß das Tagesdatum - 25. September - nicht zu 447 paßt, denn vom 25. September bis 6 . November sind es gerade einmal 6 Wochen, nicht aber 60 Tage bzw. drei Monate. Vom 6. November 447 bis 26. Januar 450 sind es zwar knapp drei Monate, doch entfallen sowohl der 6. November 447 als auch der 26. Januar 450. Das Beben des Jahres 447 kann dann nur am Sonntag, dem 26. Januar begonnen und drei Monate gedauert haben. Es richtete Schäden zwischen Troadensischen Hallen und Tetrapylon bzw. an den Stadtmauern und Gebäuden an. Nach Marcellinus Comes brachte es Teile der erst kürzlich wieder aufgebauten Mauern und 57 Türme zum Einsturz. ${ }^{190}$ Das dreimonatige Beben, das am Sonntag, dem 26. Januar 447 begann, müßte demnach bis Ende April angedauert haben. Es bleiben also für die Reparaturarbeiten nur die Monate Mai, Juni und Juli (die drei Monate des Marcellinus Comes), innerhalb derer Konstantinos an 60 Tagen sowohl die unmittelbar vorher reparierten und wieder eingestürzten Mauern und 57 Türme sowie auch die schon vor Zeiten bei einem Erdbeben eingefallenen Mauern neu aufgeführt haben müßte. In einem Punkt ist auch Croke zu widersprechen, der die eilige Reparatur mit Blick auf die Hunnengefahr bereits Ende März 447 als vollendet ansah, denn zu diesem Zeitpunkt dauerten die Beben noch an. ${ }^{191}$

Wäre das viermonatige Beben, das am 25. September 438 einsetzte (oder das angebliche von Sonntag, dem 26. Januar 441 nach Lebek) der Grund für die

190 Anders Speck, Mauerbau, 227, Nachtrag zu Anm. 42: Ein Beben mit Höhepunkten am 6. November 446 (sic) und 26. Januar 447. Aber auch ein Beben am 6. November 446 ist nur eine Fiktion.

191 Croke, Earthquakes, 138. 
dreimonatigen Reparaturen des Jahres 447 gewesen, dann ist es kaum vorstellbar, daß die (nicht näher bezeichneten) Mauern fast neun Jahre (bzw. sechs Jahre nach Lebek) in beschädigtem Zustand verblieben wären und Theodosius II. sich erst 447 wohl angesichts der drohenden Hunnengefahr veranlaßt gesehen habe, die notwendigen Reparaturen durch Konstantios in nur drei Monaten durchführen zu lassen. Schließlich sind, wie Malalas ausdrücklich hervorhob, noch unmittelbar vor 447 Mauern wiederhergestellt worden. Es ist also zu fragen, welche „vor Zeiten“ eingefallenen Mauern durch Konstantinos innerhalb von nur drei Monaten wieder aufgebaut (reaedificati) wurden, wenn diese Mauern jahrelang unrepariert geblieben sein sollten. Malalas und das Synaxar zum 26. Januar sprechen nur von Schäden zwischen Troadensischen Hallen und Tetrapylon, wobei das Synaxar auch Mauern (und Gebäude) anführt. Es besteht immerhin die Möglichkeit, daß lediglich die Hauptmauer, nicht aber die Vormauer vor 447 repariert worden war und die Leistungen des Konstantinos die wieder notwendig gewordene Reparatur der Hauptmauer und die Wiedererrichtung der „vor Zeiten“ zerstörten Vormauer umfaßten. Es darf hier daran erinnert werden, daß die neue Bauinschrift, die beide Mauern erwähnt, von manchen Forschern in diesem Sinne verstanden wird. ${ }^{192}$ Daher ist die unterschiedliche Mauertechnik an Haupt- und Vormauer, die in Lebeks Argumentation eine so wichtige Rolle spielt, kein Sachgrund, der beweisen könnte, daß erst seit 447 die Doppelmauer existiert habe.

Noch auf eine späte von Lebek herangezogene Quelle ist hier einzugehen. Im Zusammenhang mit der Belagerung Konstantinopels durch Ioannes Kantakuzenos (1344) berichtet Nikephoros Gregoras über die Mauerreparaturen des Megas Dux Alexios Apokaukos folgenderweise: ${ }^{193}$

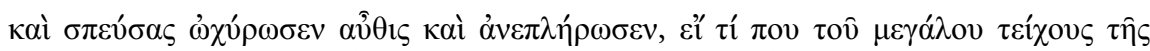

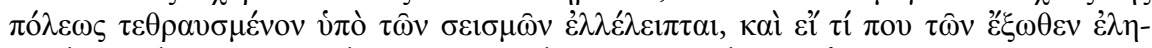

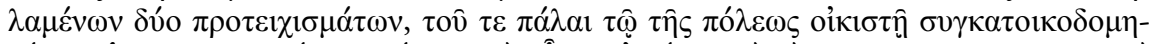

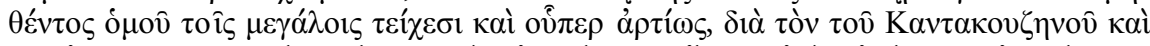

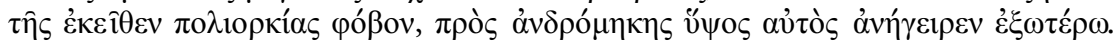

Eilends verstärkte und ergänzte er andererseits das, was irgendwo in der großen Stadtmauer durch die Erdbeben beschädigt zurückgeblieben war, und das gleiche tat er auch bei den zwei außenherum angelegten Vormauern; eine davon wurde einst vom Stadtgründer zugleich mit den großen Mauern mitgebaut und eine hatte er selbst vor kurzer Zeit aus Angst vor einer Belagerung durch Kantakuzenos noch weiter nach außen in Mannshöhe errichtet, und zwar entlang den großen und staunenswerten Gräben.

192 So von Kalkan/Şahin, Bauepigramm, 150-151; Feissel, Chronique, 61, Nr. 186.

193 Nikephoros Gregoras, 711/12-19; deutsch: Van Dieten, Nikephoros, III, 123. 
Lebek glaubte, daß hierdurch „die Frage, ob Konstantinos die Außenmauer errichtet hat, endgültig positiv zu beantworten ist" ${ }^{\text {" }}{ }^{194}$ Wenn ich die Stelle richtig verstehe, hatte Alexios Apokaukos die Hauptmauer und die beiden Vormauern repariert, wobei mit der letztgenannten Mauer, die er mannshoch aufführen ließ, die äußere Grabenmauer gemeint ist, die dadurch die Funktion eines dritten Mauergürtels erhielt. Nikephoros Gregoras behauptet weiter, daß die eine der beiden Vormauern vor alters vom Stadtgründer „zugleich mit den

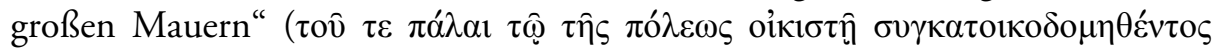

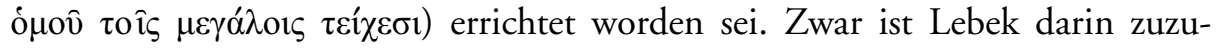
stimmen, daß hier Konstantinos mit dem Stadtgründer Konstantin dem Großen verwechselt wurde, doch müßte, um bei seiner Argumentation zu bleiben, dann auch die Hauptmauer und nicht nur die Vormauer von Konstantinos erbaut worden sein. Die Stelle taugt also nicht, um damit beweisen zu können, daß erst Konstantinos die Vormauer errichtet habe.

\subsubsection{Die archäologischen Zeugnisse}

Ein weiterer Mangel der auf philologischen und historischen Überlegungen basierenden Arbeit von Lebek ist die gänzliche Aussparung der archäologischen Zeugnisse und der dadurch zu gewinnenden Erkenntnisse. Hier sollen daher zwei archäologische Belege für die gleichzeitige Konzipierung von Vor- und Hauptmauer angeführt werden.

Bereits 1993 hatten Deckers und Serdaroğlu das nördlich von Silivrikapı (Pege-Tor) entdeckte Hypogäum ausführlich beschrieben (Abb. 73). ${ }^{195}$ Beide Autoren haben über die Bauweise und Entstehungszeit folgende Feststellungen getroffen: 1.) Die Schwelle der nach außen führenden nördlichen Pforte von Turm 37 liegt fast auf demselben Niveau wie die Sohle der Innenarkaden der Vormauer, womit das Laufniveau des Zwingers nach Errichtung der Vormauer

194 Lebek, Bauepigramm, 119.

195 Deckers/Serdaroğlu, Hypogäum I, 140-163; vgl. Deckers/Serdaroğlu, Hypogäum II, 674-681. - Ein weiteres Beispiel (vor Turm 46) bei Tunay, Findings, 218-231, bes. 220-221. Der Autor gibt aber weder Maße für das Fundniveau an noch scheint er Überlegungen angestellt zu haben, wie sich das Hypogäum zum Laufniveau des Zwingers verhalten haben könnte. Wegen der vier in Wandmalerei angebrachten Kreuze datiert er das Grab in die ikonoklastische Zeit. Dabei hätte ein Blick auf die Dekorationen im Hypogäum von Şehremini (Nezih Fıratli, Notes sur quelques hypogées paléo-chrétiens de Constantinople, in: Tortulae, 131-135, Abb.4) zeigen können, daß die Malereien noch dem 6. Jahrhundert angehören. - Die Grabanlage bei Turm 46 wird von MarieHenriette Gates, Archaeology in Turkey, in: AJA 99 (1995) 249, mit dem Hypogäum von Silivrikapı verwechselt. Für die zwischen Mevlevihanekapı und Millet Caddesi innerhalb des Zwingers gefundenen Grabsteine siehe Tunay, ebd., 220. Zu weiteren Gräbern siehe Ersen, Physical Evidence, 102-115. 
bezeichnet wird (Abb. 32, 73). ${ }^{196}$ Nach deren Erbauung war das ursprüngliche spätantike Niveau zwischen beiden Mauern um reichlich $3 \mathrm{~m}$ aufgefüllt worden: „Der Scheitel des Hypogäums lag seit der Spätantike unter dem Laufniveau, der heute freistehende Grabbau war einst also unsichtbar." - 2.) Das Hypogäum wurde erst nachträglich in die Auffüllung des Zwingers eingesenkt. Die Außenmauern sind gegen das anstehende Erdreich der Baugrubenwände gesetzt worden (anhaftende Erdreste am Mörtel). - 3.) Das flache Satteldach ist mit Kalksteinplatten abgedeckt, deren Oberseiten keinerlei Verwitterungsspuren aufweisen. Es war bis zur Höhe des Laufniveaus mit Kies aufgefüllt und hatte eine Art Entlüftung in Gestalt zweier senkrecht eingesetzter Tonröhren. - 4.) Die Eingangsseite hatte einen glatten Putzverstrich und war auf Sicht angelegt; davor muß sich der Schacht mit der Treppe befunden haben. - 5.) Die Scheinsarkophage im Inneren sind aus stilistischen und ikonographischen Gründen in das erste Viertel des 5. Jahrhunderts zu datieren.

Die Sicherung der Datierung ist schon deswegen wichtig, weil auch Deckers/Serdaroğlu von der Annahme ausgingen, daß mit der Fertigstellung der Doppelmauer „415“ ein terminus post quem für die Eintiefung des Hypogäums (und der anderen unterirdischen Grabanlagen im Zwischenmauergürtel) gegeben sei. Da jedoch kein einziges stilistisches Merkmal der im Mauerbereich gefundenen Scheinsarkophage über 450 hinausweist, ${ }^{197}$ wird dem möglichen Einwand, das Hypogäum könnte erst nach 447 angelegt worden sein, sofort der Boden entzogen. Die im Codex Theodosianus den Eigentümern der mit den Mauern überbauten Grundstücke zugestandenen Rechte und Pflichten ${ }^{198}$ schlossen also die Weiterbenutzung der vorhandenen und die Errichtung neuer Grabanlagen ein.

Ein Blick auf den Querschnitt durch den Doppelmauergürtel (Abb. 22. $73)^{199}$ und auf den heutigen Zustand des Zwingers zeigt, daß dessen Auffüllung nur abschnittsweise erhalten ist. Auf keinen Fall wäre es möglich gewesen, auf dem gewachsenen Boden vor dem etwa $3 \mathrm{~m}$ hohen Mauersockel ein freistehendes Mausoleum zu errichten, das erst später - nach Erbauung der Vormauer und Auffüllung des Zwingers - unter die Erde geriet. Die Errichtung des Hypogäums bei Silivrikapı spätestens im ersten Viertel des 5. Jahrhundert setzt also die Existenz von Haupt- und Vormauer sowie des aufgefüllten Zwingers voraus. ${ }^{200}$

196 Siehe auch Van Millingen, Walls, Faltplan nach 106.

197 So etwa das Berliner Mosesrelief, das bis 1880 als Spolie an der Landmauer befestigt war und wohl ebenfalls aus einem Hypogäum stammt; vgl. Effenberger, Mosesrelief, 237 259.

198 Siehe Anm. 2.

199 Krischen, Landmauer, Abb. 4.

200 Anders Berger, Regionen, 351, Anm.5, der den archäologischen Befund unzutreffend interpretiert: „Eine Errichtung der Vormauer länger nach der Hauptmauer ist auch 
Ein weiterer archäologischer Beleg kann aus einer Beobachtung am Goldenen Tor gewonnen werden: Die Vormauer verläuft von Norden kommend zunächst parallel zur Hauptmauer und fluchtet mit einem leichten Versatz in die Nordwestecke des nördlichen Pylonen ein. Etwa $4 \mathrm{~m}$ vor der Nordwestecke biegt sie jedoch in einem Winkel von ca. $20^{\circ}$ nach Westen ab und mündet in die Nordwand des sog. Vorwerks (Abb. 38). In den etwa $3 \mathrm{~m}$ breiten Zwischenraum zwischen Nordwestecke des Pylonen und Innenseite der abknickenden Vormauer wurde nachträglich ein Durchgang eingefügt. In diesem Bereich konnte jedoch der Rest des ursprünglichen Verlaufs der Vormauer beobachtet werden (Abb. 39) ${ }^{201}$ Meyer-Plath/Schneider beschrieben diesen Befund folgenderweise: ${ }^{202}$

In dem heutigen Baubestand ist aber leider kein Stück theodosischen Mauerwerks zu finden, so daß wir in der Herstellung des Vorwerks lediglich auf den Grabungsbefund neben der Nordwestecke des Nordturms angewiesen sind [Abb. 14; Taf. 30c]. Dort war festgestellt worden, daß eine zur Hälfte an den Turmsockel gelehnte Ziegeltonne über die Vormauerflucht hinausgeht. Wir wissen zwar nicht, wie weit, da ihr westliches Ende zerstört wurde, aber sie gibt uns die Möglichkeit, die Vormauerflucht nach Westen springen zu lassen. Führen wir die Mauer in einem solchen Abstand an der Torwand vorbei, daß sich ein quadratischer Torhof bildet, wie er z. B. auch bei dem Rhesiumtor vorkommt, so fällt dieser Mauerzug mit dem ältesten Teil des heute noch stehenden mittelbyzantinischen Vortors zusammen [Abb. I 5].

Man kann sich anhand dieses Befunds auch vorstellen, daß die Vormauer ursprünglich in gerader Linie vor dem Tor vorbeilief, aber nach Erbauung der Pylonen umgeleitet werden mußte. Damit stellt sich auch die Frage, ob das Goldene Tor bereits einen Vorgängerbau hatte, auf den der alte Verlauf der Vormauer bezogen war, worauf im folgenden Abschnitt eingegangen werden soll.

deshalb sehr wahrscheinlich, weil die meisten der im dazwischenliegenden Raum unmittelbar vor der Hauptmauer 1992/93 entdeckten Gräber auf dem Niveau der Umgebung liegen und nicht auf dem 2-3m höheren neuen, das durch die Anschüttung des Zwingers bis zum Wehrgang der Vormauer entstand."

201 Meyer-Plath/Schneider, Landmauer, 50, Abb. 14, Taf. 30c.

202 Meyer-Plath/Schneider, Landmauer, 59-60, mit Hinweis auf Abb. I 5 (gemeint ist Krischen, Landmauer, Abb. $5=$ rekonstruierter Grundriß des Goldenen Tors von Meyer-Plath). 


\subsubsection{Zur Errichtungszeit des Goldenen Tors}

Im südlichen Abschnitt der Landmauer zwischen zwei mit Marmor verkleideten Pylonen (Türme 9 und 10) befindet sich das Goldene Tor, das die Stadt mit der Via Egnatia verbindet (Abb. 3, 36, 37, 38, 120, 121). ${ }^{203}$ Während ein Tor der Konstantins-Mauer in der Notitia urbis Contantinopolitanae, die in theodosianischer Zeit - möglicherweise um $425^{204}$ - abgefaßt wurde, als porta aurea bezeichnet wird, hat der Autor das Goldene Tor der Theodosianischen Landmauer erstaunlicherweise ignoriert. ${ }^{205}$ Seit der sicheren Identifizierung mit der

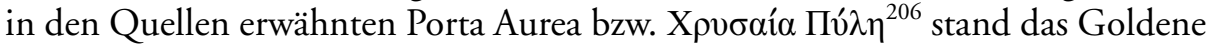
Tor häufig im Mittelpunkt der Diskussion. Dabei ging es um die Frage, ob das Tor erst zur Zeit Theodosius' II. und gleichzeitig mit der Landmauer erbaut wurde, ${ }^{207}$ oder ob ein bereits bestehendes Triumphtor des Kaisers Theodosius I. in die neue Verteidigungsanlage nur integriert worden sein könnte. ${ }^{208}$ Die einst auf dem Bogen des mittleren Durchgangs an der Stadt- und Feldseite angebrachte Inschrift, wovon heute nur noch die Aufnahmelöcher der ehernen und vergoldeten Buchstaben zu erkennen sind (Abb. 120), wurde in diesem $\mathrm{Zu}$ sammenhang unterschiedlich interpretiert. Die Inschrift lautete: ${ }^{209}$

Stadtseite: Haec loca Theudosius decorat post fata Tyranni

Feldseite: Aurea saecla gerit qui portam construit auro

203 Van Millingen, Walls, 72, meint, daß das Tor für den täglichen Verkehr gesperrt war. Meyer-Plath/Schneider, Landmauer, 39, zufolge wurde das Tor sowohl für den täglichen Verkehr als auch für die kaiserlichen Prozessionen benutzt.

204 Vgl. Anm. 129, 130, 143. - Speck, Mauerbau, 144-159, datierte die Notitia zwischen $423-427$.

205 Notitia, 239/8 und 243/56. - Als erster hatte dies Van Millingen, Walls, 30-31, erkannt, was bis heute allgemeine Akzeptanz findet (siehe Anm. 239), vgl. Berger, Regionen, 372; Mango, Triumphal Way, 175. Anders jedoch Preger, Konstantinsmauer, 459, und Schneider, Byzanz, 7.

206 Siehe Du Cagne, Historiae, 52; vgl. Dagron, Constantinople, 269, 330. - Erste wissenschaftliche Untersuchung des Tors durch Strzygowski, Goldenes Thor, 1-39. - Im folgenden wird nur die Literatur zitiert, die mit meiner Fragestellung unmittelbar zusammenhängt.

207 So z. B. Weigand, Goldenes Tor, 1-64; Janin, Constantinople, 269-270; Meyer-Plath/ Schneider, Landmauer, 39-40; Müller-Wiener, Topographie, 297; Krautheimer, Architecture, 73; Mango, Développement, 50; ders., Triumphal Way, 179; Ahunbay, Surlar, 78.

208 Strzygowski, Goldenes Thor, 1-39; Van Millingen, Walls, 67; Preger, Konstantinsmauer, 459; Wheeler, Golden Gate, 238-241. - Mamboury, Constantinople, 206, war zunächst der Meinung, daß die Pylonen erst im 14. Jahrhundert errichtet wurden, was er später (Mamboury, Istanbul, 234-238) wieder zurückgenommen hat.

209 CIL III, 735; Meyer-Plath/Schneider, Landmauer, 125, Nr. 8 (Schneider). 
Aus dem ersten Teil der Inschrift geht hervor, daß der Sieg über einen namentlich nicht genannten Tyrannen Kaiser Theodosius den Anlaß gegeben hatte, diesen Platz zu dekorieren. Der zweite Teil der Inschrift vermittelt, daß der gleiche Kaiser das Tor - als Zeugnis des anbrechenden Goldenen Zeitalters mit Gold konstruierte. Die Forscher, die sich für Theodosius I. als Erbauer des Goldenen Tors entschieden haben, gingen davon aus, daß nur dieser Kaiser einen Tyrannen bezwungen hatte und brachten den in der Inschrift erwähnten Tyrannen mit Magnus Maximus in Verbindung, ${ }^{210}$ der im Jahre 388 von Theodosius I. besiegt worden war. Daher erschien eine Datierung des Tors in die Jahre bald nach 388 plausibel. Diese Möglichkeit wurde zunächst deswegen abgelehnt, weil auch Theodosius II. gegen einen Tyrannen, und zwar gegen Johannes Primicerius zu kämpfen hatte, den ein von ihm entsandtes Heer unter Ardabur und Aspar 425 vor Ravenna besiegte. ${ }^{211}$

Die von Macridy/Casson 1927 durchgeführten Sondagen bestätigten zwar, daß die marmornen Pylone mit dem Tor gleichzeitig errichtet worden sind, doch konnten die Ausgräber nicht klären, ob auch die anschließenden Kurtinen mit den Pylonen zeitgleich sind, da die nördliche in palaiologischer und osmanischer Zeit intensiv repariert bzw. wiederhergestellt worden war $^{212}$ und die Eckverbindung der südlichen Kurtine mit dem Pylonen damals zum größten Teil unter dem Schutt lag (Abb. 126-128). Meyer-Plath/Schneider haben nur die obere Partie in Augenschein nehmen können, wo für die Verbindung des Pylonen mit der südlichen Kurtine statt Marmorquader teilweise Blöcke aus Kalkstein verwendet worden waren. Beide Autoren hatten keinen Zweifel daran, $\mathrm{da}$ die Pylone und die anschließenden Mauern in der gleichen Zeit entstanden sind. ${ }^{213}$ Nachdem im Jahre 1958/59 der Schutt abgetragen worden war, konnten auch die unteren Bereiche dieser Ecke studiert werden (Abb. 126), weshalb

210 Vgl. Anm. 208; für weitere Literatur und auch unterschiedliche Beweisführungen siehe zuletzt Bardill, Triumphal Arch, 671-696.

211 Weigand, Goldenes Tor, 1-64, bes. 4; Schweinfurth, Porte Doreé, 268-270; für weitere Diskussionen siehe Meyer-Plath/Schneider, Landmauer, 43. - Speck, Mauerbau, 141, zufolge betrifft das in der Inschrift erwähnte Wort „konstruieren“ nur die Vergoldung der bronzenen Torflügel, die nach dem Sieg Theodosius' II. über den Usurpator Johannes erfolgte, siehe auch ebd., 165, Anm 52e. - Zur Überwindung des Johannes siehe Alexander Demandt, Die Spätantike. Römische Geschichte von Diocletian bis Justinian 284-565 n. Chr., München 1989, 150.

212 Macridy/Casson, Excavations, 63-84, Taf. XLII (meine Abb. 29, mit Eintragungen). Korrigierter Grundriß bei Meyer-Plath/Schneider, Landmauer, 40, Abb. 8.

213 Schneider/Meyer, Zweiter Vorbericht, 16-17: „An der Ecke, wo Mauer und Südturm aufeinander stoßen, fanden wir Verzähnungsstellen, wo die Kalksteinquadern der Hauptmauer in die Marmorquadern des Turms einbinden. Diese Beobachtung sowie die ganz sinnvolle Eingliederung von Vormauerplattform und Toranlage beweisen jetzt endgültig, daß Goldenes Tor und Landmauer gleichzeitig gebaut sind." Siehe auch Meyer-Plath/Schneider, Landmauer, 50, Taf. 28a. 
Duyuran die Gleichzeitigkeit des südlichen Pylonen und der südlichen Kurtine erneut in Frage stellte. ${ }^{214}$ Auf diese Problematik ging unlängst Bardill ein und äußerte sich in diesem Zusammenhang wie folgt: ${ }^{215}$

There is, in fact, very little evidence of bonding. The ends of almost all of the large limestone blocks of the fortification appear to be flush with the south face of the tower. Chips in the limestone blocks where they meet the tower reveal that the $3^{\text {rd }}$, $4^{\text {th }}, 7^{\text {th }}, 10^{\text {th }}, 11^{\text {th }}, 12^{\text {th }}$, and $13^{\text {th }}$ courses of marble continue behind the west face of the fortification wall, although for how far is uncertain. The faces of the marble blocks in the $2^{\text {nd }}, 6^{\text {th }}, 10^{\text {th }}, 11^{\text {th }}, 12^{\text {th }}, 13^{\text {th }}, 18^{\text {th }}, 19^{\text {th }}$, and $20^{\text {th }}$ courses have been cracked inwards, almost certainly when the limestone blocks were pushed up against them. These observations leave little doubt that the Gate was already standing when the wall was built.

Bardill zufolge sollten sowohl diese Beobachtungen als auch die Inschrift zugunsten von Theodosius I. interpretiert werden. ${ }^{216}$ Die Verwendung von Kalkstein statt Marmor brachte er - entgegen Meyer-Plath/Schneider - mit einer Beobachtung von Davis zusammen und schlußfolgerte: ${ }^{217}$

There can therefore be little doubt that the limestone was inserted when the fortification was being built. Meyer-Plath and Schneider, who believed that the Gate and fortification were built simultaneously, explained these limestone blocks as fillers inserted because the marble blocks in the Gate were not quite long enough to reach the face of the curtain wall. The workmanship in the Gate, however, is otherwise of extremely high quality, and would it be difficult to explain these ill fitting limestone blocks as part of the original structure.,

Der Autor dokumentierte darüber hinaus anhand von Fotos, daß der plastische Schmuck dem Tor rasch und sorglos hinzugefügt worden war, und brachte diese unübersehbare Tatsache mit Theodosius II. in Verbindung. ${ }^{218}$ Doch nicht nur die Anbringung des plastischen Schmucks (Abb. 203), sondern überhaupt die Errichtung der gesamten Toranlage scheint in einer raschen Bauphase erfolgt zu sein, wie bereits Macridy/Casson festgestellt haben: ${ }^{219}$

The clearance of the courtyard revealed the lower mouldings of the arches of the Golden Gate as well as those of the towers. These mouldings were unfinished, and were cut only at the junction stones, serving as guiders for the masons who were to complete the work. In the same way the blocks in position often retained their bosses which were used for hoisting them into position.

214 Rüstem Duyuran, A Propos des Premiers Travaux de Restauration de Yedikoulé (La Château des Sept-Tours), in: TTOKB, 208/209 (1959) 23.

215 Bardill, Triumphal Arch, 673-681, Zitat 677.

216 Bardill, Triumphal Arch, 693, zufolge sei der „Triumphbogen“ bewußt auf der Route, die vom Hebdomon in die Stadt führt, errichtet worden; vgl. ders., Brickstamps, 29-30.

217 Bardill, Triumphal Arch, 677-680, Zitat 677; vgl. Davies, The Date, 74-75.

218 Bardill, Triumphal Arch, 681-683; 682, Fig. 11, 12; 683, Fig. 13, 15; 684, Fig. 16.

219 Macridy/Casson, Excavations, 68. 
Bardill wies selbst auf diese Unstimmigkeiten hin ${ }^{220}$ weshalb m. E. nicht unbedingt von einer „extremely high quality“ die Rede sein kann (Abb. 122). Es ist daher die Frage berechtigt, die bereits Schweinfurt gestellt hat, auf die aber später nie wieder eingegangen wurde: ${ }^{221} \mathrm{Ob}$ nämlich die gesamte Anlage erst im Jahre 425, also unmittelbar nach dem Sieg über Johannes Primicerius, in die Landmauer in einem schnellen Arbeitsprozeß integriert worden sein könnte, was auch das Schweigen der Notitia über dieses Tor erklären würde. Obwohl die Beobachtungen von Bardill an den Verbindungsstellen des südlichen Pylonen und der südlichen Kurtine durchaus zutreffend sind, könnten diese Unstimmigkeiten am Mauerwerk auch dadurch zustande gekommen sein, daß man hier einen Teil der Mauer abgerissen, das Goldene Tor eingefügt und die entstandenen Mauerschäden wieder repariert hatte (Abb. 126-128). Das würde auch erklären, weshalb die Quader hinter der Kurtine verschwinden. Diese Möglichkeit wurde von Bardill mit folgendem Argument abgelehnt:222

It may be added that there is clearly no possibility that the Gate is later then the fortifications. If that were the case, it would have been necessary to demolish a section of the completed Anthemian inner wall to make way for the Gate.

Diese Behauptung basiert jedoch nicht auf einer archäologischen Untersuchung. Wir wissen nämlich nicht, was unter der heutigen Anlage verborgen liegt. Darüber hinaus stammt - wie oben erwähnt - die nördliche Kurtine erst aus palaiologischer bzw. osmanischer Zeit. Auch die beiden Treppentürme verhindern eine Untersuchung an der Stadtseite. Uns ist nur bekannt, daß an der Verbindungsstelle zwischen dem südlichen Pylonen und der benachbarten Kurtine bauliche Veränderungen stattfanden.

Archäologische Hinweise können allein den Untersuchungen von Macridy/ Casson entnommen werden, die für unsere Fragestellung von großer Bedeutung sind (Abb. 29). Auf ihrem Grabungsplan befindet sich ein mit dem Buchstaben a bezeichneter Sondageschnitt direkt an der Westseite des nördlichen Pylonen. ${ }^{223}$ Ein weiterer Schnitt, der mit dem Buchstaben b gekennzeichnet ist, wurde an der Südwestecke des gleichen Turms geöffnet. An beiden Stellen

220 Bardill, Triumphal Arch, 681-683, Zitat 681, dokumentierte detailliert den raschen Zusammensetzungsprozeß der Bauplastik. Im gleichen Aufsatz (677) weist der Autor auf weitere Unstimmigkeiten hin: "The mouldings around the foot of the Gate and its towers were never completed, but lines were scored to indicate where they were to be cut, and short sections (ca. $20 \mathrm{~cm}$ long) were occasionally carved where two marble blocks abut one another." Vgl. auch Meyer-Plath/Schneider, Landmauer, 48, 58.

221 Schweinfurth, Porte dorée, 268-271, bes. 271: „C'est donc Jean le Primicère qui fut le 'tyran' de l'inscription de la PorteDorée. Elle fut installée dans le mur terrestre par Théodose II en peu de temps après l'an 425."

222 Bardill, Triumphal Arch, 681.

223 Macridy/Casson, Excavations, Taf. XLII (meine Abb. 29). 
konnte man die Fundamentierung der Pylonen in Augenschein nehmen. Die Autoren beschreiben die Befunde wir folgt: ${ }^{224}$

From these we found that this immense marble structure rests on a foundation of no less than eleven courses of stone. All the blocks of these foundation courses are rectangular and most carefully masoned. The total substructure which reaches the rock at $4.30 \mathrm{~m}$. below the level of the main courtyard is an astonishing piece of work. On some blocks are seen, cut into the surface, small crosses, a practice common among Byzantine masons.

Ein dritter Sondageschnitt (Buchstabe c auf dem Plan) wurde an der inneren Nordostecke des Hofs angelegt, wo der nördliche Pylon und das Torhaus zusammentreffen. ${ }^{225}$ Die Sondagebefunde wurden von Macridy/Casson folgenderweise beschrieben: 226

Here even more interesting details were discovered. The foundation structure here consists of three distinct elements. The foundations properly so called which rest on the rock are formed of a wall of masonry $1.86 \mathrm{~m}$. in height, constructed with small unequal stones. This wall extends continuously to the right. Above it we have another wall composed of larger stones, rectangular in shape, roughly cut, with cemented joints. This wall makes a right-angle turn into the interior of the archway. On this wall are built five rows of blocks of limestone, which are rectangular and which follow the same direction. What was the object of the architect at this point is uncertain. It is possible that the architect was using the remains of an earlier building; but this remains pure hypothesis.

Macridy/Casson haben hier einen Befund beobachtet, der möglicherweise zu einem Vorgängerbau gehörte, und damit eine interessante Hypothese aufgestellt. Hingegen haben Meyer-Plath/Schneider einen Teil der Fundamentierung (Sondage c) nur für die Gründung des nördlichen Torpfeilers gehalten, ohne die Möglichkeit eines älteren Vorgängerbaus in Erwägung zu ziehen. ${ }^{227}$ Der von Macridy/Casson freigelegte Mauerzug war in die Fundamentierung des nördlichen Pylonen und der inneren Nordostecke des Torhauses einbezogen und lief an der Innenseite des nördlichen Durchgangs weiter in Richtung Osten. Für ein solches Fundament kann eine frühere Turmnische in Betracht kommen, an deren Westseite sich ein Turm befand und ebenso eine damit verbundene Toranlage, die aber anders beschaffen gewesen sein muß als die heutige. Wenn man auf diesem Fundament einen den Tortürmen der Theodosianischen Landmauer entsprechenden Turm rekonstruiert und auch an der Südseite einen korrespondierenden Torturm annimmt, käme man auf ein ca. $9 \mathrm{~m}$ breites, mit Topkap1 vergleichbares Torhaus (Abb. 16, 29) (siehe Abschnitt 2.2.1.). Eine

224 Macridy/Casson, Excavations, 69, Taf. XLII (meine Abb. 29); Taf. XXXVII, Abb. 2; Taf. XXXVIII, Abb. 1.

225 Macridy/Casson, Excavations, Taf. XLII (meine Abb. 29).

226 Macridy/Casson, Excavations, 69-70, Abb. 2.

227 Meyer-Plath/Schneider, Landmauer, 45. 
weitere Nische - möglicherweise unterhalb der ehemaligen Tortreppe - nahm die Stelle ein, wo heute die seitlichen Torkammern liegen. Es ist also möglich, daß sich am Platz des heutigen Goldenen Tors ein älteres Stadttor befand, das ungefähr ähnlich ausgesehen haben wird wie die anderen theodosianischen Stadttore der Landmauer. Damit könnte auch der Vorschlag von Schweinfurth eine archäologische Untermauerung erfahren. ${ }^{228}$

Wie bereits oben vermerkt, hatte die Errichtung der Pylonen Auswirkung auf den Verlauf der Vormauer. Die beiden in unterschiedlichen Winkeln parallel zur Hauptmauer auf das Tor zulaufenden Schenkel der Vormauer müssen von einem gewissen Punkt an parallel zur westlichen Flucht des älteren Tors verlaufen sein und das Vortor enthalten haben. Verlängert man in diesem Sinne die beiden feldseitigen Mauerfluchten (Abb. 37), so treffen sie ziemlich genau auf die Mitte der Westseiten der Pylonen, d.h. die Westseiten der Pylonen folgen noch der ursprünglichen Außenlinie der Vormauer. Allerdings sind bei Errichtung der Pylonen nicht die Fundamente der Vormauer wiederverwendet worden, sondern diese erhielten eine eigene Fundamentierung, wie die Sondage a von Macridy/Casson zeigt. ${ }^{229}$ Nach Fertigstellung der Pylonen mußte die Vormauer umgeleitet werden, da ihr ursprünglicher Verlauf durch die beiden Pylonen unterbrochen worden war. Meyer-Plath/Schneider haben an der Nordwestecke des nördlichen Pylonen den im vorigen Abschnitt erwähnten Rest einer halben Ziegeltonne freigelegt (Abb. 39), ${ }^{230}$ die einerseits die jetzt notwendig gewordene Anbindung der inneren Mauerschale mit ihren Bogenstellungen an den neuen Turmsockel, andererseits die Abweichung der Vormauer in diesem Bereich belegt. ${ }^{231}$ In einer bereits 1933 angefertigten Zeichnung mit dem ergänzten Grundriß des Goldenen Tors hatte Meyer-Plath den hypothetischen Verlauf der Vormauer festgehalten (Abb. 38). ${ }^{232}$ Die Annahme eines Vorsprungs an dieser Stelle überzeugt jedoch nicht.

Obwohl endgültige Klarheit nur durch weitere Sondagen gewonnen werden könnte, sollte m.E. von der Existenz einer älteren Toranlage ausgegangen werden. Man kann zunächst folgende Hypothese aufstellen: Anhand der neuen Inschrift, die von einer neunjährigen Bauzeit spricht, ${ }^{233}$ ist auszuschließen, daß Kaiser Theodosius II., der zum Zeitpunkt der Planung und Errichtung der Landmauern noch ein Knabe war, diese Vorgänge mitbestimmen und beeinflussen konnte. Vieles geschah nach den Vorstellungen seines Vaters, des Kaisers Arkadius, und - nach dessen Tor (408) - des Anthemios. Aber als ein 25-

228 Vgl. Anm. 221.

229 Vgl. Anm. 223.

230 Vgl. Anm. 201 und 202.

231 Meyer-Plath/Schneider, Landmauer, 59 (Meyer-Plath).

232 Krischen, Landmauer, 11, Abb. 5 (Zeichnung von BM = Bruno Meyer).

233 Vgl. Anm. 3. 
jähriger Mann und unmittelbar nach seinem Sieg über den Usurpator Johannes Primicerius ließ er das in die Landmauer integrierte ältere Tor von 413 umbauen. Während dieser Umbauarbeiten wurden die Tortürme der ursprünglichen Toranlage entfernt und die breite Wand für das neue Torhaus aufgeführt sowie die gewaltigen, mit Marmor verkleideten Pylonen errichtet. Die Toreingänge wurden neu gestaltet und in einer raschen Arbeitsphase die Pfeiler, Kapitelle usw. angebracht und die Türöffnungen gerahmt.

Es sollte hier noch ein weiterer Punkt beachtet werden: Das nördliche Nachbartor, und zwar Belgratkapı (Abb. 11, 36), war sicherlich eines der wichtigsten Tore der Stadt, wo sich auch der dritte Meilenstein befand. ${ }^{234}$ Wie Mango dargelegt hat, verlief eine der Triumphalstraßen der konstantinischen Stadt über die heutige Cerrahpaşa Caddesi. ${ }^{235}$ Das ursprüngliche Triumphaltor der Konstantins-Mauer - die in der Notitia erwähnte porta aurea - lag in der Nähe der İsakapısı Mescidi beim Exakionion. ${ }^{236}$ Nach der Erweiterung der Stadt in Richtung Westen und nach dem Bau der Theodosianischen Mauer korrespondierte dieses Tor nur mit Belgratkapı, von dem aus ein gerader Weg direkt zum Arkadius-Forum führte (Abb. 37). ${ }^{237}$ Obwohl Kaiser Arkadius weder sein Forum noch seine Mauer vollenden konnte, ist anzunehmen, daß er an der Stelle des Goldenen Tors kein Triumphaltor vorgesehen hatte. ${ }^{238}$ Nach dem Tode des Kaisers wurden die Planungen von Anthemios weitergeführt und am Ort des Goldenen Tors zunächst ein normales Stadttor errichtet. Erst nach dem Triumph des jungen Kaisers Theodosius II. 425 wurde die alte Vormauer abgetragen und das Tor in ein Prunktor umgewandelt, wobei die Vormauer einen neuen Verlauf erhielt. Dies erklärt auch, weshalb die gewaltige Toranlage in der Notitia noch keine Erwähnung fand. ${ }^{239}$

234 Berger, Triton, 63-67.

235 Mango, Triumphal Way, 176.

236 Siehe zuletzt Mango, Triumphal Way, 176.

237 Mango, Triumphal Way, 176; für die Route der Straße außerhalb der Stadt siehe ebd., 175, und ders., Développement, 32. Zum Arkadiusforum siehe Bauer, Denkmal, 203 204; zur Arkadius-Säule siehe Konrad, Arkadiossäule, 319-401.

238 Bardill, Triumphal Arch, 686, äußerte sich, ausgehend von der Bezeichnung porta statt arcus, folgenderweise: „The proposed interpretation raises, of course, the problem of the word porta. Its use might be explained away as a poetic usage, but it is not unlikely - and I will return to this suggestion - that Theodosius I had intended the arch to be incorporated as a gate in a line of proposed fortification."

239 Van Millingen, Walls, 31: „Why the Notitia overlooks the second Porta Aurea is explained by the point of view from which that work was written. Its author was concerned with the original city. A gate in the wall of Theodosius was only the vestibule of the corresponding Constantinian entrance." - Es soll nicht vergessen werden, daß die Notitia eine Propagandaschrift der theodosianischen Dynastie war, die vor allem deren Bauten aufzählt. Eine Anlage wie das Goldene Tor wäre eigentlich für diesen Zweck bestens geeignet gewesen, wenn es bereits errichtet worden wäre. Das kann als Argument für die Datierung der Notitia kurz vor 425 angesehen werden. 
Die von Davies und später von Bardill behandelte Verbindung (bzw. die beiden Bauphasen) zwischen dem südlichen Pylonen und der südlich anschließenden Kurtine muß während dieser Umbauarbeiten entstanden sein (Abb. 127). ${ }^{240}$ Somit kann nicht länger ausgeschlossen werden, daß das Goldene Tor nicht zum Erstkonzept der Landmauer gehörte, sondern später - wahrscheinlich im Jahre 425 - hinzugefügt wurde. Daraus ist noch einmal zu ersehen, daß auch die Vormauer bereits vor 425 fertiggestellt war.

\subsubsection{Das Vortor des Goldenen Tors und seine Reliefwand}

Vor dem Goldenen Tor befindet sich ein U-formiges Vorwerk mit einem von Spoliensäulen eingefaßten und aus Spolienmaterial zusammengesetzten Tor. Die seitlich anschließenden Mauern sind an der Feldseite mit einen Rahmenwerk dekoriert, das ursprünglich jeweils sechs Reliefs in zwei Registern enthielt (Abb. 7, 8, 121, 123, 125). Obwohl das Errichtungsdatum des Vortors, die Anbringungszeit des Rahmenwerks und der Inhalt der Reliefs in der Sekundärliteratur mehrfach diskutiert wurden, sind sich die Forscher in einigen Punkten, vor allem in der Datierung des Vortors und der Anbringungszeit der Reliefs, immer noch uneins.

Das Rahmenwerk ist nicht mehr vollständig erhalten. ${ }^{241}$ Im Mauerabschnitt rechts (südlich) des Tors weist es einen besseren Erhaltungszustand auf als an der linken (nördlichen) Seite. Über einem Bankett sind an der Südseite noch vier Pfeiler fast in ganzer Tiefe erhalten, die von einem Gesims mit Konsolen überspannt werden (Abb. 8). Ca. 1,30 m von dem vierten (südlichsten) Pfeiler entfernt befindet sich ein senkrechter Mauerschnitt, der auf den ersten Blick wie eine Baunaht wirkt (Abb. 131). Der südlich anschließende Mauerabschnitt ist mit Quadern ohne Ziegel repariert. Ein weiteres Gesimsfragment ging über den Mauerschnitt hinaus nach Süden und verlief über den reparierten Teil. ${ }^{242}$ Von den vier Konsolen ist nur die dritte von links noch intakt (Abb. 8, 185). Die übrigen Konsolen wurden abgeschlagen. ${ }^{243}$ Die Profile der in die Mauer eingelassenen Gesimse sind vom dritten bis fünften Feld von links erhalten. Deutlich sind die Stoßfugen zu erkennen, wobei über den Konsolen verkröpfte

240 Mango, Triumphal Way, 179, Anm. 45: „That does not necessarily imply that the first and second phases were separated by an appreciable lapse of time. It seems obvious to me that the gate, with its massive pylons, was planned in the context of the new land walls, which, for all we know, may have been on the drawing board already in the reign of Theodosius I." Es ist durchaus möglich, daß die Stadterweiterung und eine neue Mauer bereits von Theodosius I. ins Auge gefaßt worden waren.

241 Für eine alte Aufnahme um 1890 siehe Bizans İstanbulu, 131.

242 Vgl. Meyer-Plath/Schneider, Landmauer, 56, Taf. 29b.

243 Vgl. den Zustand auf dem alten Foto von Strzygowski, Goldenes Thor, 23, Abb. 15. 
Gesimsabschnitte eingefügt wurden (über dem dritten Pfeiler von links teilweise noch bewahrt).

In den oberen Mauerabschnitt sind Teile eines ebenfalls verkröpften Gesimses eingelassen, dessen Konsolen mit den unteren genau fluchten (Abb. 8, 205). Die hier vorauszusetzenden Pfeiler fehlen, am Mauerwerk sind keinerlei Einlassungen erkennbar. Ihre Spuren wurden entweder bei einer späteren Reparatur der Mauer entfernt, oder die Pfeiler standen vor der Wand und nicht mit ihr im Verband. ${ }^{244}$ Die Fortsetzung des oberen Gesimses nach links und rechts ist nicht mehr erhalten. Das Mauerwerk unterhalb und nördlich der oberen linken Verkröpfung ist neuzeitlich repariert. Die ursprüngliche Einlassung der rechten Fortsetzung des Gesimses wurde ebenfalls mit kleinen Quadern zugesetzt. Über dem unteren Gesims verlaufen eine Ausgleichsschicht aus zwei Quaderreihen und darüber ein durchgehendes, fünfschichtiges Ziegelband. Ebenso setzt über dem oberen Gesims ein durchlaufendes, fünfschichtiges Ziegelband an. Die obere Mauerkrone wurde in osmanischer Zeit repariert. Direkt unterhalb des unteren Gesimses sind im zweiten, dritten und vierten Feld von links noch einige Ziegelschichten zu erkennen, ebenso im dritten Feld unten rechts und in der Mittelzone des rechten äußeren. ${ }^{245}$ In vier Feldern sind etwa auf halber Höhe auffällig große und regelmäßig beschnittene Quader eingesetzt. Die Mauerecke, die zur Torwand umbricht, wurde aus Spolien (von unten nach oben: Kämpfer, Schrankenpfeiler als Läufer, Schrankenpfeiler als Eckbinder) errichtet.

Die Mauer an der nördlichen Seite weist ebenfalls zahlreiche Reparaturen unterschiedlicher Zeiten auf (Abb. 7). Die zur Torwand umbrechende Ecke wird auch hier im unteren Teil aus mächtigen Spolienblöcken gebildet. Von den fünf ursprünglichen Feldern des unteren Registers des Rahmenwerks sind die vier weitgehend abgeschlagenen Pfeiler (der linke äußere nur halb) sowie die Spuren der Konsolen erhalten. Das gesamte Gesims wurde, wie die groben Schlagspuren beweisen, nachträglich weggearbeitet. Oberhalb des linken äußeren Feldes ist in die Mauer ein als Türsturz erkennbarer Marmorblock eingelassen (Abb. 7, 123). Innerhalb der Felder ist das Mauerwerk recht unterschiedlich gebildet: In den beiden rechten sind überwiegend große Spolienblöcke, in den beiden linken ziemlich wahllos Bruchstücke von Spolien und wiederverwendete Quader eingefügt. Unterhalb des Gesimses ist ein fünfschichtiges Ziegelband erhalten. Neben dem linken äußeren Pfeilerrest sind in halber Nischenhöhe noch Ziegelschichten zu beobachten, die dem Ziegelband im rechten äußeren Feld der Südseite (Abb. 8) entsprechen. Links schließt ziemlich roh die später reparierte Vormauer an. Eine dem Mauerschnitt an der Südseite (Abb. 131) entsprechende Fuge ist hier jedoch nicht zu erkennen.

244 Vgl. Strzygowski, Goldenes Thor, 21.

245 Meyer-Plath/Schneider, Landmauer, Abb. 9. 
Weiter nördlich schließt sich eine wiederum etwas ältere Mauer mit Ziegelbändern an. Das auf dem oberen Gesims des südlichen Mauerabschnitts befindliche lateinische Kreuz auf einem Globus datiert die Spolien in das 6. Jahrhundert und setzt damit einen terminus post quem für das gesamte Arrangement. ${ }^{246}$

Die Ausgrabung von Macridy/Casson, die auch direkt vor dem Rahmenwerk erfolgten, brachten vor der Südwand einen vorspringenden Fundamentrest mit Eckverstärkung ans Licht, der in Höhe des äußeren Mauerschnitts abgerundet ist und nach Norden bis zur rechten Torsäule reicht (Abb. 29). ${ }^{247}$ Reste eines vergleichbaren Banketts wurden auch vor der nördlichen Reliefwand festgestellt. Die Autoren datierten diesen Befund in die Zeit um $447 .{ }^{248}$

Die erste schriftliche Nachricht über die Dekoration der Rahmenfelder stammt noch aus byzantinischer Zeit. Manuel Chrysoloras erwähnt im Jahre 1411 die hier angebrachten antiken Stücke mit Darstellungen von Herakles und Prometheus. ${ }^{249}$ Die zweite mir bekannte Erwähnung geht auf Cyriacus von Ancona (vor 1434) zurück, der die Reliefs des Vorwerks für Arbeiten des Phidias hielt und ihre Anbringung Kaiser Manuel II. Palaiologos (1391-1425) zuschrieb. ${ }^{250}$ Spätere Nachrichten stammen aus osmanischer Zeit. ${ }^{251}$ Petrus Gyllius (1544/50) gab eine detaillierte Beschreibung der Reliefs: ${ }^{252}$

in latere portae sinistro existu(n)t sex tabulae marmoreae, singulae habentes latera clausa columellis aliis tere(n)tibus, aliis quadratis, continentes statuas eminenter expressas affabre $(\mathrm{m})$ scalptas, nudas, clauis pugnantes, quarum superiors habent supra se cupidines velut praecipites ad volandum, in latere dextro sunt item sex tabulae cinctae similiter columellis. In prima tabula inferiori iuuenis tenens organum musicum iacet supinus, tibiis implexis, supra ipsum impe(n)det imaguncula velut Cupido, supra Cupidinem mulier: in tabula superiore est statua nuda tenens clauam erectam, pelle leonis brachio inuoluto, canes ducens manu sinistra. Supra

246 Macridy/Casson, Excavations, 74, Abb.6; so auch Mango, Triumphal Way, 181. Guberti Bassett, Golden Tor, 119 zufolge sei das Jahr 600 als terminus ante quem anzunehmen.

247 Macridy/Casson, Excavations, 75-76, Tafel XLII (meine Abb. 29). - Wie weit dieser Teil nach Westen reichte, blieb aber unklar, da die Sondage hier nicht weiter geführt werden konnte.

248 Macridy/Casson, Excavations, 75-76: „In our opinion this foundation wall is part of the curtain wall of the Propylaea built by the Prefect Constantine in 447“; vgl. Janin, Constantinople, 271: „il furent construits probablement en 447.“

249 Manuel Chrysoloras, 21/33-36; deutsche Übersetzung: Grabler, Europa, 134.

250 Mitchell/Bodnar, Scalamonti, 39, 112-139.

$251 \mathrm{Zu}$ diesbezüglichen Quellen siehe Strzygowski, Goldenes Thor, 31-32; Van Millingen, Walls, 65-66; Macridy/Casson, Excavations, 77-79; Meyer-Plath/Schneider, Landmauer, 53-57; Janin, Constantinople, 271-272; Guberti Bassett, Golden Tor, $117-$ 133; Mango, Triumphal Way, 181-186.

252 Gyllius, Topographia, IV, 9, 217-218; vgl. Mango, Statuary, 55-75, bes.75; ders., Triumphal Way, 183. 
ipsam eminet Leaena turgens vberibus. Alia tabula continet duos agricolas ferentes calathos vuis plenos. In alia tabula est eques alatus, equi frenum retinet mulier. A tergo sunt mulieres duae, in summa parte tabulae, alia mulier recubat, è regione huius iacet iuuenis.

An der linken Seite des Tors befinden sich sechs Marmorplatten, jede einzelne hat einen Rahmen, teils aus rechteckigen, teils aus runden Säulchen, mit kunstvoll in Relief ausgeführten Figuren, nackt, mit Keulen kämpfend, deren obere über sich Eroten haben, die wegzufliegen scheinen. An der rechten Seite befinden sich ebenfalls sechs Platten, die ähnlich von Säulchen eingerahmt sind. Auf der ersten Platte unten liegt rücklings ein Jüngling mit verschränkten Beinen und hält ein Musikinstrument, darüber hängt ein Figürchen gleich einem Eros und über dem Eros eine Frau. Auf der obersten Platte erscheint eine nackte Gestalt, die eine Keule aufgerichtet hält, den Arm in ein Löwenfell gewickelt hat und mit der linken Hand Hunde führt. Über dieser (Platte) befindet sich eine Löwin mit prallen Zitzen. Eine andere Platte zeigt zwei Landleute, die einen Korb voller Weintrauben tragen. Auf einer anderen Platte erscheint ein geflügeltes Pferd, dessen Zaum eine Frau hält. Dahinter sind zwei weitere Frauen, im obersten Teil der Tafel liegt zurückgelehnt eine andere Frau, gegenüber von ihr liegt ein Jüngling.

Um 1625 werden die Stücke von Sir Thomas Roe in einem an den Duke of Buckingham adressierten Brief erwähnt, der diese Reliefs für seine private Sammlung erwerben wollte. Besonders sechs Stücke hielt Roe für sehr wertvoll und beschrieb die folgenderweise: ${ }^{253}$

Two, in my opinion (though Mr. Petty like them) want much of excellence, great, but brute; and as I coniecture, are some storye of Hercules, not mentioned in his labours. The fower [four] to which I have most affection, are fuller of woorke: the one is ... an Endimion ...; Luna ... and a Cupid ...The next is an historye I understand not, eyther of some race or game; in the middest is a horse, a young man naked running by yt, and reaching to pull another off... The third is a Pegasus, with the Nimphs or Muses; one representing the founteyne Pirenne powring out water ... The last is a Satyre, sckipping betweene an Hercules, or a wild man, and a women...

Das Engagement von Roe blieb erfolglos. Einige Jahre später, 1670, wurden die Reliefs von John Covel beschrieben, der hier Endymion, Phaeton, Herakles, Pegasus, Eroten, Aphrodite, Adonis, Apollo, die Kinder des Kadmos sowie einen Mann mit einem Korb voller Weintrauben sah. ${ }^{254}$ Im Jahre 1681 schrieb Guillaume Joseph Grelot über zwei Platten aus weißem Marmor, worauf eine schlafende männliche Figur und eine aus dem Himmel herabgekommene Göttin mit Fackeln in der Hand dargestellt gewesen seien. Er interpretierte die Figuren als Endymion und Selene. ${ }^{255}$ Im März 1685 wurde das Rahmenwerk in einer Zeichnung von Franceso Scarella ohne die Reliefs festgehalten

253 The Negotiations of Sir Thomas Roe on His Embassy to the Ottoman Porte, London 1790, 386-387; abgekürzt zitiert nach Mango, Triumphal Way, 184.

254 Mango, Triumphal Way, 184-185; vgl. auch Spon/Wheeler, Voyage 1, 262-263.

255 Grelot, 66-67. 
(Abb. 40). ${ }^{256}$ Um 1700 sprich Joseph Pitton de Tournefort von den Reliefs, konnte sie jedoch selbst nicht sehen. ${ }^{257}$ Die Ausgrabungen von Macridy/Casson im Jahre 1927 förderten tatsächlich einige antike bzw. spätantike Stücke zu Tage, die zumeist von Säulensarkophagen zu stammen scheinen, wobei die Darstellungen zum Teil mit den früheren Aussagen in Verbindung gebracht werden können. ${ }^{258}$

Mit der Rekonstruktion bzw. der Entstehungszeit dieser Reliefwand beschäftigte sich die Forschung seit dem 19. Jahrhundert. Die Toranlage und die hier befindlichen Stücke wurden bereits von Strzygowski behandelt. ${ }^{259}$ Er sah das Vorwerk als Teil der Vormauer an und datierte es in das Jahr 447. Von den erhaltenen Teilen und den späteren Nachrichten ausgehend rekonstruierte er fünf Relieffelder in zwei Reihen übereinander, deren drei mittlere oben jeweils einen Bogenabschluß aufweisen. Ihm zufolge waren die Reliefs nur in den drei inneren Feldern angebracht.

Von Niketas Choniates erfahren wir zwar, daß ein neuerlich reparierter Mauerabschnitt in der Nähe des Goldenen Tors im Jahre 1204 durch die Lateiner beschädigt worden war, ${ }^{260}$ doch wird weder die genaue Stelle dieser Reparatur bezeichnet noch ist ein Bezug auf das Rahmenwerk erkennbar. ${ }^{261}$ Die Reliefwand wurde auf Grund einer Mitteilung des Ioannes Kantakuzenos bzw. des Michael Dukas von Meyer-Plath/Schneider zum einen mit Kaiser Ioannes

256 Siehe Babinger, Scarella, 159, Abb. 7.

257 Hier wurde die türkische Übersetzung benutzt: Tournefort, II/45; nach Yerasimos, ebd., Anm. 53, sind die Reliefs 1795 verlorengegangen.

258 Macridy/Casson, Excavations, 60-84. - Für eine kurze Diskussion über die möglichen Dimensionen der von den Reisenden erwähnten Reliefs siehe Mango, Triumphal Way, 185.

259 Strzygowski, Goldenes Thor, 24, registrierte die Reste eines dritten oberen Gesimses, siehe ebd., 21, Abb. 13-14; auf einem Foto von Van Millingen, Walls, gegenüber 68, ist dieses noch zu erkennen.

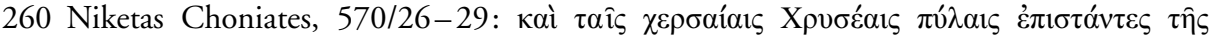

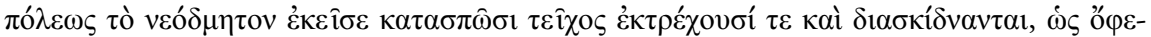

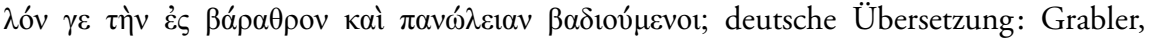
Kreuzfahrer, 146.

261 Vgl. Mango, Triumphal Way, 182, Anm 57: „Choniates, ed. van Dieten, 570.27, reports that the Byzantine notables and armed man, in their haste to flee the city in 1204, broke

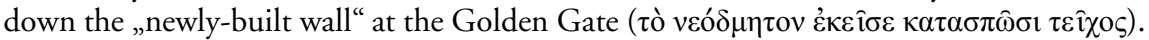
The identity of that wall remains unclear. In the Bonn edition (ed. I. Bekker [1835],

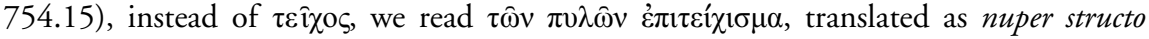
propugnaculo diruto, which has led to the unwarranted belief that the outer wall was meant. Thus Meyer-Plath and Schneider, Landmauer, 51,57: das neugebaute Vorwerk des Goldenen Tors'. 'Vgl. Meyer-Plath/Schneider, Landmauer, 57. Mayer, Staatsdenkmäler, 170, nahm augehend von der Mitteilung des Niketas Choniates an, daß diese Mauer frühestens im 13. Jahrhundert errichtet worden sei. - Auf Grund der Mitteilung von Niketas Choniates kann man nur annehmen, daß die Bereiche um das Goldene Tor 1204 ziemlich beschädigt waren. 
Kantakuzenos ${ }^{262}$ und zum anderen mit Ioannes V. Palaiologos in Verbindung gebracht - letzteres unter Bezug auf Dukas, wonach Kaiser Ioannes aus Spolien zwei Türme errichtet habe, die auf Befehl von Bayezit I. wieder abgetragen werden mußten. ${ }^{263}$ Aus Dukas geht jedoch mit keinem Wort hervor, daß Ioannes V. Palaiologos das Vorwerk des Goldenen Tors ausschmücken ließ. Vielmehr scheint es so, daß der Kaiser in der Nähe marmorne Türme und ein befestigtes Areal errichtet und dafür Spolien aus drei Kirchen genommen hatte (siehe Abschnitt 2.3.2.). Besonders die zweite Aussage von Meyer-Plath/ Schneider wurde in der wissenschaftlichen Literatur öfters zitiert. ${ }^{264}$ Guberti Bassett übernahm die Rekonstruktion von Strzygowski, wobei die drei oberen Bögen bei ihr entfielen. ${ }^{265}$ Hingegen hält Mango für die Anbringung der Reliefs das 10. Jahrhundert für wahrscheinlicher. Er sieht das Mauerstück für mittelbyzantinisch an und überlegt, ob das Rahmenwerk aus der Zeit des Kaisers Nikephoros II. Phokas (963-969) stammen könnte, zumal dieser Kaiser im Jahre 965 die beiden aus Tarsos und Mopsuestia mitgebrachten Bronzetüren im Bereich des Goldenen Tors aufstellen ließ. ${ }^{266}$

Die zahlreichen Reparaturen machen es schwer, hier eine chronologische Reihenfolge herauszufinden. Im folgenden sollen daher einige neue Befunde dargestellt und in die Überlegungen einbezogen werden. Die Stadtseite des nördlichen Abschnitts lag lange Zeit unter dem Schutt, weswegen frühere Forscher diesen Teil nur von der Feldseite aus beurteilen konnten. Die oben

262 Meyer-Plath/Schneider, Landmauer, 57: „Daß damals [kurz vor 1204] auch die Reliefs angebracht wurden, ist nicht wahrscheinlich. Vielleicht geschah das erst 1347 anläßlich der Restaurierungsarbeiten des Kaisers Cantacuzenus."

263 Meyer-Plath/Schneider, Landmauer, 60 (Meyer-Plath): „Inzwischen ist das Vorwerk und Vortor in mehreren Perioden gewachsen, ... und Kaiser Johannes V. findet 1390 noch Zeit, das Vortor mit zusammengeschleppten architektonischen Prunkstücken zu bereichern." Ebd. 42, sagt Schneider, daß die von Dukas erwähnten Türme (von Ioannes V.) stadteinwärts gesucht werden können, wo später von Mehmet II. im größeren Ausmaß die Festung Yedikule errichtet wurde. Vgl. auch Van Millingen, Walls, 104, und Janin, Constantinople, 273: „La nouvelle citadelle ainsi constituée fut le prototype du château des Sept-Tours (Yedikule) élevé en 1468 par Mahomet II.“ - Yedikule ist möglicherweise nach Maßstäben der italienischen Renaissance unter der Verantwortung von Antonio Averlino, genannt Filarete, erbaut worden, siehe dazu Restle, Filarete, 361-367.

264 So z. B. Müller-Wiener, Topographie, 297; Ousterhout, Development, 78. - Guberti Bassett, Golden Gate, 117-133, versuchte, bestimmte Stücke am Vorwerk den von Dukas erwähnten Kirchen zuzuweisen; für einen kurzen Überblick und Diskussion siehe Mango, Triumphal Way, 182, mit Anm. 58.

265 Guberti Bassett, Golden Gate, 123, Abb. 4.

266 Mango, Triumphal Way, 186; in 181 äußerte weiter: „The outer, or propylaeic, gate opens through the forward wall, which presumably had existed in one form or another since Theodosian period." - Bardill, Triumphal Arch, 671, Anm. 1, hielt eine Datierung in das 9. oder 10. Jahrhundert für möglich. 
erwähnte Mauerfuge (Abb. 131) wurde von Meyer-Plath/Schneider unter Berücksichtigung der Ergebnisse von Macridy/Casson folgenderweise gedeutet: ${ }^{267}$

Das schlechte Mauerwerk der unteren Zone und das auf Ansicht bestimmte der oberen ist wohl so zu erklären, daß die Reliefplatten zunächst nur für die untere Zone geplant waren. Dem reichverzierten Gebälk des südlichen oberen Teils ist jetzt nicht mehr anzusehen, ob es gleichzeitig mit der Mauer eingebaut wurde. Schließlich sind 12 Reliefplatten aufgestellt worden, die man sich in den mittleren drei Feldern der vier Rahmenzonen denken kann, während die acht Endfelder werden die Ecken des Torbaues gewesen sein, und die rechte Gesimsecke der unteren Zone ist beim Anbau der späten Vorwerkmauer in ihre jetzige Lage gekommen. Für eine Mauerecke sprechen auch die starken Fundamentverbreitungen an dieser Stelle.

Wie oben bereits notiert, befindet sich zwischen dem äußersten linken Pfeiler der Nordwand oberhalb der Gesimslinie ein Türsturz. Das Stück wirkt von der Feldseite her wie eine gewöhnliche Spolie, als ob damit die Mauer ausgeflickt worden wäre (Abb. 7, 123). Doch ein Blick auf die heute zugängliche Stadtseite läßt erkennen, daß es sich dabei um den Rest einer in situ erhaltenen Öffnung handelt (Abb. 129). Außer dem in zwei Hälften zerbrochenen Sturz ist noch die nördliche Wange teilweise erhalten. Der außenliegende Teil der aus zwei Marmorplatten bestehenden Türwange ist später entfernt worden (Abb. 130). Von der südlichen Wange ist nichts erhalten. An ihrer Stelle ist der linke äußerste Pfeiler fixiert, was von der Feldseite aus deutlich zu sehen ist. Die Öffnung war ca. 1,30 m breit. Die Höhe beträgt ca. 2,50 m. Man gewinnt den Eindruck, daß an dieser Stelle ursprünglich eine Pforte angebracht war. Es stellt sich daher die Frage, ob die Mauerfuge an der südlichen Seite ebenfalls der Rest einer vergleichbaren Öffnung gewesen sein könnte (Abb. 131). Die Breite des Mauerabschnitts zwischen dem erhaltenen vierten Pfeiler und der Baufuge beträgt hier ebenfalls 1,30 m. Obwohl an dieser Seite keinerlei Reste einer weiteren Türeinfassung erhalten sind, ist doch eindeutig zu erkennen, daß es sich bei dem unterhalb dieses Felds befindlichen Marmorblock um eine Türschwelle handelt, die trotz der späteren Veränderungen beibehalten worden war (Abb. 131). Es ist daraus zu schließen, daß die gesamte Vortoranlage vor der Anbringung der Reliefs ein anderes Aussehen hatte, indem das mittlere Tor (Abb. 124, 125) an beiden Seiten von je einer Öffnung flankiert wurde. Da diese Öffnungen bzw. Türen zweifellos nicht an den Mauerecken saßen, ist anzunehmen, daß die Torwand sich schon vormals an beiden Seiten in gerader Richtung fortgesetzt hatte. Während an der zugesetzten südlichen Öffnung ein Stück des Gesimses erhalten ist, sind am ehemaligen nördlichen Durchgang keinerlei Reste mehr vorhanden, doch nahm die Forschung an, daß sich das Gesims auch hier fortgesetzt hatte. Es ist also denkbar, daß es in Fortführung des Gesimses jeweils

267 Meyer-Plath/Schneider, Landmauer, 61. 
noch einen fünften Pfeiler gegeben hat. Da die Konsolen der Gesimse einem festen Rhythmus folgen und voneinander ca. 1,40 m entfernt sind, wodurch auch die Breite der Felder bestimmt wurde, kann man also annehmen, daß an beiden Enden ein weiterer Pfeiler angebracht war. Da hier eine geringere lichte Weite zu erkennen ist, müßte das Gesims etwas kürzer gewesen sein, doch läßt sich diese Möglichkeit jetzt nicht mehr überprüfen.

Nach diesen Beobachtungen stellen sich jetzt folgende Fragen: 1.) Wann wurde die Torwand errichtet? 2.) Wann wurden die seitlichen Pforten zugemauert? 3.) Welcher zeitliche Abstand lag zwischen der Schließung der Türöffnungen und der Anbringung des Rahmenwerks? Die Wand wurde auch nach der Abnahme der Reliefs bzw. Zerstörung der Gesimse in osmanischer Zeit gründlich repariert. ${ }^{268}$ Die Felder unterhalb des nordseitigen Gesimses weisen fünfschichtige Ziegelbänder auf (Abb. 7). Hingegen sind im südlichen Abschnitt die Ziegelbänder durch Quader ersetzt worden (Abb. 8). Während an der zugemauerten Tür fünfschichtige Ziegelbänder zu beobachten sind, haben die restlichen Felder auf der gleichen Flucht keinerlei Ziegelbänder. Dieser Unterschied kann entweder mit späteren Reparaturen erklärt werden, oder es lag zwischen der Errichtung der Mauer, der Verschließung der Türen und der Anbringung des Rahmenwerks mit den Reliefs jeweils eine bestimmte Zeitspanne, was anhand des Charakters der Ziegelbänder geklärt werden kann.

An der nördlichen Seite unterhalb des Karnies sind folgende Werte zu beobachten (Abb. 7): Wiederverwendete unregelmäßige Quader und fünfschichtige Ziegelbänder, Ziegelbandhöhe $62 \mathrm{~cm},{ }^{269}$ Ziegelbreite ca. $35 \mathrm{~cm}$, Ziegelhöhe 4,5 bis $6,5 \mathrm{~cm}$, Mörtelhöhe 6 bis $6,5 \mathrm{~cm}$. Ähnliche Werte begegnen an der Südseite (Abb. 8). Vergleichbares Mauerwerk kommt an verschiedenen Stellen der Landmauer vor, besonders an den stadtseitigen Kurtinen zwischen den Türmen 82 und 84 (siehe Abschnitt 2.1.2.) sowie am nördlichsten reparierten Teil der Wehrgangstreppe hinter Sulukulekapı, wobei in allen diesen Bereichen auch breitere Ziegel neben kleineren wiederverwendet worden sind. Dazu zählt weiterhin das Mauerwerk an der Nordseite des zugemauerten Tors des Leon-Vorwerks aus dem frühen 9. Jahrhundert (Abb. 149, rechts). Das unterste Ziegelband der zugemauerten Öffnung an der Nordseite des Vorwerks des Goldenen Tors (Abb. 7, 123) weist folgende Werte auf: Drei Quaderreihen - soweit erkennbar - und fünfschichtige Ziegelbänder, Ziegelbandhöhe $60 \mathrm{~cm}$, Ziegelbreite 37 bis $38 \mathrm{~cm}$, Ziegelhöhe 3,5 bis $4 \mathrm{~cm}$, Mörtelhöhe 6 bis $7 \mathrm{~cm}$. An der Südseite begegnen folgende Werte: Ziegelbandhöhe $70 \mathrm{~cm}$, Ziegelbreite $36 \mathrm{~cm}$, Ziegelhöhe 4 bis $5 \mathrm{~cm}$, Mörtelhöhe 7 bis $8 \mathrm{~cm}$. Sowohl die Mauerwerte

268 Auf dem mittleren Tor des Vorwerks stand einst eine Tuğra des Sultans Mahmut II. (1785-1839) mit Jahresangabe 1838, vgl. meine Abb. 124.

269 Die von Meyer-Plath/Schneider, Landmauer, 56, registrierten $66 \mathrm{~cm}$ hohen Ziegelbänder sind nicht zu erkennen. 
der Vortoranlage als auch der Füllung lassen sich weder mit komnenischen noch mit palaiologischen Mauerwerten vergleichen. Die über $60 \mathrm{~cm}$ Höhe erreichenden fünfschichtigen Ziegelbänder dieses Mauerabschnitts können mit großer Wahrscheinlichkeit in den Beginn des 9. Jahrhunderts datieren werden, wobei auch die Füllung m. E. nicht später als 10. Jahrhundert sein wird (siehe Abschnitt 2.1.2. und 4.2.). Es ist daher denkbar, daß im 9. Jahrhundert das mit einem mittleren und zwei flankierenden Durchgängen ausgestattet Vortor des Goldenen Tors im 10. Jahrhundert durch die Anbringung des Rahmenwerks und der Reliefs verändert wurde.

Den oben erwähnten Überlegungen von Mango kann eine weitere literarische Quelle hinzugefügt werden: Nach Leon Diakonos ritt Kaiser Nikephoros II. Phokas 963 in einer Prozession durch das Goldene Tor in die Stadt hinein. Der Autor gab in diesem Zusammenhang eine Beschreibung des Kaisers und verglich seine Tapferkeit und Stärke mit Herakles. ${ }^{270} \mathrm{Ob}$ mit diesem Vergleich auf die hier angebrachten Herakles-Darstellungen angespielt werden sollte, läßt sich natürlich nicht beweisen, doch waren Darstellungen der Herakles-Taten im 10. Jahrhundert besonders auf Objekten der Kleinkunst geläufige Motive. ${ }^{271}$

Weder in situ noch unter den von Macridy/Casson entdeckten Resten ${ }^{272}$ befindet sich ein Stück, daß in das 9./10. Jahrhundert datiert werden könnte. Nur die Adler-Platte (Abb. 10), die oberhalb des stadtseitigen Bogens des benachbarten Yedikulekapısı zwischen dem Goldenen Tor (Altınkapı) und Belgratkapı (Abb. 9, 36) als Spolie angebracht wurde, könnte vielleicht dem Rahmenwerk zugerechnet werden. Das Tor hat, wie später ausgeführt werden soll (siehe Abschnitt 2.2.2.), sein heutiges Aussehen unter Sultan Ahmet III. (1703-1730) erhalten. Das Relief zeigt einen frontal stehenden Adler mit nach rechts gewendetem Kopf. ${ }^{273}$ Allerdings ist die untere Zone mit den Hosen des Vogels beschnitten bzw. beschädigt. Die Bohrungen am Auge, an der Halskette, am oberen Rand und an den horizontalen Unterteilungen der Schwingen sowie an den diagonal angeordneten Federn des Brustgefieders waren möglicherweise mit farbigen Einlagen gefüllt. Die Federpartien der Flügel oberhalb des horizontalen Bandes wurden durch unregelmäßige, strahlenförmige Linien angedeutet. Die langen Schwungfedern der unteren Flügelteile sind durch schräge Linien akzentuiert. Die oberen Flügelteile unterscheiden sich deutlich von dem aus regelmäßigen und klar umgrenzten Dreiecken und Halbkreisen gebildeten und sorgfältig schraffierten Gefieder der Pfauenfragmente aus der Nordkirche

270 Leon Diakonos, III, 8, 48/15-18; deutsche Übersetzung: Loretto, Nikephoros Phokas, 50-51; englische Übersetzung: Talbot/Sullivan, Leo the Deacon, 98-99; Diskussion des Datums ebd., 98, Anm. 68.

271 Siehe dazu Weitzmann, Greek Mythology, 157-165.

272 Siehe Anm. 258.

$273 \mathrm{Zu}$ einer ähnlichen, im Büyük Bedesten des Großen Bazars als Spolie verwendeten Platte siehe Ayverdi, Fatih Devri IV, 559, Abb. 853. 
des Konstantinos-Lips-Klosters, die dem 10. Jahrhundert zugeschrieben werden können. ${ }^{274}$ Das Brustgefieder mit diagonal angeordneten Kreisen mit einem mittleren Loch läßt sich wiederum mit einem anderen Stück aus derselben Kirche vergleichen. ${ }^{275}$ Ähnliche Bohrungen zur Aufnahme farbiger Einlagen weisen auch zwei zusammengehörige Stücke in den İstanbuler Archäologischen Museen auf, die in das 10./11. Jahrhundert datiert werden. ${ }^{276}$ Die Lochreihen an Ärmeln und Nimbus eines Marienreliefs aus dem späten 11. Jahrhundert, das aus der Kadırga Sokollu Mehmet Paşa Moschee in die İstanbuler Archäologischen Museen verbracht wurde, zeigen eine ähnliche Machart. ${ }^{277}$ Fıratlı hatte bereits darauf hingewiesen, daß Einlagen auf Säumen und Besätzen der Gewänder oder auf Reliefs mit Vogeldarstellungen als ein Merkmal des 10./11. Jahrhunderts angesehen werden können. ${ }^{278}$ Ein prominentes Beispiel mit Darstellung einer Gans wurde in Kazlıceşme an einem osmanischen Brunnen wiederverwendet; es stammt möglicherweise ebenfalls aus dem 10./11. Jahrhundert. ${ }^{279}$ Daher sollte auch das Adler-Relief in die mittelbyzantinische Zeit, und zwar in das 10. Jahrhundert datiert werden.

Doch in keiner der bisher zitierten Quellen, die über das Rahmenwerk Auskunft geben, ist von einer Adler-Platte die Rede. Nur Stephan Gerlach, der von 1573 bis 1578 - also wenige Jahre nach Petrus Gyllius und vor der Bautätigkeit Sultan Ahmets III. im Bereich von Yedikulekapısı - in İstanbul weilte, fand das Vorwerk noch in besserem Zustand vor. Er berichtet darüber folgenderweise: ${ }^{280}$

Auf diesem Weg haben wir auch die Triumphpforte (portam triumphalem) bey den Sieben Thürmen an welcher die Thaten Herculis und ein Adler, in Marmelstein gehauen stehet, gesehen, ist gar ein altes Werck.

Ob Gerlach diese Adler-Platte gemeint hatte oder die an den Eckgesimsen der Pylonen angebrachten Adler, ${ }^{281}$ ist jedoch nicht sicher auszumachen.

Zusammenfassend kann gesagt werden, daß das Vortor, das möglicherweise aus dem Anfang des 9. Jahrhundert stammt, vor der Anbringung des Rahmenwerks an beiden Seiten mindestens von je einer Nebenöffnung flankiert wurde. Wahrscheinlich sind die Öffnungen im Zusammenhang mit der Anbringung des Rahmenwerks im 10. Jahrhundert zugemauert worden. Inwieweit

274 Firatl, Sculpture, 190-191, Nr. 407-409, Taf. 115, Abb.407-409.

275 Firatl, Sculpture, 191, Nr.411, Taf. 116, Abb. 411.

276 Demangel/Mamboury, Manganes, 131, Abb. 175; Tezcan, Topkap1, 90 und Abb. 89; Firatl1, Sculpture, 181-182, Nr.372 und 375, Taf. 110, Abb. 372 und 375.

277 Firatli, Sculpture, 74, 77, 79, Nr. 131, Taf.46, Abb. 131; Effenberger, Reliefikonen, 21, Abb. 13.

278 Firatli, Sculpture, 181.

279 Maguire, Gardens, 256, und Anm. 5-6.

280 Gerlach, Tagebuch, 406B.

281 Meyer-Plath/Schneider, Landmauer, Taf. 28 i. 
das Vortor bzw. die flankierenden Türöffnungen auf ein mit dem Goldenen Tor in Verbindung stehendes theodosianisches Propylon zurückgehen, könnte nur anhand einer durchgehenden archäologischen Untersuchung geklärt werden. Bis dahin muß auch die Frage unbeantwortet bleiben, ob es an der Wand vor Anbringung der Reliefs mehr als eine Nebenöffnung gegeben hat, und ob das davor liegende Bankett, das seinem Mauerwerk nach in palaiologischer Zeit renoviert wurde (Quader mit Ziegeln) mit diesen in irgendeiner Beziehung stand.

\subsection{Zur Frage der Tore}

\subsubsection{Zur Gestalt der Tore und zum Begriff der „Militär-“ bzw. „Nebentore“}

Die architektonischen Besonderheiten mehrerer Tore wurden bereits von Meyer-Plath/Schneider behandelt, wobei die Autoren ein Haupttor - ihrer Ansicht nach das 4. Nebentor - wegen der hohen Aufschüttungen nur teilweise sehen konnten. ${ }^{282} \mathrm{Da}$ die Tore in den folgenden Teilen der Arbeit eine zentrale Rolle spielen, sollen sie hier zunächst skizzenhaft dargestellt werden. An der Theodosianischen Landmauer von Konstantinopel befinden sich zwei unterschiedliche Typen von Öffnungen. Die eine Gruppe wird durch einen bogenartigen Durchgang gekennzeichnet und ist in der Kurtine der Hauptmauer bzw. der Vormauer angebracht. Die erste Öffnung dieser Gruppe befindet sich südlich vom Goldenen Tor zwischen den Türmen 1 und 2 (Abb. 36, 112) und liegt direkt nördlich neben Turm 1. Der Schlußstein ihres Keilsteinbogens aus Kalkstein trägt an der Feldseite ein Christogramm. ${ }^{283}$ Die lichte Weite des Durchgangs beträgt 2,30 m. Da die Vormauer in diesem Abschnitt seit langem nicht erhalten ist, konnte auch von früheren Forschern nicht mehr ermittelt werden, ob sich an der Vormauer ein korrespondierendes Tor befand. Eine ähnliche einfache Öffnung bietet die Kurtine zwischen den Türmen 30 und 31 (Abb. 118), zwischen Begratkapı und Silivrikapı (Abb. 36). Ihr Bogen besteht aus Ziegeln. Die lichte Weite beträgt hier ca. 3,70 m. An der Stadtseite etwas nördlich des Durchgangs erhebt sich eine einseitige Wehrgangstreppe. Die Vormauer weist eine leicht nach Süden versetzte Öffnung auf, die $2,85 \mathrm{~m}$ breit ist (Abb. 118). ${ }^{284}$ Sowohl diese als auch der Durchgang in der Hauptmauer sind heute über Stufen zugänglich. Ein weiterer Durchbruch, der zugemauert ist,

282 Meyer-Plath/Schneider, Landmauer, Taf. 32c.

283 Für alte Aufnahmen der Stadtseite siehe Krischen, Landmauer, Taf. 40, oben und unten; Meyer-Plath/Schneider, Landmauer, Faltplan 1 („1. Nebentor“).

284 Siehe MISN-Karte I; Meyer-Plath/Schneider, Landmauer, Faltplan 1 („2. Nebentor“); vgl. folgende Anm. 
liegt in der Kurtine 42/43 (Abb. 119), unmittelbar nördlich vom sog. Sigma (Abb. 36). An der linken Seite erkennt man einen Rest des Kämpfers und des Sturzes sowie einen einzigen Keilstein des Bogens. An der rechten Seite sind noch die Konsole, der Kämpfer und ein Rest des Sturzes erhalten. Es besteht kein Zweifel, daß es sich hierbei um einen Durchgang handelt. Die Breite beträgt 3,30 m.Inwieweit es an der Vormauer eine korrespondierende Öffnung gab, kann nicht mehr festgestellt werden. ${ }^{285}$

Ein Tor (Yedikulekapıs1, Abb. 9, 36), dessen byzantinischer Ursprung immer wieder diskutiert wurde, befindet sich zwischen den Türmen 11 und 12 unmittelbar nördlich vom Goldenen Tor. Der Durchgang wurde in osmanischer Zeit und auch neuzeitlich gründlich repariert und als Haupttor benutzt. Inwieweit er byzantinisch ist, wird in Abschnitt 2.2.2. diskutiert.

Während die Öffnung in der Kurtine 30/31 sowohl mit dem Haupt- als auch mit dem Vorzwinger korrespondiert (Abb. 118), ist dieser Sachverhalt bei den Durchgängen in den Kurtinen 1/2 und 42/43 - wie bereits erwähnt - nicht mehr festzustellen. $\mathrm{Ob}$ in byzantinischer Zeit vor solchen kleinen Toren eine Brücke lag und diese sich dadurch zur Feldseite hin geöffnet haben, ist ebenfalls nicht mehr zu erkennen.

Außer diesen kleinen Durchgängen befinden sich an der Landmauer monumentale Tore, die von zwei Tortürmen flankiert werden und charakteristische Gemeinsamkeit aufweisen. Ihre Namen wurden bereits oben als Fixpunkte erwähnt. Das erste Monumentaltor von Süden ist das Goldene Tor (Porta Aurea; Altınkapı) mit einem 29,34 breiten Torhaus (Abb. 36, 120, 121). ${ }^{286}$ Es wurde bereits im Abschnitt 2.1.4. behandelt. Das zweite von rechteckigen Tortürmen flankierte Tor liegt zwischen den Tortürmen 22 und 23 und ist unter seinem türkischen Name Belgratkapı geläufig (Abb. 11, 36, 65, 68). ${ }^{287}$ Obwohl das Tor neuzeitlich durchgehend renoviert wurde, kann sein ursprünglicher Charakter noch nachvollzogen werden. ${ }^{288}$ Das Torhaus ist ca. $12 \mathrm{~m}$ breit und überwiegend aus großen Quadern errichtet. An beiden Seiten sind Torausklinkungen vorhanden. An der Stadtseite befindet sich eine zweiläufige Wehrgangstreppe

285 Meyer-Plath/Schneider, Landmauer, 63-64, müssen dieses Tor noch gesehen haben, plazieren es jedoch an Kurtine 30/31: „In byzantinischer Zeit wurde es bereits vermauert, so daß nur noch der Umriß in der Kurtine kenntlich ist. Über einst vorkragenden und profilierten, jetzt an den Zierformen zerstörten Kämpfersteinen liegt ein Türsturz mit verziertem Schlußstein (Kopf?). Der Entlastungsbogen aus Kalkstein ist nur im nördlichen Anfang erhalten." Dagegen lokalisieren die Autoren das eigentliche Tor in Kurtine 30/31 nirgendwo, geben aber 38, Abb. 5 eine Zeichnung und bezeichnen es auf Faltplan 1, Kurtine 30/31, als „2. Nebentor.“ Für die Kurtine 42/43 schreiben sie (ebd. 82): „Sehr zerstört oder paläologisch ergänzt." Anscheinend liegt hier eine Verwechslung vor.

$286 \mathrm{Zu}$ den Maßverhältnissen des Goldenen Tors siehe Krischen, Landmauer, 15-16.

287 Meyer-Plath/Schneider, Landmauer, 63-64, Faltplan 1.

288 Siehe Ricci, Belgrat Kap1, 465-466. 
(Abb. 68, rechter Ansatz erkennbar). Das Vortor war bereits zur Zeit von Meyer-Plath/Schneider nicht mehr erhalten. ${ }^{289}$ Es wurde neuzeitlich in provisorischer Gestalt wieder aufgebaut (Abb. 11). Das nächste Tor nach Norden ist Silivrikapı, dessen polygonale Türme 35 und 36 in mittel- bzw. spätbyzantinischer Zeit erneuert worden sind (Abb. 12, 36, 69-71). ${ }^{290}$ Das Torhaus, das ebenfalls aus Quadern errichtet wurde, ist $16,50 \mathrm{~m}$ breit (Abb. 70). Wie Belgratkap1 zeigt auch Silivrikapı intensive postbyzantinische und neuzeitliche Reparaturen. ${ }^{291}$ In osmanischer Zeit wurde der Durchgangsbogen weitgehend verändert (Abb. 69, 70), doch blieben die Torausklinkungen bestehen. Die zweiläufige Wehrgangstreppe ist auch hier an der Stadtseite erhalten. Ein korrespondierendes Vortor ist zwar heute noch vorhanden, wurde aber in osmanischer Zeit gründlich repariert und zum Teil verändert. In kurzer Entfernung in Richtung Norden begegnet man einem weiteren Tor, das keinen türkischen Namen hat und im allgemeinen als 3. Nebentor bezeichnet wird (Abb. 36). ${ }^{292}$ Es befindet sich zwischen den beiden rechteckigen Tortürmen 39 und 40 und hat eine Torhausbreite von $12 \mathrm{~m}$ (Abb. 13, 75). Das Mauerwerk des Tors macht deutlich, daß die gesamte Anlage in mittel- bzw. spätbyzantinischer Zeit von Grund auf neu errichtet worden war (ihre Zugehörigkeit zum theodosianischen Konzept wird in Abschnitt 2.2.2. diskutiert). Die südliche Hälfte der Stadtseite besaß eine spätere angefügte Wehrgangstreppe, die ebenfalls dem Mauerwerk nach palaiologisch ist. Sie ist heute nur schwer zu erkennen. Meyer-Plath/ Schneider haben hier Reste eines korrespondierenden Vortors mit Wendeltreppe registriert, von dem nichts mehr erhalten ist. ${ }^{293}$

Die nächste und trotz der neuzeitlichen Restaurierungen in ihrer byzantinischen Struktur noch gut erkennbare Toranlage ist Mevlevihanekapı zwischen den rechteckigen Tortürmen 50 und 51 (Abb. 14, 36), die 16,22 m voneinander entfernt stehen und in nachtheodosianischer Zeit aus Quadern neu errichtet wurden. ${ }^{294}$ Das Torhaus ist ebenfalls aus Quadern erbaut (Abb. 78, 80). Die Verkleinerung der einstmals hohen Bogenöffnung, die Torausklinkungen und die stadtseitigen Wehrgangstreppen sind erhalten. Der Durchgang korrespondiert mit dem an der Vormauer angebrachten und in seinem ursprünglichen Zustand bewahrten Vortor, dessen Fallgatterschlitze (Abb. 81) sowie die beiden flankierenden Wendeltreppen in der Mauerstärke heute noch zu sehen sind. Die am Vortor angebrachten Inschriften (Abb. 79) wurden oben in Ab-

289 Ein vor dem Erdbeben von 1894 aufgenommenes Foto bei Ousterhout/Başgelen, Postcards, 82, Abb. 50; ein wahrscheinlich danach angefertigtes Foto ebd., 83, Abb. 51.

290 Meyer-Plath/Schneider, Landmauer, 64, Faltplan 2.

291 Zum Zustand um 1911 siehe Ousterhout/Başgelen, Postcards, 81, Abb. 49.

292 Schneider, Kalagrou, 96; Meyer-Plath/Schneider, Landmauer, 64-65, Faltplan 1 („3. Nebentor"); Janin, Constantinople, 276.

293 Meyer-Plath/Schneider, Landmauer, 66; ebd. 35 (Meyer-Plath).

294 Meyer-Plath/Schneider, Landmauer, 66-67, Faltplan 2 („,Tor von Rhesium“). 
schnitt 2.1.3.1. behandelt. Das Vortor war ursprünglich aus Quadern mit gelegentlichen Ziegelbändern errichtet, wobei die flankierenden Abschnitte des Durchgangs überwiegend aus Quadern bestehen (Abb. 14).

Nördlich von Mevlevihanekapı zwischen den rechteckigen Tortürmen 59 und 60 liegt ein weiteres Tor (Abb. 36), das keinen türkischen Namen besitzt und bislang als 4. Nebentor bezeichnet wurde - das Romanos-Tor (Abb. 15). ${ }^{295}$ Sein Torhaus weist die beachtliche Breite von $26,50 \mathrm{~m}$ auf, womit es an zweiter Stelle hinter dem Goldenen Tor steht. Das ursprüngliche Quadermauerwerk ist an beiden Seiten des Durchgangs zu erkennen. Das aufgehende Mauerwerk stammt aus palaiologischer und osmanischer Zeit. Die Bogenöffnung muß hier ebenfalls später verkleinert worden sein, wobei die Reparaturen den ursprünglichen hohen Bogen nicht mehr sichtbar werden lassen. An der Stadtseite befanden sich Wehrgangstreppen. Das zugemauerte Vortor kann neben dem des Mevlevihanekap1 zu den besser erhaltenen Vortoren gerechnet werden (Abb. 86). ${ }^{296}$ An der Innenseite sind die Fallgatterschlitze weitgehend vorhanden (Abb. 82). Auch hier wurden die flankierenden Seitenwangen des Durchganges aus Quadern errichtet. Auf dem İstanbul-Plan von Kauffer/Lechevalier (1786) ist das Tor als „Porte bouché" bezeichnet.

Etwas weiter nördlich davon, aber noch an der Südseite des Lykos, liegt zwischen den Tortürmen 65 und 66 das Topkapı genannte Tor (Abb. 16, 36, 89). Das Tor besitzt ein schmales Torhaus von $9,50 \mathrm{~m}$ Breite, das in neuerer Zeit fast bis zur Unkenntlichkeit überrepariert wurde. Das Vortor ist nur teilweise erhalten, die beiden Seiten des Durchgangs sind aus Quadern errichtet. Auf dieses Tor wird im Abschnitt 2.2.3. eingegangen.

Das bereits an der Nordseite des Lykos gelegene Tor zwischen den Tortürmen 77 und 78 ist Sulukulekapı (Abb. 17, 36). Sein aus Quadern errichtetes Torhaus hat eine Breite von 21,50 m; das zu einer späteren Verkleinerung gehörende Torgewände und die Torausklingungen sind hier wieder zu erkennen. ${ }^{297}$ In Bereich von Sulukulekapı ist die Vormauer völlig verschwunden, daher auch keine Spur eines Vortors mehr zu sehen ist. ${ }^{298}$ Auffällig ist die sehr hohe und nur ca. 1,05 m dicke Torwand (Abb. 93). Die stadtseitige Wehrgangstreppe befindet sich heute noch in einem guten Zustand (Abb. 94).

295 Meyer-Plath/Schneider, Landmauer, 68-69, Faltplan 2 („4. Nebentor“), vgl. Taf. 22c (teilweise unter dem Schutt); Asutay, Romanos-Tor, 1-4.

296 Das Vortor wurde erstmals von Dethier, Bosphor, 53-54, registriert.

297 Meyer-Plath/Schneider, Landmauer, 70, Faltplan 3 („Tor des Pempton“).

298 Auf einem um 1865 aufgenommenen Foto der Gebrüder Abdullah (Abdullah Frères) ist die Vormauer in diesem Abschnitt noch zu erkennen. Auf dem Foto ist das Tor als „Circo Porta" beschriftet, siehe Bizans İstanbulu, 113. In diesem Katalog, der wichtige alte Aufnahmen enthält, wurden die falschen Beschriftungen auf den Fotos einfach übernommen; siehe auch Anm. 718. 
Das letzte Tor der Theodosianischen Landmauer ist Edirnekapı zwischen den polygonalen Tortürmen 86 und 87 (Abb. 18, 36). Die Tortürme wurden mehrmals repariert und haben eine andere Gestalt erhalten (Abb. 96, 97). ${ }^{299}$ Das Torhaus hat eine Breite von 23,88 m. In der unteren Hälfte erkennt man Quaderbauweise. Nur hinter dem Südturm, an der Stadtseite, ist eine Wehrgangstreppe zu sehen, die jedoch vor einigen Jahren bis zur Unkenntlichkeit repariert wurde (Abb. 98, 99). Das Vortor ist nicht erhalten. ${ }^{300}$ Auf Edirnekap1 wird ebenfalls im Abschnitt 2.2.3. kurz eingegangen.

Zusammengefaßt lassen sich an der Landmauer zwei Arten von Durchgängen unterscheiden:

1. Durch einen einfachen Bogen gekennzeichnete Öffnungen: Kurtine 1/2; Kurtine 11/12 (Yedikulekapis1); Kurtine 30/31; Kurtine 42/43.

2. Von zwei Tortürmen flankierte Tore: 1.) Altınkapı, 2.) Belgratkapı, 3.) Silivrikapı, 4.) sog. 3. Nebentor, 5.) Mevlevihanekapı, 6.) sog. 4. Nebentor, 7.) Topkap1, 8.) Sulukulekapı und 9.) Edirnekapı.

Während bei dem sog. 3. Nebentor, Mevlevihanekapı und Edirnekap1 ${ }^{301}$ die Vortore jeweils einen Vorsprung aufweisen, ist dies bei Silivrikapı, beim 4. Nebentor und Topkapı nicht der Fall. ${ }^{302}$ Die Torausklingungen, die von MeyerPlath/Schneider gezeichnet wurden, sind heute noch gut zu erkennen. ${ }^{303}$ Die an

299 Meyer-Plath/Schneider, Landmauer, 70-71, Faltplan 3.

300 Das Vortor ist besonders auf einer Abbildung bei Van Millingen, Walls, gegenüber 80 (unteres Bild) und auf einem Foto von Wilhelm Berggren (1835 Stockholm - 1920 İstanbul) zu erkennen; siehe dazu Schiele/Müller-Wiener, İstanbul Hayat1, 82; das gleiche Foto als Postkarte bei Ousterhout/Başgelen, Postcards, 84, Abb. 52. - Auf dem Bild sind eine möglicherweise mit unregelmäßigen Quadern reparierte Mauer und der getreppte Bogen des Tors zu sehen. Nach einer kürzlich vom Archiv der Belediye (Stadtverwaltung) von Üsküdar herausgegebenen Quelle (Tagebuch des Erdbebens von 1894) muß Edirnekap1 während des Erdbebens im Jahre 1894 eingestürzt sein, siehe Anonim bir Günlük, 45. Da das Werk von Van Millingen 1899, also vier Jahre nach diesem Erdbeben publiziert wurde, ist es denkbar, daß das Vortor nicht betroffen war. Es ist aber auch möglich, daß der Autor hier entweder ein älteres Bild benutzt oder sein Buch bereits vor diesem Ereignis zum Druck gegeben hatte, da er nämlich nirgendwo auf dieses Erdbeben eingeht. Das Foto von Berggren wurde in Bizans İstanbulu, 121, als "Silivrikapı" bezeichnet.

301 Vgl. Meyer-Plath/Schneider, Landmauer, 38, Abb. 5 (Meyer-Plath). - Ein Stich, der bei Ahmet Muhtar Paşa, Kostantiniyye, VI, mit dem Unterschrift „Blick auf einen Teil der Stadtmauer und einer Toranlage in der ersten Hälfte des 19. Jahrhunderts" abgebildet ist, zeigt eine Toranlage zwischen zwei polygonalen Türmen und eine großen Moschee an der rechten Seite des Tors innerhalb der Stadt. Ohne Zweifel handelt es sich hier um Edirnekapı mit der Mihrimah Moschee im Hintergrund. Das Vortor ist mit einem Vorsprung wiedergegeben. Es findet sich in diesem Buch leider keine Information über die Herkunft des Stichs.

302 Meyer-Plath/Schneider, Landmauer, 38, Abb. 5.

303 Meyer-Plath/Schneider, Landmauer, 38, Abb. 6. 
der Vormauer angebrachten korrespondierenden Öffnungen der ersten Gruppe sind überwiegend verschwunden.

Bereits im 19. Jahrhundert wurden einige von diesen Toren als „Militärtore“ bezeichnet. Im Jahre 1873 sprach Dethier von zwei unterschiedlichen Torsystemen an der Landmauer ${ }^{304}$

Dazu erfand er [Cyrus Constantinus] dann sinnreich ein System von zwei verschiedenen, wechselnden Thoren, ein bürgerliches, denen der constantinischen (mit nichten abgetragenen) Mauer entsprechend, und ein militärisches zwischen bürgerlichen. Die bürgerlichen, sieben an der Zahl, dienten als Verbindungsmittel mit den constantinischen, vermittelst einer breiten Gasse, welche die Cohorten und Wohnungen abgrenzte.

Ihm zufolge waren Yedikulekapısı in der Kurtine 11/12, Silivrikapı, Mevlevihanekapı, Topkapı und Edirnekapı bürgerliche Tore und das Goldene Tor, Belgratkap1, das sog. 3. Nebentor, das sog. 4. Nebentor und Sulukulekapı Militärtore (Abb. 36). ${ }^{305}$ Seine Bezeichnungen beruhten hauptsächlich auf einer Interpretation des Berichts von Nestor Iskander, wo im Zusammenhang mit der Belagerung von Konstantinopel im Jahre 1453 eine Kirche erwähnt wird, die durch osmanischen Kanonenbeschuß zerstört worden sei. ${ }^{306}$ Obwohl Nestor Iskander nicht den Namen dieser Kirche mitteilt, nahm Dethier an, daß diese die Kyriake-Kirche gewesen sei. Die Kirche wurde bereits im Jahre 1422 von Ioannes Kananos unter Bezug auf die Belagerung durch Sultan Murat II. $(1421-1451)$ erwähnt und in der Nähe des Lykos lokalisiert: ${ }^{307}$

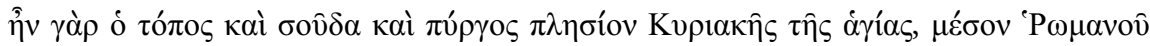

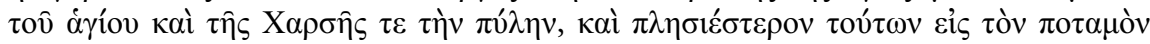

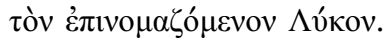

denn es war der Ort mit Graben und Turm nahe der heiligen Kyriake, zwischen dem heiligen Romanos und dem Charisios-Tor, und sehr nahe dieser [beiden] an einem Fluß, der Lykos genannt wird.

Nach Dethier befand sich diese Kirche direkt hinter Sulukulekapı. Er vertrat daher die Meinung, daß während der Belagerung von 1453 die größte Kanone der osmanischen Armee vor diesem Tor stationiert gewesen sei, wodurch die dahinter stehende Kyriake-Kirche zerstört wurde. ${ }^{308}$ Da aber in den Schriftquellen fast ausnahmslos davon die Rede ist, daß die größte Kanone Mehmets II. während der Belagerung bzw. kurz vor der Eroberung vor dem Romanos-Tor

304 Dethier, Bosphor, 12.

305 Für den angeblichen Bezug der acht Haupttore auf acht Quartiere siehe Dethier, Bosphor, 51-55. Ablehnend Meyer-Plath/Schneider, Landmauer, 15 (Schneider).

306 Zur betreffenden Stelle siehe Hanak/Philippides, Nestor-Iskander, 42-43.

307 Cananus, 462/2-5; vgl. Pinto, L'assedio, 57/111-114.

308 Diskussion bei Hanak, Mesoteikhion, 83-85; ebd. 90, Abb. 1, lokalisiert er die KyriakeKirche hinter Sulukulekapı. 
stand, mußten alle diese Informationen logisch miteinander verbunden werden. Die Lösung lautete dann: Jedes bürgerliche Tor bzw. Haupttor hatte ein benachbartes Militärtor, und im Falle einer Belagerung seien die Ziviltore zugemauert und ihre Namen auf die benachbarten Militärtore übertragen worden. ${ }^{309}$ Das bürgerliche Romanos-Tor sei zwar das heutige Topkapı, aber zur Zeit der Belagerung habe man unter dem Romanos-Tor das heutige Sulukulekapı verstanden, das dem Topkapı nach Norden benachbart ist (Abb. 36). Also müsse die größte Kanone der osmanischen Armee vor diesem Tor gestanden haben. ${ }^{310}$

Van Millingen übernahm die Unterscheidung in "Military“ und „Public Gates“, wenn auch seine Identifizierungen von denen Dethiers abweichen: ${ }^{311}$

The Theodosian Walls were pierced by ten gates, and by several small posterns. Of the former, some led only to the different parts of the fortifications, serving exclusively the convenience of the garrison. These may be styled Military Gates. Others connected the capital, moreover, with the outside world by means of bridges thrown across the Moat, and constituted the Public Gates of the city. ${ }^{312}$

Wie Dethier rechnete er Belgatkapı, obwohl die Grabenbrücke auch zu seiner Zeit noch zu erkennen war (Abb. 65), ${ }^{313}$ das sog. 3. Nebentor (Abb. 13, 75), das sog. 4. Nebentor (Abb. 15) und Sulukulekap1 (Abb. 17) den Militärtoren zu. Meyer-Plath/Schneider lehnten als erste den Begriff „Militärtore“ ab und bevorzugten statt dessen die Bezeichnung „Nebentore.“314 Die in den Patriar-

309 Diskussion bei Meyer-Plath/Schneider, Landmauer, 69.

310 Dethier, Bosphor, 54. - Es gibt noch spätere Autoren, die diese Meinung vertreten, vgl. z. B. Pears, Destruction, 429-435; Runciman, The Fall, 91; Setton, Papacy, 113.

311 Van Millingen, Walls, 59; vgl. auch Preger, Konstantinsmauer, 460, und Lietzmann, Vorbericht, 16.

312 Wie oben dargestellt, weist die Landmauer vier Bogenöffnungen an den Kurtinen einschließlich Yedikulekapısı und acht stattliche Tore auf, die von zwei Tortürmen flankiert werden.

313 Van Millingen, Walls, 74-75, fügte aber hinzu: „It is the finest and largest of the military gates, and may sometimes have served as a public gate in the period of the empire, as it has since.“ Vgl. schon Dethier, Bosphor, 52: „Das Militärtor Deutera [Belgratkapi] ... hat ausnahmsweise über dem Graben eine Brücke, die aber aus der mohamedanischen Zeit stammt, wo Soliman I. dieses Thor in ein bürgerliches verwandte ... Man hat sie wahrscheinlich später wieder zugemauert, um die Punkte, wo polizeiliche Controle über das Eingehende ist, zu vermindern. “- Wie lange dieses Tor in osmanischer Zeit offen war bzw. wann es zugemauert wurde und aus welcher Zeit die Brücke stammen könnte, wird im Exkurs II diskutiert.

314 Meyer-Plath/Schneider, Landmauer, 15 (Schneider): „Es wird doch gar nirgends gesagt, daß die in Frage stehenden Tore nur militärischen Zwecken dienten; ja es ist nicht einmal wahrscheinlich. Um von der Kurtine aus in das Gelände zwischen Haupt- und Vormauer zu gelangen, genügen die kleineren Türen, die vielfach von den Türmen aus in den Peribolos führen, völlig. Wenn man aber Haupt- und Vormauer durchbrach, so konnte es nur den Zweck haben, den Verkehr der Zivilbevölkerung ins Vorgelände zu erleichtern, um die großen Tore, die dem Durchgangsverkehr nach Thrakien dienten, zu 


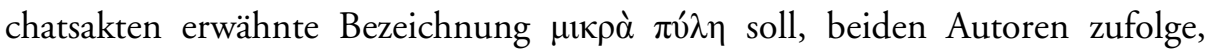
besser zu einer Nebenöffnung passen, was zunächst plausibel erscheint. ${ }^{315}$ Meyer-Plath/Schneider bezeichneten demnach das Goldene Tor (Porta Aurea), Belgratkapı (Xylokerkos-Tor), Silivrikapı (Pege-Tor), Mevlevihanekapı (Rhesion- oder Polyandrion-Tor), Topkapı (Romanos-Tor), Sulukulekapı (PemptonTor) und Edirnekapı (Charisios-Tor) als Haupttore (Abb. 36) ${ }^{316}$ und die restlichen Öffnungen als Nebentore. An der nördlichen Seite von Yedikule in Kurtine 11/12 (Yedikulekapisı) hielten sie für einen osmanischen Durchbruch (siehe Abschnitt 2.2.2.). ${ }^{317}$ Ihrer Meinung nach kann man die Tore nur gemäß der literarischen Überlieferung, nicht aber nach ihrem Bautypus klassifizieren. Die Tore seien vermutlich über vorhandenen Landstraßen errichtet worden und erst spätere Verkehrsverlagerung hätten ursprüngliche Haupttore zu Nebentoren gemacht. ${ }^{318}$ Besonders für das Romanos-Tor zwischen den Türmen 59 und 60

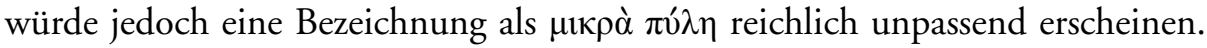

Obwohl die architektonischen Gemeinsamkeiten der monumentalen Tore die beliebige Unterscheidung in Haupt- oder Nebentore nicht zulassen, werden sie, wie dies bisher für das sog. 4. Nebentor fast ohne Ausnahme und für Sulukulekapı, Belgratkapı sowie für das Tor zwischen den Türmen 39/40 hin und wieder geschah, als solche klassifiziert. ${ }^{319}$ Inwieweit diese Bezeichnungen gerechtfertigt sind, wird sich aus den weiteren Ausführungen ergeben.

Im folgenden soll zunächst auf zwei Tore, und zwar auf Yedikulekapısı und das sog. 3. Nebentor näher eingegangen werden. Darüber hinaus werden einige neuere Beobachtungen bzw. Funde am Topkapı und am Edirnekapı diskutiert.

\subsubsection{Das ursprüngliche Aussehen von Yedikulekapısı und das sog. 3. Nebentor}

Im Falle von Yedikulekapısı (Abb. 9) ist sich die Forschung - wie bereits oben erwähnt - nicht einig, ob es sich hierbei um eine byzantinische Öffnung oder um einen osmanischen Durchbruch handelt. ${ }^{320}$ Von der Anlage ist heute nur der

entlasten. Es ist darum wohl angemessen, von Haupt- und Nebentoren statt von Zivilund Militärtoren zu sprechen."

315 Acta et Diplomata, 391.

316 Die in Klammer gesetzten byzantinischen Tornamen beziehen sich auf Schneiders Identifizierungen.

317 Meyer-Plath/Schneider, Landmauer, 62-63.

318 Meyer-Plath/Schneider, Landmauer, 28 (Meyer-Plath).

319 Siehe z. B. Hanak, Mesoteichion, 86: „The design of the Gate [Sulukulekapi] demonstrates that it had only a military function with no bridge or ramp over the moat for commercial and civilian traffic."

320 Nach Dethier, Bosphor, 51, war es ein bürgerliches Tor. Paspatis, Meletai, 78, identifizierte es als osmanischen Tordurchbruch. Mordtmann, Esquisse, 13, und Van Mil- 
Durchgang in der Hauptmauer vorhanden. Auf einem Foto bei Van Millingen erkennt man deutlich, daß sie früher aufwendiger ausgestaltet war. ${ }^{321}$ Der Durchgang befindet sich an einer Stelle der Hauptmauer, die in osmanischer Zeit intensiv repariert wurde. Byzantinisches Mauerwerk ist besonders an der Nordseite des Tors zu erkennen. An der Stadtseite ist oberhalb des Bogens die rechteckige Marmorplatte mit dem Adler-Relief (Abb. 10) angebracht, das aus dem Rahmenwerk am Vortor des Goldenen Tors stammen könnte (siehe Abschnitt 2.1.5.). An der Feldseite ist das Tor mit osmanischen Laibungen eingefaßt und mit einem gerahmten Spitzbogen abgeschlossen (Abb. 9). Innerhalb des Spitzbogens befindet sich die Reparaturinschrift Sultan Ahmets III. (17031730). Die Baumaßnahme muß gleichzeitig mit der Errichtung des an der Südseite stehenden oktogonalen Turms 11 stattgefunden haben, also unter demselben Sultan. ${ }^{322}$ Der Turm wurde während der Regierungszeit Sultan Osmans III. (1754-1757) erneut renoviert.

Älteres Bildmaterial läßt ein korrespondierendes Vortor an der Vormauer erkennen, das südlich des verkleinerten Turms 11a angelegt worden war. ${ }^{323}$ Das Vortor ist heute verschwunden. Aus dem erwähnten Foto geht hervor, daß das Vortor ebenfalls osmanische Laibungen aufwies. Sowohl dem Plan von MeyerPlath/Schneider als auch den Abbildungen aus dem 19. Jahrhundert ist zu entnehmen, daß das Vortor und das Tor in der Hauptmauer nicht auf gleicher

lingen, Walls, 71-72, zufolge sei es byzantinisch. Meyer-Plath/Schneider, Landmauer, 28 und 62-63, bringen die Öffnung wiederum mit der osmanischen Zeit in Verbindung. Janin, Constantinople, 273: „il est probable qu'elle a existé dès l'epoque byzantine." - Die Forscher, die die Öffnung für byzantinisch halten, gehen zumeist davon aus, $\mathrm{da}$ an der Kurtine byzantinisches Mauerwerk teilweise immer noch zu erkennen sei (für eine ältere Aufnahme siehe Meyer-Plath/Schneider, Landmauer, Taf. 31b). Diejenigen, die sich dagegen aussprachen, bezogen sich auf die am Tor angebrachte osmanische Inschrift (ebd., 164-165). Yedikulekapısı wird in der modernen Forschung hin und wieder als „Yenikap“" bezeichnet, siehe dazu besonders Schneider, Yedikule, 200, oder Meyer-Plath/Schneider, Landmauer, 62-63, doch haben die Osmanen unter dem Namen Yenikapı seit dem 15. Jahrhundert Mevlevihanekapı verstanden, das auch Yenimevlevihanekapı genannt wurde; siehe dazu besonders Kanunname, 47. Die von Preger, Tor, 276, vgl. auch Preger/Pantchenko, Verzeichnis, 466, vertretene Meinung muß daher korrigiert werden: Da Mevlevihanekapı nach den ihnen bekannten Quellen erstmals 1573/78 erwähnt wird (von Löwenklau), gingen die Autoren noch davon aus, daß dieses Tor bis dahin zugemauert gewesen sein müsse.

321 Van Millingen, Walls, Abb. gegenüber 72.

322 Kumbaracilar/Tamer, Yedikule, Abb.96, 97, 98. - Der erste Abschnitt des Buchs präsentiert vor allem die historischen Daten zu Yedikule, die in den dreißiger Jahren des 20. Jahrhunderts durch İzzet Kumbaracilar zusammengestellt worden waren; der zweite Teil stellt die Restaurierungsarbeiten von Frau Cahide Tamer vor, die zwischen 1958 und 1970 in verschiedenen Kampagnen durchgeführt wurden.

323 Siehe Anm. 321. 
Flucht lagen (Abb. 41). ${ }^{324}$ Der Durchgang an der Hauptmauer ist nach Norden verschoben, das Vortor befindet sich an der Südseite des Vorturms 11a. Der Vorturm liegt direkt vor dem Durchgang der Hauptmauer. Dieser Zustand läßt überlegen, ob das Vortor wie die Öffnung in Kurtine 30/31 gegenüber dem Haupttor leicht versetzt stand (Abb. 118) oder das eigentliche Tor - byzantinisch oder osmanisch - sich nicht an der heutigen Stelle, sondern etwas weiter südlich befand. Es ist daher die Frage berechtigt, ob dieser Bereich vor der Reparaturtätigkeit Sultan Ahmets III. anders ausgesehen haben könnte. Auf der Zeichnung von Francesco Scarella aus dem Jahre 1686 - ca. 50 Jahre vor diesen Reparaturen (Abb. 40) ${ }^{325}$ - erscheint in der Hauptmauerkurtine 11/12 ein rechteckiges Tor, das möglicherweise mit theodosianischen Laibungen eingerahmt war. Das Tor korrespondiert hier exakt mit einem kleinen Tor in der Vormauer. Das Vortor grenzt an die Südseite des kleinen Vorturms 11a. Der Vorturm ist seinem tatsächlichen Zustand entsprechend in kleineren Dimensionen wiedergegeben. ${ }^{326}$ Beide Tore stehen vor allem auf gleicher Flucht. Es ist natürlich nicht sicher, ob die Zeichnung in allen Details dem tatsächlichen Zustand entspricht, doch die Kurtine zwischen Turm 11 (aus Quadern errichteter Turm Sultan Ahmets III.) und der nördlich anschließenden Kurtine, die in palaiologischer bzw. osmanischer Zeit gründlich repariert wurde, liefert ein wertvolles Indiz dafür, wie dieser Mauerabschnitt vor der osmanischen Reparatur ausgesehen haben könnte: Nördlich von Turm 11 setzt sich eine ca. 4,30 m starke Kurtine, die aus Quadern mit Ziegeldurchschuß erbaut ist und sich mit palaiologischem Mauerwerk vergleichen läßt (Abb. 114), in Richtung Norden fort und trifft mit einer etwas schmaleren osmanischen Mauer zusammen (Abb. 115, 116). Aufgrund der unterschiedlichen Stärke beider Mauern entstanden sowohl an der Feld- als auch an der Stadtseite Rücksprünge, wobei der stadtseitige Rücksprung tiefer ist. ${ }^{327}$ An der Feldseite erkennt man,

324 Meyer-Plath/Schneider, Landmauer, Faltplan 1; MISN-Karte I. - Dieser Zustand ist auf einem Kupferstich von Antoine-Ignace Melling vom Beginn des 19. Jahrhunderts zu erkennen, abgebildet bei Kumbaracilar/Tamer, Yedikule, 28 (meine Abb. 41). - Siehe auch Anm. 321 und vgl. Meyer-Plath/Schneider, Landmauer, Faltplan 3.

325 Siehe Anm. 256.

326 Vgl. Meyer-Plath/Schneider, Landmauer, Faltplan 1.

327 Meyer-Plath/Schneider, Landmauer, Faltplan 1, zeichneten die Mauer durchgehend gleich stark und brachten an der Stelle, wo die Mauern aneinanderstoßen, einen feldseitigen Strebepfeiler an. Auf Taf.31a und b ist jedoch zu erkennen, daß sowohl die Stadt- als auch die Feldseite dieses Mauerabschnitts zur Zeit ihrer Forschungen von Bauten bzw. von Bäumen verdeckt waren. Müller-Wiener, Topographie, 338, Abb.388, zeichnete die Mauer ebenfalls durchgehend, brachte aber einen Strebepfeiler an der Stadtseite an, wie heute noch zu erkennen ist. Für den Zustand vor 1960 siehe Kumbaracilar/Tamer, 87, oberstes Bild, vgl.95, unteres Bild. Für eine vor 1754 entstandene vereinfachte Zeichnung von Yedikule siehe ebd., 27, wo die Mauer ebenfalls gleich stark angegeben wurde. 
daß die südliche, also die palaiologische Mauer, im unteren Bereich ca. $30 \mathrm{~cm}$ weit in die nördliche dünnere osmanische Mauer eingreift und dann senkrecht herabführt (Abb. 113). Dieses Detail erinnert an die vorspringenden Torausklingungen, wie sie z. B. am Mevlevihanekapı (Abb. 78) oder am Sulukulekapı (Abb. 17).

Es ist also denkbar, daß die byzantinische Mauer mitsamt dem Durchgang an dieser Stelle abgebrochen, die schmalere osmanische Mauer angeschlossen und ein neues Tor etwas weiter nördlich errichtet wurden. Demnach scheint die Plazierung des Tors auf Scarellas Zeichnung (Abb. 40) zutreffend zu sein. Dagegen beließ man anscheinend das Vortor an seiner alten Stelle, wobei es mit osmanischen Elementen verkleidet wurde. Auch die osmanische Brücke, die sicherlich vor dem 17. Jahrhundert entstanden ist, liegt weiter südlich und nahm offenbar Bezug auf den alten Durchgang, wie Scarella gezeichnet hat (Abb. 40). Es bleibt jedoch die Frage, ob das byzantinische Tor zum theodosianischen Konzept gehörte oder eine palaiologische Zutat war. Da es sonst auf der langen Strecke zwischen Goldenem Tor und Belgratkapı keine weitere Nebenöffnung gibt, kann angenommen werden, daß hier bereits in theodosianischer Zeit eine solche existierte, die in der palaiologischer Epoche mit dem gesamten Mauerabschnitt repariert worden war. Falls die Zeichnung von Scarella in allen Details zuverlässig ist, müßte das Tor dann einst ein feingegliedertes, möglicherweise an der gleichen Stelle wiederverwendetes Torgewände gehabt haben, was eigentlich für eine Ersterrichtung in theodosianischer Zeit spräche. Solche Torgewände sind - abgesehen von den Seemauern (Abb. 184) und den unteren Blachernen-Mauern ${ }^{328}$ - von anderen Nebenöffnungen zwar nicht bekannt, doch könnten auch diese ursprünglich solche Torgewände gehabt haben.

Es soll jetzt das sog. 3. Nebentor in Augenschein genommen werden (Abb. 36, 75), da es für die Frage der Torgewände eine Lösung bieten könnte. Der gesamte Bereich zwischen den Türmen 39 und 42 einschließlich dem Tor weist keinerlei Spuren aus theodosianischer Zeit auf. ${ }^{329}$ Die fortgeschrittenen Zerstörungen in diesem Teil, die im Abschnitt 2.1.2. behandelt wurden, erlauben keine Aussage mehr über das Verhältnis zwischen Mauer und Graben (Abb. 74). Wie erwähnt, haben Meyer-Plath/Schneider hier ein Vortor mit Wendeltreppen registriert, das anscheinend mit den erhaltenen Vortoren vergleichbar war. Die Autoren machten jedoch keine Angaben zum Mauerwerk. Obwohl dieses Vortor ein starkes Argument dafür bietet, daß sich hier schon in theodosianischer Zeit ein monumentales Tor befand, lassen das erhaltene

328 Weitere Beispiele an der Seemauer bei Demangel/Mamboury, Manganes, 71, Abb.73; 72, Abb. 74; 77, Abb. 82; für das Torgewände des Blachernen-Tors siehe Müller-Wiener, Topographie, 303, Abb. 346.

329 Meyer-Plath/Schneider, Landmauer, 64-65. 
Mauerwerk der gesamten Umgebung und die Anbringung der Vortürme (siehe Abschnitt 2.1.2.) überlegen, ob die beiden Tortürme 39 und 40 gleichzeitig konzipiert worden sind. Auch müßte die Frage gestellt werden, weshalb in einer so kurzen Entfernung von Silivrikapı noch ein monumentales Tor mit zwei Tortürmen - wenn auch nur als Nebentor bezeichnet - notwendig gewesen sein soll. Doch reichen diese Überlegungen ohne weitere schriftliche oder archäologische Belege nicht aus, um sagen zu können, ob es an dieser Stelle ursprünglich eine einfache Nebenöffnung gegeben haben könnte. Daher soll das bereits von Meyer-Plath/Schneider zwischen den Tortürmen noch in situ registrierte Torgewände, das heute möglicherweise unter dem Schutt begraben liegt, betrachtet werden. ${ }^{330}$ Das Torgewände kann anhand der im Archiv des Deutschen Archäologischen Instituts in İstanbul befindlichen Fotos studiert werden (Abb. 75). Es handelt sich um ein fein profiliertes Stück, das mit den massiven frühbyzantinischen Torgewänden der Theodosianischen Landmauer nicht vergleichen läßt. Solche feingliedrigen Torgewände sind von den monumentalen Toranlagen, die von zwei Tortürmen flankiert werden, nicht bekannt: Diese Tore besaßen in theodosianischer Zeit eine hohe und breite Öffnung. ${ }^{331}$ Die Spuren am Mauerwerk einiger Tore wie z. B. am Mevlevihanekap1 (Abb. 78) oder am Sulukulekapı (Abb. 17) unterrichten uns zudem, daß diese Öffnungen später verkleinert worden sind. Bei der Verkleinerung sind die ursprünglichen Torstürze (und die massiven Gewände) wieder eingesetzt worden, wie dies besonders im Falle des Romanos-Tors (Abb. 15) nachvollzogen werden kann. ${ }^{332}$

Das profilierte Torgewände am sog. 3. Nebentor kann daher nicht aus einer Verkleinerungsphase stammen. Es ist denkbar, daß der Durchgang mit ähnlich feinprofilierten Torgewänden wie Yedikulekapısı ausgestattet war und es hier in theodosianischer Zeit kein Tor mit zwei flankierenden Tortürmen, sondern nur eine einfache Nebenöffnung gegeben hat, deren Torgewände später an gleicher Stelle wiederverwendet wurden. Erst durch Hinzufügung eines zusätzlichen Turms muß dieser Durchgang in ein stattliches Tor umgewandelt worden sein. Schneider schlug für das Tor (außer der Bezeichnung als 3. Nebentor) den Namen Kalagros-Tor vor. ${ }^{333}$ Diesen Namen überliefert der frühpalaiologische Kirchendichter Nikephoros Kallistos Xanthopulos, der die Euphrosyne-Kirche

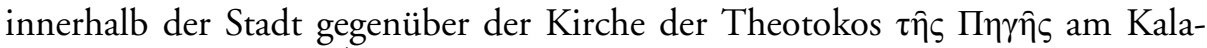
gros-Tor lokalisierte. ${ }^{334}$ Da die Pege-Kirche außerhalb der Stadt, aber gegenüber

330 Meyer-Plath/Schneider, Landmauer, 64, jedoch ohne Abbildung.

331 Siehe die Idealrekonstruktion mit derartigen Torgewänden bei Krischen, Landmauer, Taf. 15.

332 Vgl. Anm. 382.

333 Vgl. Anm. 292.

334 ASS. Nov. III. 859B. - Zur Euphrosyne-Kirche siehe Janin, Églises, 130-131. 
dem Pege-Tor liegt, das sicher mit Silivrikapı identisch ist (Abb. 36, 37), kommt für eine Identifizierung des Kalagros-Tors tatsächlich nur unser Tor in Betracht, zumal es nur um $200 \mathrm{~m}$ von Silivrikapı entfernt liegt. ${ }^{335}$ Bisher sind aber für die Nebenöffnungen keine eigenen Namen belegt. Der Name, der erst ab dem 13. Jahrhundert nachweisbar ist und sich mit diesem Tor verbinden läßt, verstärkt die Vermutung, daß die kleine Nebenöffnung tatsächlich vor dem 13. Jahrhundert in eine stattliche Toranlage umgewandelt worden war. In diesem Fall wäre es nicht mehr gerechtfertigt, von einem 3. Nebentor zu sprechen. Wie die Reste des Mauerwerks im sog. Sigma zeigen (siehe Abschnitt 2.1.2.), kann die Änderung in mittelbyzantinischer Zeit erfolgt und in palaiologischer Zeit fortgesetzt worden sein. Palaiologisches Mauerwerk ist besonders an der Stadtseite des Tors zu erkennen (Abb. 13). Der nördliche Torturm, also Turm 40 (Abb. 77), wird auf Grund einer nur fragmentarisch erhaltenen Inschrift in das Jahr 685 datiert (Abb. 199). ${ }^{336}$ Es ist daher wahrscheinlich, daß der südliche Torturm, also Turm 39 (Abb. 76), derjenige ist, der später hinzugefügt wurde. Auch die unterschiedliche Größe beider Türme weist darauf hin, daß sie nicht aus dem gleichen Konzept stammen. ${ }^{337}$ Spätestens zu diesem Zeitpunkt muß auch das Vortor in der von Meyer-Plath/Schneider beobachteten Weise umgestaltet worden sein, doch ist dessen Mauerwerk, das für eine Datierung wichtig wäre, leider unbekannt. Wenn man den theodosianischen Rhythmus berücksichtigt, ist kurz hinter einem Haupttor - in diesem Fall dem Pege-Tor (Silivrikap1) - eine Nebenöffnung nichts Ungewöhnliches. Da wir in Kurtine 42/43 eine weitere solche Öffnung haben, würde dies bedeuten, daß zwischen Silivrikapı und Mevlevihanekapı gleich zwei Nebenöffnungen existierten.

\subsubsection{Topkapı und Edirnekapı}

Der kürzlich durchgehend renovierte Nordturm (Turm 66) von Topkap1 weist Quader und fünfschichtige Ziegelbänder auf (Abb. 16, 89). ${ }^{338}$ In der erhaltenen unteren Zone des Südturms (Turm 65) ist nur Quadermauerwerk zu erkennen, wobei auch er neuzeitlich renoviert wurde (Südflanke jedoch mit Ziegelbändern, Abb. 90). Ob das aufgehende Mauerwerk Ziegelbänder hatte, entzieht sich unserer Kenntnis. Zur Zeit von Meyer-Plath/Schneider war nur die Nordflanke sichtbar, die eine erheblich dickere Mauer als die anderen Türme

335 Vgl. Berger, Patria, 646-647.

336 Vgl. Anm. 118.

337 Vgl die Zeichnung bei Meyer-Plath/Schneider, Landmauer, Faltplan 2.

338 Vgl. Meyer-Plath/Schneider, Landmauer, 69. 
der Landmauer aufwies und zwei Lichtschlitze besaß. ${ }^{339}$ Das Torhaus wurde ebenfalls mit neuem Material intensiv restauriert (Abb. 16). ${ }^{340}$ Heute dient eine neue Bogenöffnung als Tordurchgang. Auf alten Fotos ist jedoch zu sehen, daß das Tor noch am Ende des 19. Jahrhundert mit osmanischen Laibungen eingerahmt und mit einem Spitzbogenrahmen abgeschlossen war, die wahrscheinlich von der Reparatur des 18. Jahrhunderts stammten, ${ }^{341}$ wie überhaupt das Tor sein Aussehen einer Reparatur im 18. Jahrhundert verdankt. ${ }^{342}$ Der südliche Torturm besitzt keine stadtseitige Öffnung (Abb. 89). ${ }^{343}$ Auch eine Wehrgangstreppe wurde nicht festgestellt. Meyer-Plath/Schneider notierten zur gesamten Kurtine 63-66: „nur untere Hälfte aufrecht. “344 Es ist wahrscheinlich, daß auf Grund der Verbauung besonders die Kurtine an der Stadtseite des Südturms nicht zugänglich war. Heute ist dieser Mauerabschnitt wieder sichtbar. Drei Bogenreste sind bei der neuzeitlichen Reparatur beibehalten worden. Vom nördlichen (rechten) sind nur einige Ziegelschichten des linken Bogenansatzes erhalten (Abb. 91). Hier befand sich einst der ursprüngliche Zugang zum Torturm 65. Der südliche (linke) Bogen sitzt tiefer. Erhalten ist das rechte Drittel des aus zwei Ziegelbögen bestehenden Ansatzes (das Ziegelband darunter ist neuzeitlich ergänzt). Von einem dritten Bogen etwas weiter südlich davon ist ebenfalls noch der aus zwei Ziegelbögen bestehende linke Ansatz zu sehen (Abb. 92). Die beiden auf gleicher Höhe stehenden vermauerten Bögen weisen auf eine Wehrgangstreppe hin und sind wahrscheinlich die Reste der ehemals in die Mauerschale einbindenden Stützgewölbe. Die stadtseitige Öffnung des Nordturms ist nicht ursprünglich. An diesem Abschnitt sind keinerlei Anhaltspunkte für eine Wehrgangstreppe festzustellen (Abb. 89).

Das Torhaus von Edirnekapı geht ebenfalls überwiegend auf osmanische bzw. neuzeitliche Reparaturen zurück (Abb. 18). Seine beiden polygonalen Tortürme weichen von den theodosianischen Türmen ab, indem sie auffällig groß und in ihrer architektonischen Gestalt nicht identisch sind. Während der Nordturm (Turm 87) fünfseitig ist (Abb. 96), weist der Südturm (Turm 86) einen sechsseitigen Umriß auf (Abb. 97). ${ }^{345}$ Abgesehen davon ist der Nordturm breiter, aber kürzer als der Südturm. Meyer-Plath/Schneider hielten die Nordflanke des Nordturms für theodosianisch und nahmen an, daß der Turm ur-

339 Meyer-Plath/Schneider, Landmauer, 69, und Faltplan 1; vgl. ebd., 38, Abb. 5 (geschönte Zeichnung).

340 Vgl. Meyer-Plath/Schneider, Landmauer, Taf.53d.

341 Van Millingen, Walls, Abb. gegenüber 80.

342 Vgl. Anm. 376 und 377.

343 Meyer-Plath/Schneider, Landmauer, Faltplan 2, geben keine stadtseitige Öffnung an.

344 Meyer-Plath/Schneider, Landmauer, 83 (Meyer-Plath).

345 Meyer-Plath/Schneider, Landmauer, Faltplan 3 (beide fünfeckig gezeichnet). 
sprünglich rechteckig gewesen sei. ${ }^{346}$ Obwohl hinter dem Südturm eine Treppenanlage vorkommt (Abb. 98, 99), ist an der Rückseite des Nordturms weder ein Treppenrest noch ein stadtseitiger Eingang zu erkennen. ${ }^{347}$

Das Mauerwerk der an den Nord- sowie an den Südturm anschließenden Kurtinen (Abb. 102, 103) läßt sich an der Feldseite mit anderen Abschnitten der Mauer aus dem frühen 9. Jahrhundert, vor allem mit den drei TheophilosTürmen der unteren Blachernen-Mauer (Abb. 143) vergleichen (siehe Abschnitt 2.1.2.). ${ }^{348}$ Die feldseitige Mauerschale stößt an der Südostseite von Turm 86 an und scheint jünger als dieser zu sein (Abb. 103). Das Mauerwerk der Stadtseite weist dagegen folgende Werte auf (Abb. 101): Vier- bzw. sechs Lagen Quader, fünfschichtige Ziegelbänder, Ziegelbandhöhe $62 \mathrm{~cm}$, Ziegelbreite $35 \mathrm{~cm}$, Ziegelhöhe 4,5 bis $5 \mathrm{~cm}$, Mörtelhöhe 6 bis $8 \mathrm{~cm}$. Vergleichbares Mauerwerk ist auch am Südturm zu beobachten: Vier bzw. fünf Lagen wiederverwendete Quader, Ziegelbandhöhe $65 \mathrm{~cm}$, Ziegelbreite $35 \mathrm{~cm}$, Ziegelhöhe 4,5 bis $5 \mathrm{~cm}$, Mörtelhöhe 6 bis $8 \mathrm{~cm}$. Diese Werte sind mit denjenigen der stadtseitigen Kurtine zwischen den Türmen 82 und 84 vergleichbar, die wahrscheinlich aus dem früheren 9. Jahrhundert stammt, aber noch vor der Michael bzw. Theophilos zuschreibbaren Mauerschale der Feldseite entstand.

Der Eingang von Turm 86 (Abb. 98), der zur Zeit von Meyer-Plath/ Schneider nicht zugänglich war, ist bis zum Bogenansatz mit Schutt aufgefüllt. Heute sind nur die Bögen an der Eingangs- und Ausgangsseite und die Einwölbung des ca. 4,5 m langen und 2,10 m breiten Durchgangs zu erkennen. Der Bogen besteht im Unterschied zu den theodosianischen Ziegelbögen aus keilförmig geschnittenen Kalksteinquadern (Abb. 100). Welche Gestalt die Toranlage hatte, die hier ursprünglich stand, ist heute nichts mehr $\mathrm{zu}$ sicher zu ermitteln, doch fanden anscheinend im 9. Jahrhundert einschneidende Veränderungen statt, wobei auch die ursprünglich wohl rechteckigen Tortürme in polygonaler Gestalt wieder aufgeführt worden sind.

346 Vgl. Meyer-Plath/Schneider, Landmauer, 71 (Schneider); „Der Nordturm hat an seinen Flanken Reste theodosischen Mauerwerks mit dem Bogen eines Lichtschlitzes. Nach dem rechtwinkeligen Anschluß seiner Nordflanke zu urteilen, wird der ursprüngliche Torturm nicht polygonal, sondern rechteckig gewesen sein."

347 Vgl. Meyer-Plath/Schneider, Landmauer, Faltplan 3.

348 Vgl. auch Meyer-Plath/Schneider, Landmauer, Taf.61a, 62a; zu der in der Umgebung von Edirnekap1 registrierten Inschrift mit Jahresangabe 826/827 (aus der Zeit Michaels II.) siehe Anm. 116. 


\subsubsection{Die Identifikation der Tore}

Die byzantinischen Quellen - soweit mir bekannt - erwähnen folgende Tor-

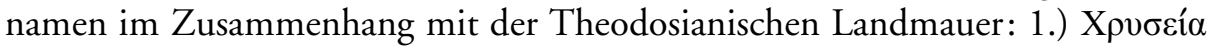

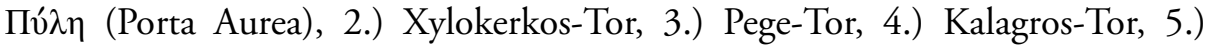
Myriandrion- bzw. Polyandrion-Tor, 6.) Rhesion-Tor, 7.) Romanos-Tor, 8.) Pempton-Tor, 9.) Charisios-Tor. Diesen fügte man einen weiteren Tornamen hinzu, und zwar 10.) Kyriake-Tor. ${ }^{349}$ Da die byzantinischen Tornamen nach der osmanischen Eroberung durch türkische Bezeichnungen ersetzt wurden, sind sie im Laufe der Zeit in Vergessenheit geraten. ${ }^{350}$ Heute befinden sich an der Landmauer - wie oben mehrfach erwähnt - folgende Tore mit türkischen Namen (Abb. 36): 1.) Altınkap1, 2.) Belgratkap1, 3.) Silivrikap1, 4.) Mevlevihanekap1, 5.) Topkapı, 6.) Sulukulekapı und 7.) Edirnekapı. Ihnen können zwei weitere Tore hinzugerechnet werden, die keine türkischen Namen besitzen: 8.) das Tor zwischen den Tortürmen 39 und 40 und 9.) das Tor zwischen den Tortürmen 59 und 60 .

Seit dem 19. Jahrhundert versucht die Forschung die zehn byzantinischen Tornamen mit den acht Toren der Landmauer zu verbinden. ${ }^{351}$ Es sind des-

349 z. B. Runciman, The Fall, 91 (siehe Abschnitt 2.2.4.1.). - Dukas, 353/19 (englische Übersetzung: Magoulias, Doukas, 221), berichtet im Zusammenhang mit der osmanischen Eroberung von einem weiteren Tor Namens Kerkoporta, das unmittelbar vor der Eroberung von den Byzantinern versehentlich offengelassen worden sei, weshalb die osmanische Armee eindringen konnte. In keiner anderen Quelle ist von diesem Tor die Rede. In der Sekundärliteratur (z. B. Mordtmann, Esquisse, 34; Van Millingen, Walls, 89-94; Schlumberger, Îles, 381-382; MISN-Karte I; Runciman, The Fall, 66) wird diese Kerkoporta zwar zwischen Turm 96a und Tekfur Sarayı gesucht, wo sich eigentlich kein Tor befand. Kerkoporta bedeutet einfach „Zirkus-Tor“ und ruft sofort den Namen Xylokerkos-Tor in Erinnerung, das mit Belgratkapı zu identifizieren ist und „HolzzirkusTor" bedeutet. Das Xylokerkos-Tor wird von Niketas Choniates, 404/4-7, im Zusammenhang mit Isaakios II. Angelos erwähnt, wonach dieser Kaiser von den durch das Xylokerkos-Tor in die Stadt einmarschierenden Feinden geträumt habe und das Tor zumauern ließ. Wie Brandes, Belagerung, 90, zu Recht angenommen hat, könnte Kerkoparta eine Verballhornung von Xylokerkos sein, vgl. auch Brandes, Prophetien, 249. Meyer-Plath/Schneider, Landmauer, 16, haben Xylokerkos-Tor und Kerkoporta als zwei unterschiedliche Tore betrachtet und die Kerkoporta vielmehr an der Komnenen-Mauer vermutet. Zu beiden Tornamen im Zusammenhang mit der Eroberung 1453 siehe auch Nicol, Immortal Emperor, 62, Yerasimos, Soyağac1, 291-332, bes.297, Emecen, İstanbul'un Fethi, 43, oder Kidonopoulos, Urban Physiognomy, 100, Fig. 59; vgl. weiterhin Janin, Constantinople, 265-266 und 282. - Siehe auch Anm. 354.

350 Einige Tore wurden in osmanischer Zeit geschlossen. Sowohl in den bildlichen Darstellungen als auch in den schriftlichen Quellen kommen nur Yedikulekapısı, Silivrikapı, (Yeni) Mevlevihanekapı, Topkapı, Edirnekapı und Eğrikapı vor. Belgratkapı und Sulukulekapı werden bis ins 19. Jahrhundert nicht erwähnt. Zu Belgratkapı siehe Exkurs II.

351 Die Identifizierungsvorschläge durch einzelne Forscher bis zum Jahr 1943 haben MeyerPlath/Schneider, Landmauer, 11 (Schneider), in einer Liste zusammengefaßt. 
wegen nur acht Tore, weil man das Tor zwischen den Tortürmen 59 und 60 (Romanos-Tor) trotz seiner auffälligen Größe als Nebentor bzw. als Militärtor klassifiziert und niemals in die diesbezüglichen Überlegungen einbezogen hat, obwohl erstaunlicherweise weitere und ebenfalls als Nebentore bezeichnet Öffnungen immer wieder in Augenschein genommen wurden. Dabei fand ein weiteres Tor, das in den byzantinischen Schriftquellen sowie auf alten Stadtansichten (Buondelmonti) unter der Bezeichnung "Johannes-Tor" vorkommt, kaum Berücksichtigung (Abb. 45). Die bisherigen Gleichsetzungen wurden sehr kontrovers diskutiert, weshalb sich die Forschung über mehrere Tornamen nach wie vor nicht einig ist. Mevlevihanekapı ist auf Grund der in der Anthologia graeca kopierten Inschrift mit Sicherheit mit dem byzantinischen Rhesion-Tor zu identifizieren und wird auch mit dem Myriandrion- bzw. Polyandrion-Tor in Verbindung gebracht. ${ }^{352}$ Silivrikapı kann wegen der außerhalb des Tors lie-

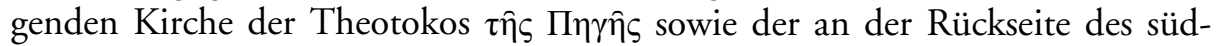
lichen Torturms (an der späteren Treppenanlage) befindlichen Reparaturinschrift von 1438, die den Namen $\pi \eta \gamma \eta$ erwähnt, als das byzantinische Pege-Tor bestimmt werden (Abb. 72). ${ }^{353}$ Auch die Identifizierung von Belgratkap1 mit dem byzantinischen Xylokerkos-Tor dürfte auf Grund topographischer Fixpunkte unzweifelhaft sein. ${ }^{354} \mathrm{Im}$ folgenden werden die Tore diskutiert, deren bisherige Identifikation noch nicht als gesichert gilt.

\subsubsection{Das sog. 4. Nebentor (Romanos-Tor) und das Topkap1}

Obwohl die Lage des Romanos-Tors (Abb. 15, 85-88) nunmehr gesichert ist, lassen sich dennoch aus der im folgenden dargelegten Geschichte seiner falschen Identifizierung mit dem heutigen Topkap1 (Abb. 16, 36, 89) seit dem 16. Jahrhundert ${ }^{355}$ wichtige Hinweise auf dessen osmanischen Namen gewinnen. Da diese Identifizierung als unzweifelhaft angesehen wurde, obwohl es hierfür keinerlei archäologische oder epigraphische Zeugnisse gibt, galt Topkap1 stets als Fixpunkt für die Lösung bestimmter topographischer Fragen. ${ }^{356}$ Für die

352 Erstmals von Preger, Tor, 272-280; zur Inschrift siehe Anm. 124.

353 Meyer-Plath/Schneider, Landmauer, 64 (Meyer-Plath/Schneider), kann die Inschrift

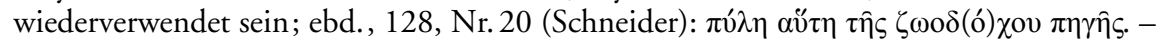
Diese Inschrifttafel wurde von Foss, Fortifications. 252, Abb. 17, mit einer anderen Tafel an der Nordseite des Südturms verwechselt.

354 Meyer-Plath/Schneider, Landmauer, 63. - Van Millingen, Walls 89-94, brachte das Xylokerkos-Tor noch mit der in Anm.349 erwähnten Kerkoporta in Verbindung und plazierte es zwischen Vorturm 96a und Tekfur Sarayı: „According to its place in the order of the gates, this entrance should be the sixth military gate."

355 Löwenklau, Annales, 479A, Tor Nr. XIV; Crusius, Turcograeciae, 51.

356 Das Tor soll seinen Namen von einer in der Nähe gelegenen Kirche des heiligen Romanos erhalten haben, siehe dazu Janin, Constantinople, 280, 420-421; ders, Églises, 448-449. - Davon ausgehend identifizierte Hanak, Mesoteikhion, 78-79, die Ro- 
Gleichsetzung spielten mehrere Gründe eine Rolle: Das Romanos-Tor wurde in spätbyzantinischer Zeit besonders im Zusammenhang mit den Belagerungen der Stadt immer wieder erwähnt, wobei die Quellen auch indirekte topographische Hinweise enthalten. ${ }^{357}$ Bereits aus dem oben angeführten Bericht des Ioannes Kananos geht hervor, daß das Romanos-Tor und das Charisios-Tor die Endpunkte einer Strecke markiert haben, innerhalb derer sich eine KyriakeKirche befand. ${ }^{358}$ Wir wissen zwar nicht, wo genau diese Kirche stand, doch geht aus Kananos hervor, daß innerhalb dieses Abschnitts der Lykos floß. Es ist also anzunehmen, daß die Kyriake-Kirche tatsächlich in unmittelbarer Nachbarschaft des Baches lokalisiert werden muß. Da das Charisios-Tor sicherlich an der Nordseite des Lykos liegt, wurde das Romanos-Tor an dessen Südseite gesucht. Weitere Argumente für die Gleichsetzung von Romanos-Tor und Topkapı wurden aus den Quellen über die osmanische Eroberung von Konstantinopel 1453 bezogen, unter anderem aus dem Bericht des venezianischen Arztes Nicolò Barbaro. ${ }^{359}$ Danach war das Romanos-Tor während der Belagerung die am meisten bombardierte Stelle der Landmauer. ${ }^{360}$ Aus dem Bericht von Barbaro geht hervor: $:^{361}$

prima ne messe tre bombarde per mezzo del palazzo del serenissimo imperador, e tre altre bombarda messele per mezo la porta del Pege, e do altre bombarde messele a la porta del Cresu, e altre quatro bombarde messele alla porta de san Romano, dove che sun la piû debel porta de tuta la terra.

Zunächst wurden vor dem Palast des glorreichen Kaisers drei Kanonen aufgestellt. Drei weitere wurden vor dem Pege-Tor und zwei weitere wurden vor dem Cresu-Tor

manos-Kirche mit der heutigen armenischen Kirche Surp Nikogogos, die sich hinter Topkapı befindet.

357 Das Tor ist nur auf einer einzigen Buondelmonti-Kopie namentlich bezeichnet, siehe Abb. 45; vgl. Effenberger, Buondelmonti, 52, Abb. 1.

358 Vgl. Anm. 307 und 308.

359 Pertusi, La Caduta I, 8-38. - Barbaro war auf einem am Goldenen Horn verankerten venezianischen Schiff als Arzt tätig und blieb dort während der gesamten Belagerung. Sein Bericht gilt als eine der zuverlässigsten Quellen über das Geschehen im Jahre 1453.

360 Dukas, Chalkokondyles, Sphrantzes sind hier als die wichtigsten byzantinischen Quellen zu erwähnen. Mehrere Quellen, darunter auch nichtbyzantinische Berichte, wurden von Pertusi, La Caduta I und II, abgedruckt. Für einen umfassenden Überblick über die Sekundärliteratur siehe Philippides, Urban, 1-67. - Im Rahmen meiner Arbeit wurden nur diejenigen Quellen benutzt, die mit meiner Fragestellung unmittelbar zu tun haben. Obwohl die Quellen über die Standorte der verschiedenen Kanonen unterschiedliche Aussagen machen, erwähnen alle gemeinsam die Plazierung einer Kanone im Bereich des Mesoteichion bzw. des Romanos-Tors, die besonders kurz vor der Einnahme eine große Rolle spielte. Dabei handelt es sich um ein aus Bronze gegossenes Riesengeschütz. Die Kanone wird von der Vfn. an anderer Stelle behandelt.

361 Pertusi, La Caduta I, 14/198-203. 
[Charisios-Tor ${ }^{362}$ ] und vier weitere wurden vor dem Sankt Romanus-Tor in Stellung gebracht, welches das schwächste Tor der ganzen Gegend war.

Eine weitere Quelle, und zwar das Mehmet II. gewidmete Geschichtswerk des Kritobulos von Imbros, verdeutlicht die besondere Rolle des Romanos-Tors im Zusammenhang mit der Aufstellung der Armee des Sultans während der Belagerung und gibt in der Gegenüberstellung mit zeitgenössischen osmanischen Quellen wertvolle Hinweise für die Lösung der Torfrage: ${ }^{363}$

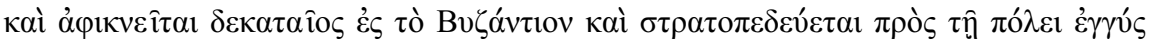

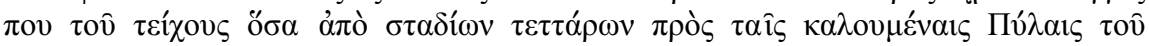
'P $\omega \mu \alpha v o \hat{v}$

Und am zehnten Tage gelangte er [Mehmet II.] nach Byzanz und schlug sein Lager vor der Stadt in der Nähe der Mauer in einer Entfernung von etwa vier Stadien zum sogenannten Rhomanos-Tor auf.

Kritobulos berichtet weiterhin über die verzweifelte Lage der byzantinischen Verteidiger, nachdem der verwundete genuesische Kommandant Giovanni Giustiniani Longo seine Stellung am Romanos-Tor verlassen hatte: ${ }^{364}$

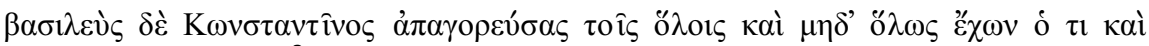

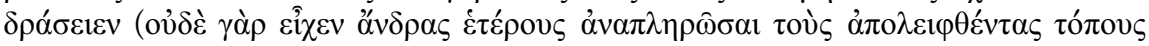

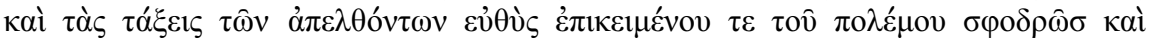

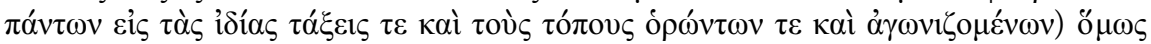

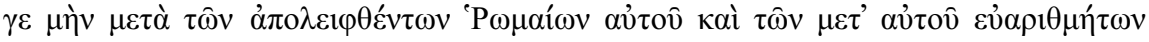

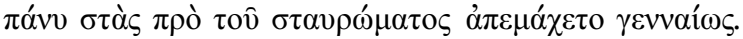

Kaiser Konstantin aber verlor alle Hoffnung und wußte überhaupt nicht mehr, was er noch tun sollte (denn er hatte keine weiteren Männer zur Verfügung, um die

362 Pertusi, La Caduta I, 351, Anm. 43, hielt die „porta Cresu“ für das Goldene Tor, doch wird dieses an anderer Stelle (14/186) als „Cresea" bezeichnet. „Cresu“ ist eine der vielen Namensformen für das Charisios-Tor, vgl. Mordtmann, Esquisse, 17. - Auf der MISNKarte II, werden für „Cresu“ (Eğrikapı) und Charisios“ (Edirnekapı) zwei unterschiedliche Tore angenommen.

363 Kritobulos, 39/28-31; deutsche Übersetzung: Reinsch, Mehmet, 77.

364 Kritobulos, 69/26-32; deutsche Übersetzung: Reinsch, Mehmet, 118. - Nachdem Giovanni Giustiniani verwundet worden war und seinen Platz verlassen hatte, übernahm der Kaiser persönlich die Verteidigung des Romanos-Tors, dem gegenüber der Sultan mit seiner Armee stand. Aus den Quellen geht hervor, daß während der Belagerung sowohl der Kaiser als auch der Sultan hin und wieder ihre Stellungen gewechselt hatten, doch das Romanos-Tor blieb von Anfang an der wichtigste Punkt sowohl für die Verteidiger als auch für die Angreifer. Nach mehreren Quellen soll der Kaiser hier gefallen sein, siehe z. B. Kritobulos, 70-2/11; deutsche Übersetzung: Reinsch, Mehmet. 119; ähnlich auch zwei Kleinchroniken, siehe Schreiner, Kleinchroniken, I, 271, Nr. 34, \$21 und 369, Nr. 51, $\$ 17$; II, 481-482; III, 76, $\$ 21$. Die Nikon-Chronik, 30, berichtet dagegen, daß der Kaiser in der Nähe des Goldenen Tors ums Leben gekommen sei. Osmanische Quellen geben unterschiedliche Auskünfte. Siehe die Diskussion bei Meyer-Plath/Schneider, Landmauern 8, Anm. 1 (Schneider), und Nicol, Immortal Emperor, 74-94. 
verlassenen Stellungen und die Reihen derer, die geflohen waren, aufzufüllen, da unmittelbar darauf die Schlacht sie hart bedrängte und alle ihre Aufmerksamkeit auf ihre eigenen Reihen und Stellungen richten und dort kämpfen mußten), dennoch aber stellte er sich mit den dort verbliebenen Rhomäern und seiner sehr kleinen Gefolgschaft vor der Palisade auf und lieferte dort einen tapferen Kampf.

Diese Aussagen wurden in der Sekundärliteratur ohne Differenzierung zusammen mit einigen osmanischen Quellen bewertet, welche die Geschehnisse mit dem Topkapı in Verbindung bringen. Obwohl Tursun Bey, ${ }^{365}$ Enveri, ${ }^{366}$ Aşıkpaşazade $^{367}$ und Neşri ${ }^{368}$ in ihren Geschichtswerken mit Bezug auf die Eroberung keine Tornamen erwähnen, kommen solche in späteren Quellen häufiger vor. Gelibolu'lu Mustafa Âli ${ }^{369}$ nennt nur ein einziges Tor, und zwar Edirnekap1, doch spricht er nicht vom Tor selbst, sondern von einer Gegend in Richtung des Tors, „Edirnekapı Semti“. Hingegen erwähnt İbn-i Kemâl (Kemalpaşazade) das Topkapı bereits Ende 15./Anfang 16. Jahrhundert in Zusammenhang mit den Geschehnissen am Romanos-Tor: ${ }^{370}$

365 Tursun Bey, 46-65. - Tursun Bey stand während der Belagerung und Eroberung im Dienste Mehmets II. Nach Tulum verfaßte er sein Werk möglicherweise zwischen 1490 und $1495 . \mathrm{Zu}$ seinem Leben siehe die Diskussion bei Tulum in dem hier zitierten Werk, XI-XXXII.

366 Enveri, 50. - Der Autor beendete sein Buch bereits in der Regierungszeit des Sultans Mehmet II. im Jahre 1465. Siehe die Diskussion von Öztürk in dem hier zitierten Werk, XXXIII-XLIII.

367 Aşı kpaşazade, 217-219. - Der Autor nahm an die Eroberung teil und beendete sein Buch, wie er selber mitteilt, am 26. Recep 890 (8. August 1485, Montag). Siehe die Diskussion von Yavuz/Saraç in dem hier zitierten Werk, 31-47.

368 Neşri, 689-709. - Für die Fertigstellung des Buches wird das Jahr 1492 angenommen. $\mathrm{Zu}$ seinem Leben siehe die Diskussion von Unat/Köymen in dem hier zitierten Werk, IX-XVI.

369 Gelibolu'lu Mustafa Âli, ed. Şentürk, 12. - Wie der Autor selbst vermerkt, verfaßte er sein Buch zwischen 1591/92 und 1598/99. Zu seinem Leben siehe die Diskussion bei Şentürk in dem hier zitierten Werk, XXXV-LXII. - Tâci Beyzâde Cafer Çelebi spricht in seinem Mahrûse-i İstanbul Fetihnâmesi (um 1500) von dem südlichen Mauerabschnitt von Edirnekap1; siehe Pertusi II, 277/283-284, vgl. die türkische Übersetzung von Pertusi durch Şakiroğlu II, 142.

370 İbn-i Kemâl, Tevârih-i Âli Osman, 50. - İbn-i Kemâl schrieb sein Geschichtswerk in mehreren Heften. Das hier zitierte Heft VII wurde in der Regierungszeit des Sultans Bayezıt II. (1481-1512) verfaßt. Sowohl sein Großvater Kemal Paşa als auch sein Vater Süleyman Çelebi gehörten zum Kreis Mehmets des Eroberers und dienten ihm als höhere Offiziere. Zu seinem Leben siehe die Diskussion von Şerafettin Turan in dem hier zitierten Werk, IX-CX. Es soll an dieser Stelle vermerkt werden, daß der aus dem Jahr 1588 stammende Bericht von Löwenklau, Annales, 479A, Tor Nr. XIV, wonach „recenti vocabulo Turcica dicta Top Capisi, quo significatur porta bombardario..." nicht zutreffend ist, da das Tor schon viel früher (um 1480) als „Topkapusı“ bezeichnet wurde, vgl. Kanuname, 47. 
Şehriyâr-1 Kâmkâr, rikâb-ı kâmyâbında mülâzim olan haşem-î mansûrla Top-Kapusu dimekle meşhûr dervâzenin karşusında kondı.

Der glückliche Herrscher und seine Gefolge nahmen vor dem Tor, das unter dem Namen ,Topkapusı' bekannt war, Aufstellung.

Einige Passagen später berichtet İbn-i Kemâl, daß die in der byzantinischen Armee tätigen europäischen Kräfte eine in der Nähe des „Topkapusı“ entstandene Bresche verteidigt haben. ${ }^{371}$ Diese Aussage ist tatsächlich mit europäischen und byzantinischen Berichten in Verbindung zu bringen, wonach das RomanosTor durch den genuesischen Kommandanten Giovanni Giustiniani Longo verteidigt wurde, bis er wegen seiner Verwundung die Stellung aufgab. ${ }^{372}$ Aus dem Buch von İbn-i Kemâl geht weiterhin hervor, daß die osmanische Armee durch das "Topkapusı“ in die Stadt eingedrungen war. ${ }^{373}$ Es scheint, daß der Autor wie die byzantinischen und europäischen Quellen vom selben Tor spricht, ${ }^{374}$ wenngleich er dafür einen türkischen Namen angibt. Alle diese Aussagen wurden zumeist mit den intensiven osmanischen Reparaturen am heutigen Topkapı in Zusammenhang gebracht, welche die schweren Schäden infolge des heftigen Kanonenbeschusses belegen sollen. ${ }^{375}$ Aus den Schriftzeugnissen erfahren wir jedoch, daß Topkapı vor der Thronübernahme Sultan Ahmets III. bei dem Erdbeben des Jahres 1690 eingestürzt war, wovon der Chronograph Râşid berichtet: ${ }^{376}$

Mâh-1 şevvâlû'l-mükerreminin dördüncü sülâsâ gicesi salât-1 mağribden sonra emr-i Hakk'la vâki olan zelzele-i azîme zuhûru ile Fâtih Sultan Mehmed Hân aleyhi'r rahmetü ve'l ğufrân hazretlerinin câmi’i şerîfi haremi kubbelerinin birkaçı rahne-dâr olup İstanbul sûru ebvâbından Topkapusı dahi sâ’ir nice kârgir binâlar münhedim oldu

371 İbn-i Kemâl, Tevârih-i Âli Osman, 58: „Zirâ ol mu'âvenete gelen fireng bahâdırları ki her biri neheng-i tîz-çenge-i deryây-1 sıtîz ü ceng idi, peykâre râgıb oldılar; mizmâr-1 celâdetde izhâr-1 cür'et eyleyüb Top-kapusı cânibindeki dîvâr gediğinün müstakil muhâfazasına tâlib oldılar."

372 Die Quellen geben unterschiedliche Auskünfte darüber, an welcher Stelle seines Körpers Giovanni Giustiniani verwundet wurde. Da er auch in den osmanischen Quellen als ein tapferer Mann bezeichnet wird, ist nicht verständlich, weshalb er seine Stellung am Tor wegen dieser an sich harmlosen Verwundung verlassen hatte, in Lethargie verfiel und bald darauf verstarb. Ausführlich zur Person siehe Philippides, Giustiniani, 13-53; kurze Zusammenstellung der Quellen bei Emecen, İstanbul'un Fethi, 78, Anm. 65.

373 İbn-i Kemâl, Tevârih-i Âli Osman, 66: „Sâbıka Hazret-i şeyh ta'yin etdiğü mahalden ki Top-Kapusı dimekle iştihârı vardur bâb-1 feth açlub'arûs-1 zaferün dâmenine ceyş-i nusret-kîşün eli irdi." Enveri, 875, berichtet - ohne einen Tornamen anzugeben -, daß die Osmanen durch eine große Bresche in die Stadt eingedrungen waren.

$374 \mathrm{Vgl}$. Anm. 361, 363 und 364.

375 Meyer-Plath/Schneider, Landmauer, 69.

376 Râşid Tarihi II, 122; vgl. Sakin, Deprem, 142. - Eine Parallelquelle, und zwar Zübde-i Vekâyi'ât, bestätigt das Ereignis und den Einsturz des Topkapı; siehe dazu, Zübde-i Vekâyi'ât, 364; vgl. Sakin, ebd., 142; siehe auch Ürekli, Deprem, 13. 
Am 10. Juli 1690, Dienstag abends, nach dem Abendgebet, ereignete sich auf Gottes Befehl ein Erdbeben. Es verursachte Schäden an einigen Kuppeln der Moschee von Fatih Sultan Mehmet Han [Fatih Moschee]. Auch eines von den Stadtmauertoren, das Topkapı, und einige Steinhäuser stürzten ein.

Nach den Quellen fanden weitere Erdbeben auch in der früheren Regierungszeit des Sultans Ahmet III. in den Jahren 1707, 1709, 1710, 1711, 1712 statt. ${ }^{377}$ Die Schäden hat man erst im Jahre 1722 behoben, in dem auch Yedikulekapisı repariert wurde. ${ }^{378}$ Diese Reparaturen können also nicht mit dem Kanonenbeschuß während der Belagerung von 1453 in Verbindung gebracht werden.

Auch der türkische Name des Tors, Topkap1 („Kanonen-Tor“), wurde als zusätzliches Indiz genommen und auf die Bombardierungen bezogen. ${ }^{379}$ Dennoch wurde niemals die Frage gestellt, ob das von İbn-i Kemâl erwähnte "Topkapusı" tatsächlich mit dem heutigen Topkapı identisch ist, oder ob der Autor wegen des damals vermauerten Zustands des eigentlichen Romanos-Tors das Geschehen irrtümlich oder bewußt mit dem Topkapı verbunden haben könnte. Diese Frage wäre sicherlich gegenstandlos, wenn nicht die unlängst von der Verfasserin entdeckte Inschrift das tatsächliche Romanos-Tor gesichert hätte (Abb. 15, 85, 87, 88). Die genannte Inschrift befindet sich auf dem Türsturz der bisher als 4. Nebentor bezeichneten Toranlage zwischen den Tortürmen 59 und 60 und lautet: ${ }^{380}$

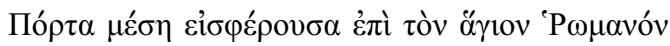

Diese Entdeckung brachte nicht nur etliche topographische Gewißheiten zu Fall, sondern zeigt, wie unsicher topographische Identifizierungen ohne archäologische oder epigraphische Unterstützung sein können. Auch ist es erstaunlich, daß bisher niemals die Frage gestellt wurde, warum eigentlich ein so gewaltiges Tor mit zwei Tortürmen, einem auffällig breiten Torhaus und einem gut erhaltenem Vortor als „Militär-Tor“ bzw. „Neben-Tor“ eingestuft und zu keiner Zeit in die topographischen Überlegungen einbezogen wurde. ${ }^{381}$ Die Inschrift auf dem Torsturz wurde kürzlich von Feissel in Augenschein genommen und in die theodosianische Zeit datiert. ${ }^{382}$ Es zeigt sich damit, daß bei der

377 Siehe Sakin, Deprem 142-143.

378 Siehe Ahunbay, Surlar, 79.

379 Das Tor wird im osmanischen Sprachgebrauch als Topkapusu (Tor der Kanonen) bzw. Bâb-1 Top bezeichnet.

380 Asutay, Romanos-Tor, 1-4.

381 Vor dem Tor liegen heute noch aus unterschiedlichen Steinsorten gefertigte Kanonenkugeln, deren größte einen Durchmesser von $71 \mathrm{~cm}$ aufweist, die nur aus der größten, von Urban gegossenen Kanone abgefeuert worden sein kann. Sie werden von der Vfn. an andere Stelle behandelt.

382 Feissel, Chroniques, 63, Nr. 196: „manifestement d'époque théodosienne.“ - Trotzdem findet sich auch in der neuesten Literatur immer noch ein Plan abgebildet, worauf das 
Verkleinerung des Tors der originale Sturzbalken (wahrscheinlich etwas verkleinert) wiederverwendet wurde, was auch bei Sulukulekapı der Fall gewesen sein muß (Abb. 17).

Es scheint also möglich, daß die Ereignisse am Romanos-Tor von den späteren osmanischen Quellen, vor allem von İbn-i Kemâl, auf das nördlich benachbarte und offene Tor übertragen wurden. In diesem Zusammenhang kann eine Urkunde im Archiv des Topkapı Sarayı erwähnt werden, worin von Reparaturarbeiten an einem Mauerabschnitt zwischen Topkapı und Balikapısı durch den ersten Kadı (Richter) von İstanbul, Hızır Çelebi (gest. 1457), die Rede ist. ${ }^{383}$ Zwar existierte auch an der Seemauer bei Sarayburnu wegen der hier stationierten Kanonen ein als Topkapı bezeichnetes Tor (das vormalige byzantinische Demetrios-Tor), doch ist ein Balikapı sonst nirgendwo belegt. Da das benachbarte Tor zum Topkapı an der Seemauer des Goldenen Horns Yalıkapısı bzw. Yalıköşkükapısı hieß, wird das in der Urkunde erwähnte Balıkapı in der Sekundärliteratur entweder als Yalıkapısı ${ }^{384}$ oder als Balikapısı gelesen, ${ }^{385}$ zumal die arabischen bzw. osmanischen Buchstaben ? (be) und ? (ye) in den handschriftlichen Texten leicht verwechselt werden können. Die Namen Yalıkapı (Strand-Tor) bzw. Yalıköşkükapısı (Strandkiosk-Tor) kommen in den osmanischen Quellen erst in Verbindung mit der Errichtung von Yalıköşkü (Strandkiosk) vor. ${ }^{386}$ Obwohl eine endgültige Aussage nur durch die Auffindung weiterer Parallelquellen getroffen werden kann, scheint sich die Urkunde auf eine Reparatur der Landmauer zu beziehen. Es würde dies bedeuten, daß man unter Topkapı zunächst das später geschlossene Romanos-Tor und unter Balikapı das heutige Topkapı verstand. Demnach hat İbn-i Kemâl die Ereignisse entweder irrtümlich auf das heutige Topkapı übertragen oder spricht tatsächlich vom Romanos-Tor, das zunächst als „Topkapusı“ bezeichnet wurde.

Romanos-Tor mit Topkapı gleichgesetzt wird; siehe z. B. Johannes G. Deckers, Die frühchristliche und byzantinische Kunst, München 2007, Karte.

383 Topkapı Sarayı, Archiv-Nr. E. 1175. - Ich danke Prof. Dr. Hüsamettin Aksu und Prof. Dr. İdris Bostan, beide von der Universität İstanbul, für ihre Hilfe bei der Lesung.

384 Inalcık, Policy, 235, bringt die Reparatururkunde mit der Seemauer in Verbindung. Tezcan, Sur-i Sultani, 72, stimmte dieser Identifizierung zu und las den Tornamen als „Yalıköşkükapısı" (Strandkiosk-Tor), obwohl in der Urkunde von einem Köşk keine Rede ist.

385 Tunay, Karasurları, 338, erwähnt die Urkunde in Verbindung mit der Landmauer und entziffert den Tornamen als „Balikapısı“, ebenso Ahunbay, Surlar, 79, wo die UrkundenNr. mit TSMA D. 11975 angegeben wird. Beide Autoren stellen aber nicht die Frage, wo sich dieses Balikapısı befunden haben könnte.

386 Der Strandkiosk wurde im Jahre 1593 durch Murat III. (1574-1595) erbaut. An seiner Stelle befand sich vorher wahrscheinlich der Kiosk des Sultans Bayezit II. (1481-1512); siehe Eldem, Köşkler, 173-207; Necipoğlu, Topkapı Palace, 231-240. - Yalıköşü̈kapısı wird in der Sekundärliteratur zumeist mit dem byzantinischen Eugenios-Tor in Verbindung gebracht; vgl. zuletzt Effenberger, Buondelmonti, 25. 
Die im Zusammenhang mit dem Romanos-Tor erwähnte Romanos-Kirche befand sich also in unmittelbarer Nachbarschaft des Tors ${ }^{387}$ das bisher für die Lokalisierung der Kirche nicht herangezogen wurde. Tatsächlich geht aus einer osmanischen Stiftungsurkunde hervor, daß die Romanos-Kirche ungefähr in der

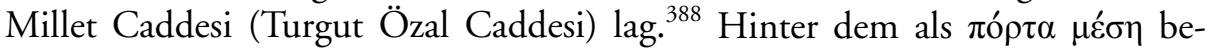
zeichneten Tor befand sich zweifellos eine bisher noch nicht identifizierte Hauptstraße der Stadt (siehe Exkurs I und Abb. 37). ${ }^{389}$ Somit stellt sich jetzt die Frage, mit welchem byzantinischen Tor das heutige Topkapı in Verbindung gebracht werden kann.

\subsubsection{Das Pempton-Tor}

Im Zusammenhang mit der Awarenbelagerung ${ }^{390}$ im Jahre 626 vermerkt das Chronicon Paschale, daß der Awaren Chagan Krum die Mauerabschnitte bzw. Tore zwischen Polyandrion und Pempton auf das heftigste angegriffen hatte: ${ }^{391}$

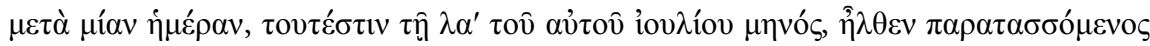

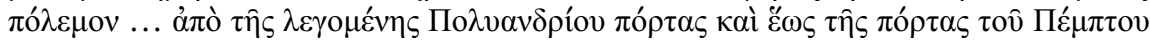

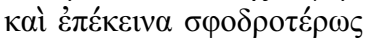

Einen Tag später, am einunddreißigsten des gleichen Monats Juli, läßt er [Chagan] vorrücken und seine Truppen für den Angriff ... vom sogenannten Polyandrion-Tor bis zum Tor des Pempton aufstellen.

Der Chagan griff am nächsten Tag jedoch an einem anderen Mauerabschnitt an, wo er zwölf bewegliche Türme aufgestellt hatte: ${ }^{392}$

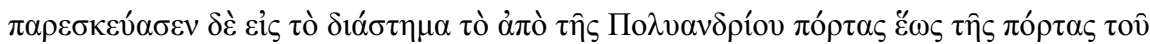

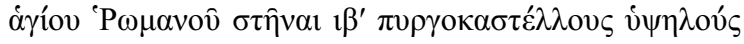

Er ordnete aber an, in dem Zwischenraum vom Polyandrion-Tor bis zum Tor des heiligen Romanos zwölf hohe bewegliche Türme aufzustellen.

387 Vgl. Anm. 356.

388 Tahrir Defteri II, 371, Nr. 1648: „Hâne-i beyt-i süfli ve muhavvata der mahalle-i Câmi-i Bâyezıd Ağa mahdûd tarafeynden tarîk-i âm ve tarafeyn-i ahareynden Kenîse-i Ayağomones." - Diese Urkunde wird von Vfn. an anderer Stelle behandelt.

389 Siehe Anm. 427.

390 Die Awarenbelagerung wird in der Sekundärliteratur mehrfach behandelt; als Beispiele siehe Speck, Bellum Avaricum, passim; Tsangadas, Fortifications, 80-106; HowardJohnston, Siege, $131-142$

391 Chron. Pasch. ad ann. 626, 719/7-10; englische Übersetzung: Whitby/Whitby, Chronicon, 173. - Du Cagne, Historiae, 51, bezeichnete das Tor als Porta Quinti; für eine Diskussion der Ortsbezeichnung Pempton und weitere Literatur siehe Meyer-Plath/ Schneider, Landmauer, 12-14 (Schneider); vgl. Janin, Constantinople, 452; Berger, Patria, 604-605.

392 Chron. Pasch. ad. ann.626, 719/22-720/2; englische Übersetzung: Whitby/Whitby, Chronicon, 174. 
Van Millingen interpretierte die beiden Aussagen des Chronicon Paschale gemäß der Annahme, wonach das Romanos-Tor mit dem heutigen Topkapı und das Polyandrion-Tor mit Edirnekapı identisch seien und das Pempton-Tor sich zwischen diesen beiden befunden haben müsse. Demzufolge bestimmte er Sulukulekapı als Pempton-Tor. ${ }^{393}$ Obwohl Meyer-Plath/Schneider bei ihren Überlegungen zu Recht davon ausgingen, daß das Polyandrion- bzw. Myriandrion-Tor das heutige Mevlevihanekapı war, kamen sie hinsichtlich der Identifizierung des Pempton-Tors zum gleichen Ergebnis wie Van Millingen und schlugen folgende Aufstellung der awarischen Armee vor: ${ }^{394}$

Unter persönlicher Führung des Avaren Chagan griff damals die slavische Belagerungsarmee auf dem Abschnitt zwischen Myriandrion und Porta Pempti an. Dabei ließ der Chagan zwölf Belagerungstürme ungefähr in Höhe des Vorwerks bauen, die zwischen Myriandrion und Romanustor vorrücken sollten. Zählt man nun die Vortürme, die zwischen Mevlevihanekapı und Topkapı liegen, so erhält man eine fast entsprechende Anzahl, nämlich dreizehn. Damit ist aber der Abschnitt Myriandrion (Mevlevihanekapı) und Romanustor (Topkapı) eindeutig festgelegt. Die Angriffsfront war aber breiter, sie reichte über das Romanustor hinaus bis Porta Pempti, welche nun nur das Tor im Lycustal [Sulukulekapi] sein kann.

Doch allein die Lage des Romanos-Tors und des Polyandrion- bzw. Myriandrion-Tors (Mevlevihanekap1) ${ }^{395}$ ist gesichert. In diesem Bereich befinden sich aber nur acht Vortürme, wohingegen zwischen Mevlevihanekap1 und Topkap1 tatsächlich dreizehn Vortürme erschließbar sind. Die Aussage des Chronicon Paschale kann dann auf zweierlei Weise interpretiert werden: Entweder stellte der Chagan seine beweglichen Türme nicht nur vor den Türmen, sondern auch vor den Kurtinen auf, oder er stellte diese zwar tatsächlich vom Polyandrion-Tor über das Romanos-Tor hinaus bis zum heutigen Topkapı auf, jedoch vor den Türmen, was der Verfasser der Osterchronik mißverstanden haben könnte. Es würde dies in beiden Fällen bedeuten, daß der dem Romanos-Tor nördlich benachbarte Durchgang, und zwar das heutige Topkapı, das Pempton-Tor war. Da jedoch in der bisherigen Forschung Sulukulekapı für das Pempton-Tor gehalten wird, soll diese Toranlage zunächst näher betrachtet und dabei überprüft werden, ob die Gleichsetzung berechtigt ist, oder ob für das Tor ein anderer Namen vorgeschlagen werden muß.

Zuvor ist kurz auf ein anderes Problem einzugehen: Da der Name Pempton in den Quellen außer in den Patria nur noch einmal vorkommt, nämlich in der Vita des hl. Philaretos (gest. 792), ${ }^{396}$ und eine Kyriake-Kirche in der Nähe des Lykos erwähnt wird, erfand man - wie oben bereits erwähnt - ein Kyriake-Tor

393 Van Millingen, Walls, 81. - Dethier, Bosphor, 54, setzte Pempton- und Charisios-Tor gleich und identifizierte es mit Sulukulekapı.

394 Meyer-Plath/Schneider, Landmauer, 12 (Schneider).

395 Preger, Tor, 272-280.

396 Siehe Fourmy/Leroy, Philarète, 159; vgl. Berger, Patria, 604. 
und vertrat die Meinung, daß der Name Pempton später durch Kyriake-Tor verdrängt worden sei. Diese Annahme setzt natürlich voraus, daß Sulukulekapı ebenfalls Kyriake-Tor hieß, zumal in der Nachbarschaft von Sulukulekapı eine Kyriake-Kirche existierte (siehe Abschnitt 2.3.4.3.). Solange aber keine neuen Erkenntnisse von philologischer Seite beigebracht werden können, darf m.E. nicht von einem Kyriake-Tor geredet werden.

\subsubsection{Das Charisios-Tor und das Johannes-Tor}

Für die Gleichsetzung von Sulukulekapı (Abb. 17, 36) mit dem Pempton-Tor spielte eine weitere Überlegung eine Rolle, die das Charisios-Tor betrifft. ${ }^{397} \mathrm{Da}$ Edirnekap1 (Abb. 18, 36) mit großer Übereinstimmung für das byzantinische Charisios-Tor gehalten wird, blieb für Sulukulekapı zwangsläufig der Name Pempton übrig. ${ }^{398}$ Die Identifizierung von Edirnekapı mit dem Charisios-Tor wird u. a. mit einer vor der inneren Nordseite des Tors stehenden Georgs-Kirche begründet, die wiederum mit der in den Quellen im Zusammenhang mit dem Charisios-Tor erwähnten byzantinischen Georgs-Kirche verbunden wurde und als deren Nachfolgerin gilt. ${ }^{399}$ Diese in der Forschung fest verankerte Auffassung basiert auf einer Aussage des nachmaligen Patriarchen Konstantios I. (1830$1834)^{400}$ und bedarf einer eingehenden Überprüfung. In seinem Buch behauptete Konstantios, daß an der Stelle der Mihrimah Moschee einst eine Georgs-Kirche gestanden habe, die im Jahr 1556 auf Befehl Sultan Süleymans des Gesetzgebers abgetragen und unmittelbar danach auf der anderen Straßenseite neu errichtet worden sei, ohne dafür eine Quelle zu erwähnen. Die Georgs-Kirche gegenüber der Mihrimah Moschee stammt aus dem 18. Jahrhundert. ${ }^{401}$ Die älteste Inschrift an der Kirche von 1726 erwähnt, daß das Gebäude um diese Zeit erneuert wurde. ${ }^{402}$ Aus zwei weiteren Inschriften erfahren wir, daß die Kirche im Jahre 1736 von Grund auf renoviert oder besser

397 Seinen Namen erhielt das Tor von einer in der Nähe liegenden Klosteranlage, siehe Meyer-Plath/Schneider, Landmauer, 70; Berger, Patria, 619-620.

398 Für eine Gleichsetzung von Charisios-Tors und Sulukulekapı siehe Mijatovich, Conquest, 142; vgl. auch Dethier in Anm. 393.

399 Für eine Zusammenstellung der diesbezüglichen Quellen siehe Mordtmann, Esquisse, $16-29$, bes. $21-22$.

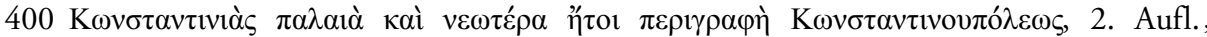
Konstantinopel 1844, 143 (mir nicht zugänglich, hier zitiert nach Mordtmann, Esquisse, 21); vgl. die französische Ausgabe: Constantiniade ou description de Constantinople ancienne e moderne composée par un philologue et archéologue, Konstantinopel 1846, 134.

401 Karaca, Rum, 121-129; vgl. die Karte von Müller-Wiener, Konstantinopel, C/3, Nr. 8. 402 Karaca, Rum, 123 (Inschrift und türkische Übersetzung). 
gesagt, neu errichtet worden war. ${ }^{403}$ Die Informationen der beiden späteren Inschriften stimmen mit einer osmanischen Quelle überein, worin mitgeteilt wird, daß im Jahre 1730 Sultan Mahmut I. (1730-1754) für die Restaurierung der Georgs-Kirche in der Nähe von Edirnekapı die Genehmigung erteilt hatte. $^{404}$

Auf Grund der ersten Inschrift von 1726 ist mit Sicherheit anzunehmen, daß die Bautätigkeit tatsächlich nur im Rahmen einer Reparatur stattfand und hier eine ältere Kirche stand. Diese kann durchaus die bereits 1583 in der Kirchenliste des Trifon Karabejnikov erwähnte Georgs-Kirche gewesen sein. ${ }^{405}$ Es ist damit aber nicht zu beweisen, daß der Vorgängerbau dieser Kirche einst an der Stelle der Mihrimah Moschee stand und die byzantinische Georgs-Kirche beim Charisios-Tor war, die angeblich 1556 auf Befehl Süleymans abgetragen wurde. Die Baugeschichte der Mihrimah Moschee läßt daran nämlich zweifeln.

Zwischen der Errichtung der Mihrimah Moschee und dem Bericht des Konstantios liegen fast 300 Jahre. Obwohl Konstantios von einem Befehl Sultan Süleymans des Gesetzgebers spricht und die Moschee dem Jahre 1556 zuschreibt, geht dieses Datum weder aus einer Schriftquelle noch aus Bauinschriften in der Moschee hervor. ${ }^{406}$ Selbst für diejenigen Kunsthistoriker, deren Schwerpunkt die osmanische Architektur ist, stand lange Zeit nicht fest, wann die Moschee erbaut wurde und ob sie aus der Regierungszeit Süleymans I. (1520-1566) oder Selims II. (1566-1574) stammt. Die Bauhistoriker, welche die Moschee der Regierungszeit Süleymans zuschreiben, ${ }^{407}$ gingen hauptsächlich von zwei Quellen aus: Dem Buch von Evliya Çelebi aus dem 17. Jahrhundert, wo die Moschee im Zusammenhang mit Sultan Süleyman erwähnt wird, ${ }^{408}$ und dem Hadikat-ül Cevâmi des Ayvansarâyî Hüseyin Efendi aus dem 18. Jahrhundert, wo das Todesdatum der Prinzessin Mihrimah irrtümlich mit 1558 angegeben ist. ${ }^{409}$ Die Forscher, die für eine spätere Datierung eintreten, berücksichtigten besonders die Tatsache, daß Mihrimah nach ihrem Vater verstorben war und stützen sich auf die Stiftungsurkunde aus dem Jahre 1570/71, wonach der erste Müderris der Moschee 1568 sein Amt angetreten hatte. ${ }^{410}$

403 Ebd., 124.

404 Siehe vorige Anm.

405 Die ersten Arbeiten, die der Feststellung der griechisch-orthodoxen Kirchen im osmanischen İstanbul dienten, stammen von Trifon Karabejnikov (1583), Antonios Petarakis (1604), Thomas Smith (1669); vgl. Schneider, Byzanz, 38-49; für eine jüngere Diskussion und die Literatur siehe Karaca, Rum, 19-53 und 57-70. Für die byzantini-

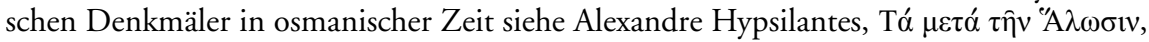
Konstantinoupolis 1870 [Nachdruck: Athen 1972], passim.

406 Siehe Goodwin, Ottoman Architecture, 252.

407 Siehe dazu Sözen, Mimar Sinan, 184.

408 Evliya Çelebi, I, 233.

409 Hadikat-ül Cevâmî, 65.

410 Kuran, Mimar Sinan, 123. 
Doch osmanische Quellen geben wertvolle Hinweise für die Bauzeit: Im August 1563 erhielt Mihrimah Sultan, die Tochter Süleymans des Gesetzgebers, von ihrem Vater die Erlaubnis ihre Moschee bauen zu dürfen. ${ }^{411}$ Ein Ferman (Erlaß) aus dem Jahre 1565 weist darauf hin, daß die Moschee erst gegen Ende der Regierungszeit Süleymans vollendet war, und zwar neun Jahre nach dem von Konstantios angegebenen Datum: ${ }^{412}$

İstanbul kadısına hükümki. Hâliya cânibinden darüssaltanatülâliyye mahmiyyei Kostantiniyye Edirne kapusınun iç yüzünde müceddeden binâ olunan camii kurbinde hamam binâ eylemek isticâze etdügi ecilden izni şerifim mukarin olup buyurdumki zikrolunan camii kurbinde milk yerinde mûmâileyhimâ cânibinden hamam binâ etdükte ser'i şerife muhâlif kimesniye dahl ve taaruz etdirmiyesin. Fi 11 Muharremülharam 973 (1565).

Befehl an den Kadı von İstanbul: Da jetzt von Seiten der [Wort fehlt] um die Erlaubnis gebeten wurde, am Sitz des Sultanats, dem wohlbehüteten Kostantiniyye, in der Nähe der innerhalb des Edirnekapı neu errichteten Moschee [Mihrimah Camii] einen Hamam zu bauen, erteile ich dazu meine Erlaubnis und befehle dir, sobald der Hamam von den beiden erwähnten auf ihrem eigenen Grund und Boden erbaut ist, nicht zuzulassen, daß jemand sich gegen die edle Scharia einmische und störe. (Geschrieben) am 11. Muharremülharam H. 973 (8. August 1565). ${ }^{413}$

Der Bau der Mihrimah Moschee begann also im August 1563 und war um den August 1565 im Großen und Ganzen fertiggestellt. Das von Konstantios erwähnte Datum entspricht demnach nicht den Tatsachen und beruht anscheinend auf einer Vermischung byzantinischer und osmanischer Quellen. Weder die heutige Georgs-Kirche noch der Bericht des Konstantios bieten eine sichere Grundlage, um Edirnekapı auf dem Umweg über die Georgs-Kirche mit dem Charisios-Tor identifizieren zu können.

Auch anhand byzantinischer Quellen wurde versucht, die Identität von Edirnekapi und Charisios-Tor zu beweisen und die Georgs-Kirche mit Edirnekapı zu verbinden. So berichtet Anna Komnene zunächst über die Einnahme von Konstantinopel durch die Komnenen, deren zusammengewürfeltes Heer durch das Charisios-Tor in die Stadt eingedrungen war. ${ }^{414}$ Zwei Kapitel später lesen wir: ${ }^{415}$

411 Konyalı, Koca Sinan, 161; siehe auch Necipoğlu, Sinan, 307, 540, Anm. 111 (Vakıflar Genel Müdürlügü Arşivi, Defter 635/1 Mükerrer, Nr. 6, datiert Zilhicce 970 [Juni/ August 1563], S. 6).

412 Ahmet Refik, I, 22/16. - Prof. Dr. Hans-Georg Majer (München) danke ich herzlich für seine Hilfe bei der Auseinandersetzung mit diesem Text.

413 Zur Lage des Hamam siehe die Karte von Müller-Wiener, Topographie, C/3, Nr. 10.

414 Anna Komnene, II, 10, $\$ 4,81 / 98$; deutsche Übersetzung: Reinsch, Alexias, 98; siehe auch Zonaras. 727/12-728/16; deutsche Übersetzung: Trapp, Militärs, 159.

415 Anna Komnene, II, 12, $\$ 1,84 / 89-90$; deutsche Übersetzung: Reinsch, Alexias, 101; vgl. auch Buckler, Anna Comnena, 75-76. 


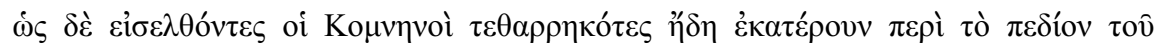

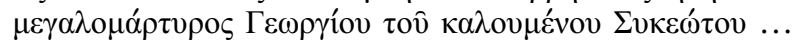

Als die Komnenen die Stadt betreten hatten und nunmehr bereits voller Zuversicht auf dem ebenen Platz des Großmärtyrers Georgios, der den Beinamen Sykeotes trägt, hielten ...

Bereits Mordtmann hatte in seinem Kapitel über das Charisios-Tor beide Stellen nacheinander zitiert und dadurch den Eindruck erweckt, daß die byzantinische Georgs-Kirche beim heutigen Edirnekapı lag. ${ }^{416}$ Ähnlich verfuhr auch Janin. ${ }^{417}$ Die Mitteilungen, wonach die Truppen durch das Charisios-Tor in die Stadt eingedrungen waren und die Komnenen (Isaakios und Alexios) an einem ebenen Platz anhielten, dürfen jedoch nicht miteinander vermengt und dahingehend interpretiert werden, daß die Georgs-Kirche bei Edirnekapı gesucht werden muß und dieses demzufolge das Charisios-Tor war. Dieser Georgios (und damit auch dessen Kirche) könnte mit dem in einer Stiftungsurkunde von 1490 erwähnten „Hızır ve İlyas“ (die islamische Bezeichnung für den heiligen Georgios) identisch sein. ${ }^{418}$ Einen sicheren Beleg für die Lage der byzantinischen Georgs-Kirche bietet die İstanbul-Karte von Kauffer/Lechevalier (1786), auf der Sulukulekapı allerdings nicht eingetragen ist, da dieses Tor damals vermauert war. Etwa in der Mitte zwischen der anzunehmenden Stelle des Tors und der Mihrimah Camii findet sich der Eintrag „Ayos Yoryhios.“ Demzufolge muß sich eine Georgs-Kirche weiter südlich der Mihrimah Moschee, in der Nähe von Sulukulekapı, befunden haben.

Für die Identität von Edirnekapı und Charisios-Tor wurde auch eine Stelle im Zeremonienbuch Konstantins VII. Porphyrogennetos herangezogen, wonach Kaiser Justinian I. durch das Charisios-Tor in die Stadt eingezogen und vorbei am Deuteron zur Apostel-Kirche gegangen sei, um das Grab seiner Frau Theodora aufzusuchen. ${ }^{419}$ Das zeigt allerdings, daß hinter dem Charisios-Tor eine Straße lag, die gelegentlich als Einzugsweg diente. Nach allgemeiner Ansicht folgte die Prozession dem sog. Nordstrang, der heutigen Fevzi Paşa Caddesi ${ }^{420}$ da man die Route Charisios-Tor (also „Edirnekap“"), Deuteron und

416 Mordtmann, Esquisse, 18.

417 Janin, Églises, 77-78, Nr.9.

418 Tahrir Defteri I, 395, Nr.2318, wobei der Name „Hızır ve İlyas“ jedoch nicht im Zusammenhang mit einer Kirche begegnet und auch auf Personen bezogen werden könnte.

419 Konst. Porph. I, 497/13-16. - Diese Stelle wurde ebenfalls von Mordtmann, Esquisse, 17, zitiert und diskutiert; siehe auch Mango, Triumphal Way, Abb.2, wo die Route eingezeichnet ist; vgl. Haldon, Treatises, 138/707-711, 265; Bauer, Urban Space, 47, Abb. 21.

420 Mango, Triumphal Way, 177, machte zu Recht darauf aufmerksam, daß die heutige Fevzi Paşa Caddesi eine moderne Anlage ist. Für die Straßenführung im 19. Jahrhunderts siehe Ayverdi, İstanbul Haritası; für das 18. Jahrhunderts siehe die İstanbul-Karte von 
Apostel-Kirche sich nur so erklären konnte. ${ }^{421}$ Edirnekapı muß selbstverständlich mit einer Straße verbunden gewesen sein, doch ist die Frage berechtigt, ob diese die einzige Straße nördlich des Lykos war. Die Notiz im Zeremonienbuch liefert zwar ein starkes Argument für die Gleichsetzung von Charisios-Tor mit Edirnekapi. Das Deuteron konnte aber auch von einem benachbarten Tor - in diesem Fall von Sulukulekap1 - aus erreicht werden, zumal von diesem Tor eine wichtige byzantinische Straße parallel zum Lykos in die Stadt hineingeführt haben muß (Abb. 37). Dafür spricht auch folgendes Argument: Die Via Egnatia verlief ursprünglich von Herakleia in nördlicher Richtung und umging die sumpfigen Lagunen von Athyras (Büyük Çekmece) und Rhegion (Küçük Çekmece). ${ }^{422}$ Die Straße passierte 18 oder 19 Meilen vor Konstantinopel einen Ort namens Melantias. ${ }^{423}$ Aus den Quellen kennen wir ein Melantias-Tor, wo die Straße geendet haben wird. ${ }^{424}$ Das Melantias-Tor befand sich in der Nähe des Deuteron an der Nordseite des Lykos. ${ }^{425}$ Es ist daher recht wahrscheinlich, daß diese alte Straße bei der Anlage der Tore der Theodosianischen Landmauer - in unserem Falle von Sulukulekap1 - beibehalten worden war.

Vom einstigen Verlauf der Straße und von der Wichtigkeit dieses Tors zeugt heute noch ein Monument, nämlich die im Jahre 450/52 durch den Stadtpräfekten Tatianos für Kaiser Markian errichtete Monumentalsäule (türkisch „Kıztaş“") (Abb. 212). ${ }^{426}$ Da jenseits des Lykos im allgemeinen keine weitere Straße angenommen und die einzige Hauptstraße im Bereich der heutigen Fevzi Paşa Caddesi gesucht wird, werden für das Verhältnis der Säule zu dieser Straße die unterschiedlichsten Lösungen angeboten, ${ }^{427}$ was zum Teil von der Tatsache

Kauffer/Lechevalier (1786). Tournefort II, 17, schrieb zwar, daß die Straße, die vom Palast zu Edirnekapı führte, verglichen mit den anderen die angenehmere war, doch geht daraus nicht die genaue Route hervor. - $\mathrm{Zu}$ weiteren Plänen vgl. Anm. 427.

421 Berger, Patria, Faltplan gegenüber 196. - Zur Lage des Deuteron siehe Schneider, Deuteron, 181-186; Janin, Constantinople, 336-339 (Quellen); Berger, Patria, 518521; Mango, Développement, 25, 32; ders., Triumphal Way, 175; Asutay-Effenberger/ Effenberger, Columna Virginea, 377-383.

422 Mango, Développement, 32; vgl. Triumphal Way, 174-173.

423 Zur Lage (Yarım Burgaz an der Lagune von Küçük Çekmece) siehe Mango, Développement, 32, Anm. 55.

424 Janin, Constantinople, 388.

425 Zur Lage vgl. Anm. 421.

426 Für eine Diskussion mit weiteren Literaturangaben siehe, Bauer, Denkmal, 213-215. $\mathrm{Zu}$ Tatianos siehe PLRE II, 1053-1054 (Tatianus 1).

427 In der Sekundärliteratur begegnet man häufig schematischen Karten von Konstantinopel, worauf einige Straßen eingetragen sind. $\mathrm{Zu}$ den verschiedenen Vorschlägen siehe Preger, Konstantinsmauer, 451; Schneider, Straßen, 71; Janin, Constantinople, Karte V; Mango, Développement, Plan II; Berger, Patria, Faltplan gegenüber 196; ders, Streets, Karte 4; ders., Processions, 87; Bauer, Denkmal, 146, Abb. 47; Ciggaar, Travellers, Map 3; Magdalino, Constantinople, 106 (Plan); Mango, Triumphal Way, 177; Jacoby, Venetian Quarter, 154. - Auf meinem Plan Abb. 37 sind alle Streckenführungen ebenfalls nur schematisch angegeben. 
beeinflußt ist, daß die Schauseite der Basis zur heutigen Fevzi Paşa Caddesi, also zum angeblichen „Nordstrang“ der Mese gerichtet ist. ${ }^{428}$ Es erscheint mir jedoch nicht plausibel, daß die Säule an einer beliebigen Nebenstraße lag, sondern an einer Hauptstraße. Diese führte von Sulukulekap1 geradewegs in die Stadt hinein (Abb. 37). ${ }^{429}$ Insofern ist es möglich, daß die Hauptansicht der Kaiserstatue in Richtung Sulukulekap1 wies. ${ }^{430}$

Das schließt nicht aus, daß der Standort der Säule, der eine Platzanlage (Forum Markians) gewesen sein muß, ${ }^{431}$ von weiteren Straßen gekreuzt wurde. Für die Identifizierung von Sulukulekapı mit dem Charisios-Tor lassen sich weitere Argumente finden. Nicolò Barbaro bezeichnete im Zusammenhang mit der Belagerung des Jahres 1453 das Cresu-Tor als schwächstes Tor dieser Gegend. ${ }^{432}$ Selbst wenn die Überlieferung in diesem Punkt zweifelhaft ist, zeigt ein Vergleich der Lage von Edirnekapı und von Sulukulekapı deutlich, daß nicht das auf dem höchsten Punkt bei ca. $78 \mathrm{~m}$ Seehöhe aufragende Edirnekapı, sondern das in der Nähe des Lykos an einem Abhang gelegene Sulukulekapı strategisch gesehen - sich an einer weniger günstigen Position befindet. Damit stünde nicht im Widerspruch, daß Barbaro in der weiter oben zitierten Stelle auch das Romanos-Tor als schwächstes Tor bezeichnet. ${ }^{433}$ Zwar befinden sich hinter Sulukulekapı sehr starke Wehrgangstreppen, doch der hohe Torbogen

428 Bauer, Denkmal, 214: „Die Hauptansichtsseite der Säule richtet sich so auffällig zum Standort der ehemaligen Apostel-Kirche, daß man geneigt ist, diese und die MarkiansSäule miteinander zu verbinden. Andererseits ist das Kapitell des Säulenmonuments gegenüber dem Sockel derart verschoben, daß es mit einer Seite zur Polyeuktos-Kirche weist. Möglicherweise ist hierin ein Indiz zu sehen, daß die Straße direkt zur PolyeuktosKirche verlief: Die Ansichtseite der Kaiserstatue wies vielleicht in diese Richtung." Zum Verhältnis der Straße zur Polyeuktos-Kirche siehe Exkurs I.

429 Über diese Straße hat Vfn. auf dem 21. International Congress of Byzantine Studies, London (2006) referiert; siehe Asutay-Effenberger, Mese, 98-99.

430 Schreiner, Schlechte Straßen, 583 Plan, akzeptierte meinen Vorschlag zur Gleichsetzung von Sulukulekapı mit dem Charisios-Tor und der zur Markians-Säule führenden Straße, benutze jedoch als Grundlage den Plan von Bauer, Denkmal, 146, Abb. 47, der in einem wichtigen Detail (Straße vom Exakionion zum Pege-Tor) unzutreffend ist.

431 Vgl. dazu Bauer, Denkmal, 213-215.

432 So steht es allerdings nur in der Textfassung von Enrico Cornet (Nicolò Barbaro, Giornale dell'Assedio di Costantinopoli. Corredato di note e documenti per Enrico Cornet, Wien 1856, 728-729: „,a una porta la qual se chiama Cressu. La qual porta si è più debele cha porta niunta de la tera"). Pertusi gibt diese Stelle nicht wieder; 351, Anm 44, erwähnt er lediglich, daß ab hier nur die Stellung der westlichen Marine am 9. April am Goldenen Horn entlang der Hafensperrkette beschrieben wird. - Für die Bezeichnung „Cresu“ siehe Anm. 362.

433 Siehe Anm. 361. 
war mit einer nur ca. 1,05 m dicken Wand verschlossen, die einem intensiven Kanonenbeschuß kaum standgehalten hätte (Abb. 93). ${ }^{434}$

Die türkischen Reparaturen am Edirnekapı werden zumeist mit der Bombardierung durch die osmanische Armee 1453 in Verbindung gebracht und als weiteres Indiz für die Identifizierung mit dem Charisios-Tor genommen. ${ }^{435} \mathrm{Die}$ älteste Reparaturinschrift des Tors stammt aus der Regierungszeit des Sultans Bayezıt II. (1481-1512) und erwähnt das Datum H. 915/1509. ${ }^{436}$ Dieses Datum erinnert an das große Erdbeben, das in den osmanischen Quellen als „Kıyamet-i Suğra“ (kleine Apokalypse) bezeichnet wird, und dessen Folgen u.a. von Gelibolu’lu Mustafa Âli beschrieben werden: ${ }^{437}$

Amma nefs-i İstanbul'da yüzdokuz mescid ve binyetmiş hâne harap olduktan sonra beş bin mikdârı er u avret ü sibyân helâki mukarrer oldu. Şehir içre bîli bütün asla minâre kalmadı ve sûr-1 Konstantin'in üç kat hisârı kara cânibinden Eğri Kapu’dan başlayıp, yıkıldı Yedikule’ye gelince ... Yẩni ki, yer yer yıkılup, bâ’zı tahtaları ancak yerinde kaldı ... Fe-emmâ hemen İstanbul sûrı değil ... cemi’an altmış dört günde tâmir ve termim eylediler.

Aber in İstanbul selbst sind 109 Mescids, 1070 Häuser zusammengestürzt und 5000 Menschen - Männer, Frauen, Kinder - gestorben. Es blieb kein einziges aufrecht stehendes Minarett übrig. Die dreifache Mauer Konstantins an der Landseite wurde vom Eğri Kapı bis Yedikule beschädigt, so daß von ihnen zum Teil nur die Fundamente übrig geblieben waren ... Die Reparaturarbeiten nicht nur an den Mauern ... wurden innerhalb von 64 Tagen durchgeführt.

Weder die Inschrift noch die auf das Erdbeben folgende Reparaturtätigkeit können also mit Bombardierungen des Tors in Zusammenhang gebracht werden. Zwei Stiftungsurkunden Mehmets II., die in dieser Hinsicht von Bedeutung sind, geben einen weiteren Hinweis für die Gleichsetzung von Sulukulekapı mit dem Charisios-Tor: Unmittelbar nach der Eroberung wurde die Stadt in verschiedene Quartiere eingeteilt. Während die Umgebung von Edirnekap1 die Bezeichnung „Edirnekapı Mahallesi“ (Edirnekapı-Quartier) erhielt, wurde die heutige Neslişah Sultan Mahallesi hinter Sulukulekapı in „Topyıkığı Mahallesi“" (Kanonenbreschen-Quartier) umbenannt. ${ }^{438}$ Es zeigt sich damit noch einmal, daß die von Nicolò Barbaro im Zusammenhang mit dem Charisios-Tor

434 Als weiteres Argument für die Gleichsetzung von Sulukulekapı mit dem Charisios-Tor kann man erwähnen, daß die Straße, die zu Sulukulekapı führte, in einer Quelle als besonders schlammig bezeichnet wird, was darauf hinweist, daß diese Straße nahe am Lykos-Bach verlief, vgl. Schreiner, Schlechte Straßen, 581-588.

435 Meyer-Plath/Schneider, Landmauer, 71.

436 Meyer-Plath/Schneider, Landmauer, 159, Nr. 52 (Schneider); Tunay, Kara Surlar1, 339.

437 Gelibolu’lu Mustafa Âli, 920-22; für weitere Parallelquellen siehe Sakin, Deprem, 97 113; für eine kurze Zusammensetzung der Erdbeben in osmanischer Zeit siehe auch Pamukçiyan, Depremler, 34-35.

438 Fatih Vakfiyeleri, 224 (148) und 341 (236); vgl. Ayverdi, Mahalleler, 170; siehe auch Tahrir Defteri I, 395, Nr. 2313. 
erwähnten beiden Kanonen im Jahre 1453 vor Sulukulekapı aufgestellt waren ${ }^{439}$ und dort großen Schaden an der Mauer angerichtet hatten (Abb. 95). Es ist hier daran zu erinnern, daß Edirnekapı von den osmanischen Autoren, die Augenzeugen der Eroberung waren, nicht erwähnt wird. Wie oben vermerkt, benutzte Gelibolu'lu Mustafa Âli den Tornamen nur zur Kennzeichnung der Richtung, ${ }^{440}$ während Cafer Çelebi von dem Gebiet südlichen von Edirnekapı spricht. ${ }^{441}$ Allein İbn-i Kemâl scheint die Geschehnisse am Charisios-Tor mit dem heutigen Edirnekapı in Verbindung gebracht zu haben. ${ }^{442} \mathrm{Da}$ Sulukulekapı unmittelbar nach der Eroberung vermauert wurde, sind wahrscheinlich auch hier wie schon im Falle des Romanos-Tors die historischen Ereignisse von dem zugemauerten Tor auf das benachbarte und weiterhin passierbare Tor übertragen worden. Es würde dadurch auch der byzantinische Name des heutigen Topkap1 als Pempton-Tor gesichert, da zwischen Romanos-Tor und Charisios-Tor (Sulukulekapı) nur noch dieses eine Tor südlich des Lykos existiert (Abb. 36, 37).

Eine Passage im Gedicht eines byzantinischen Anonymus vom Ende des 14. Jahrhunderts liefert schließlich den entscheidenden Beweis dafür, daß CharisiosTor, Georgs-Kirche und Kyriake-Kirche in unmittelbarer Nähe nördlich des Lykos gelegen haben. ${ }^{443}$ Der betreffende Abschnitt des Gedichts berichtet von der Auseinandersetzung zwischen Michael VIII. Palaiologos und Balduin II. 1261. Eingangs erfahren wir, daß das Haus des heiligen Georgios beim

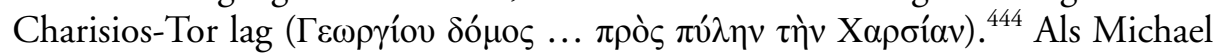
mit seinem zahlreichen Heer von Selymbria anrückte, ließ Balduin alle Landmauertore mit großen Steinen verschließen, mit Ausnahme des Tors, das nahe

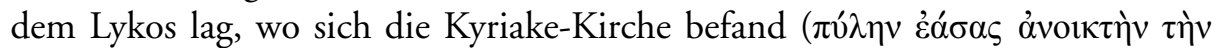

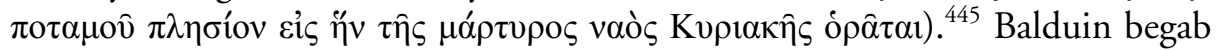
sich mit seinen Reitern zum Charisios-Tor, wo jedoch der Heilige stand und das

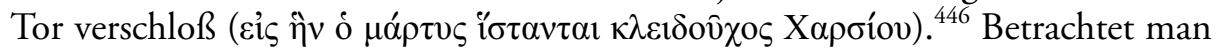
alle diese Aussagen im Zusammen mit dem oben erwähnten Bericht des Ioannes Kananos, ${ }^{447}$ wo eine bestimmte Örtlichkeit durch die Nachbarschaft der Kyriake-Kirche und zugleich durch die sehr große Nähe zu den beiden dem Lykos

439 Siehe Anm. 361.

440 Gelibolu’lu Mustafa Âli, ed. Şentürk, 12.

441 Siehe Anm.369.

442 İbn-i Kemâl, Tevârih-i Âli Osman, 68.

443 Müller, Analekten, 378-379; siehe dazu Hunger, Literatur, II, 163. - Van Millingen, Walls, 82-83, mit Anm. 1, meinte, daß der Autor sowie Kananos (Anm.306) „expressively distinguish the Gate of Charisius [Edinekapı nach Van Millingen] from the gate situated beside the Lycus."

444 Müller, Analekten, 378/372-373.

445 Müller, Analekten, 378/390-391.

446 Müller, Analekten, 378/394.

447 Siehe Anm.307. 


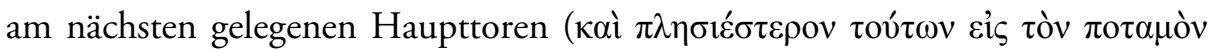

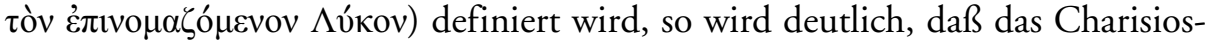
Tor nur mit Sulukulekapı identifiziert werden kann, in dessen Nachbarschaft die Kyriake-Kirche lag. Damit ist aber nicht erwiesen, daß diese Kyriake-Kirche mit derjenigen identisch ist, die nach Nestor Iskander durch Kanonenbeschuß zerstört wurde (siehe Abschnitt 2.2.1.).

Damit stellt sich die Frage, welche byzantinische Bezeichnung dann für Edirnekapı in Betracht kommt, wenn alle in den Quellen erwähnten Tornamen bereits vergeben sind. Einige spätmittelalterliche Schrift- und Bildquellen, die jedoch in der diesbezüglichen wissenschaftlichen Diskussion bisher kaum berücksichtigt worden sind, belegen die Existenz eines Johannes-Tors an der Theodosianischen Landmauer und an der Nordseite des Lykos. Das Tor kommt auf Kopien der Buondelmonti-Ansicht von Konstantinopel mit der Beischrift porta s. johannis unmittelbar südlich von Tekfur Sarayı vor (Abb. 45). ${ }^{448}$ Mordtmann brachte die Beischrift ausgehend von einer Buondelmonti-Kopie im Vatikan mit Tekfur Sarayı in Verbindung. ${ }^{449}$ Claudia Barsanti erwähnte in ihrer Arbeit über die Buondelmonti-Darstellungen zwar die Beischrift, lehnte aber das Vorhandensein eines Johannes-Tors an der Landmauer mit der Begründung $a b$, daß ein Tor dieses Namens nur an der Seemauer des Goldenen Horns vorkomme. ${ }^{450}$ Zwar befand sich dort tatsächlich ein Johannes-Tor, das seinen Namen möglicherweise von einer benachbarten Kirche des Ioannes Prodromos erhalten hatte, ${ }^{451}$ doch ist das nur eine der vielen Bezeichnungen, die für Balatkapı überliefert sind. ${ }^{452}$

Auch byzantinische und russische Quellen sprechen von einem Landmauertor, das in der Nähe eines Prodromos-Klosters gelegen haben soll und bestätigen damit die Beischrift der Buondelmonti-Karten. In seinem Bericht über die Auseinandersetzungen zwischen Kaiser Ioannes V. Palaiologos und seinem Enkel Ioannes VII. Palaiologos erwähnt der russische Pilger Ignatij von Smolensk ein Tor, das sich in der Nähe eines Prodromos-Klosters befand: ${ }^{453}$

In the year 6898 [1390] Kalojan, the son of Andronicus, began to seek the rule of Constantinople with Turkish aid. He took the towns and fortresses as he approached

448 Zusammenstellung der Buondelmonti-Kopien bei Barsanti, Buondelmonti, wo alle Ansichten von Konstantinopel abgebildet sind, auf denen ein Johannes-Tor verzeichnet ist: Abb.61, 71, 76, 79, 84, 87, 91, 95; siehe auch Effenberger, Buondelmonti, 51.

449 Mordtmann, Esquisse, 34, Anm. 2.

450 Barsanti, Buondelmonti, 200; zum Johannes-Tor am Goldenen Horn siehe Schneider, Mauern und Tore, 71.

451 Schneider, Mauern und Tore, 68-69; ders., Blachernen, 92; zu dieser Kirche siehe Janin, Églises, 411, Nr. 4.

452 Schneider, Blachernen, 94; Effenberger, Buondelmonti, 51, Tabelle III, Nr.3B.

453 Majeska, Travelers, 100 (danach die englische Übersetzung des altslavischen Textes); Eckklammern und Kursive stammen von Majeska. 
Constantinople, and began the siege there around Holy Easter. On Holy Thursday Manuel, the son of the old Emperor Kalojan, came from Lemnos with galleys to relieve Constantinople ... Then all the land gates of the city except the gate near the Prodromos [Monastery] were walled up and orders went out the stores [enough] for two years be maintained.

Majeska nahm an, daß der Pilger mit dem einen nicht zugemauerten Tor das Charisios-Tor gemeint habe, das er mit dem Edirnekapı gleichsetzte. ${ }^{454}$ Dagegen sprechen aber eine andere Passage des Berichts und eine weitere Quelle. Ignatij fährt fort: ${ }^{455}$

But in the middle of the night on Wednesday of the second week after Easter the common people opened the city gates to Kalojan, the son of Andronicus, and to the Greeks [with him]

Darüber hinaus erfahren wir aus einer Kleinchronik, daß Kalojan (Ioannes VII. Palaiologos) durch das Charisios-Tor in die Stadt eingedrungen war. ${ }^{456}$ Daraus geht hervor, daß das Charisios-Tor wie alle anderen Stadttore vormals zugemauert gewesen sein muß, somit nicht mit dem einen offen gelassenen und wahrscheinlich auch am stärksten bewachten Tor beim Prodromos-Kloster identisch sein kann. Damit stellt sich die Frage, wo sich dann dieses ProdromosKloster befand. Den Quellen zufolge lag in der Nähe der Aetios-Zisterne eine der wichtigsten religiösen Gründungen Konstantinopels und zwar das Kloster

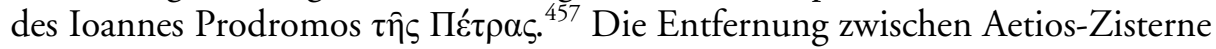
und Edirnekapı beträgt ungefähr $300-400 \mathrm{~m}$, weshalb nur bedingt von einer engen Nachbarschaft von diesem Tor und der Klosteranlage gesprochen werden kann. Ein weiteres Kloster, das dem Ioannes Prodromos geweiht war, soll Patriarch Dositheos zufolge sich unmittelbar neben Edirnekapı befunden haben und im Jahre 1637 durch den Großvezir Bayram Paşa in eine Moschee konvertiert worden sein. ${ }^{458}$ Es gab also ein Johannes-Kloster in unmittelbarer Nachbarschaft des Tors und ein ca. 300-400 Meter entfernt liegendes zweites Johannes-Kloster in dieser Gegend.

Die beiden Tore nördlich des Lykos hatten also andere byzantinische Namen, als man bisher annahm. Das heutige Edirnekapı war das Johannes-Tor, Sulukulekapı das Charisios-Tor. Von den beiden Toren südlich des Lykos war

454 Majeska, Travelers, 410; vgl. Reinert, Palaiologi, 311.

455 Majeska, Travelers, 100.

456 Schreiner, Kleinchroniken I, 68, Nr.7, \$21; II, 340-341; III, 24-25, \$21.

457 Für eine Zusammenstellung der Quellen siehe Janin, Églises, 421-429, und Kidonopoulos, Bauten, 45-49. - Die Kirche gilt heute als verschollen; sie wird von der Vfn. an einem anderen Ort behandelt. $\mathrm{Zu}$ einem Johannes-Hagiasma in dieser Gegend siehe Ousterhout, Later Churches, 241-250, bes. 242-243.

458 Dositheos, 1174/43-45; siehe Janin, Églises, 410. 
das heutige Topkapı das Pempton-Tor und das Tor zwischen den Tortürmen 59/ 60 das Romanos-Tor (Abb. 36, 37).

\subsection{Lokalisierung und Identifizierung mit der Theodosianischen Mauer verbundener Örtlichkeiten}

\subsubsection{Das Mesoteichion}

Besonders in spätbyzantinischer Zeit wird ein bestimmter Mauerabschnitt, das Mesoteichion, häufig erwähnt, das auch im Zusammenhang mit der Bezeichnung Myriandrion vorkommt. Das Wort Myriandrion begegnet in synonymer Bedeutung als Polyandrion-Tor erstmals in Chronicon Paschale mit Bezug auf die Awarenbelagerung im Jahre 626 auf. $^{459}$ Die Patria berichten über das Myriandrion-Tor bzw. das Polyandrios-Tor, das auch Koliandron ${ }^{460}$ genannt wurde, folgenderweise: ${ }^{461}$

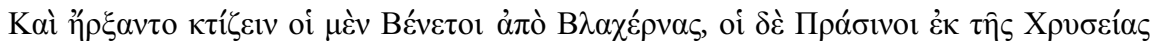

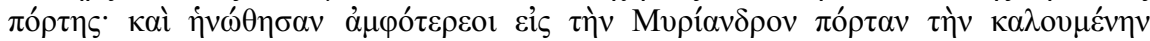

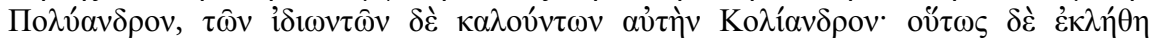

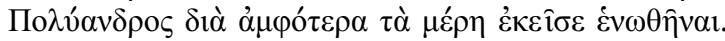

Und die Blauen begannen von den Blachernen aus zu bauen, die Grünen aber vom Goldenen Tor. Beide trafen sich am Myriandrontor, das Polyandros genannt wird, und die Leute nennen es Koliandron. Es wurde deshalb Polyandros genannt, weil sich beide Demen dort vereinigten.

Wie allgemein angenommen, bezieht sich der Name möglicherweise auf einen benachbarten Friedhof ${ }^{462}$ - entweder auf die alten Nekropolen des 4./6. Jahrhunderts im Zwingerbereich oder auf die vor der Mauer neu angelegten. ${ }^{463} \mathrm{Nur}$ als Myriandrion tritt die Ortsbezeichnung - wie gezeigt wurde - in späteren Quellen auf, zumeist im Zusammenhang mit der osmanischen Belagerung von

459 Chron. Pasch. ad ann.626, 719/9 und 720/1; englische Übersetzung: Whitby/Whitby, Chronicon, 173, 174.

460 Preger, Tor, 272, zur Entstehung des Namens Koliandros.

461 Patria II 58, 182/14-19 (die Übersetzung nach Berger, Patria, 367), vgl. III 140, 259/ 7-9. - Zur Auseinandersetzung mit diesem Bericht siehe auch Dagron, Constantinople, 356-357, und Berger, ebd., 622.

462 Vgl. Mordtmann, Esquisse, 28, Anm. 1; Meyer-Plath/Schneider, Landmauer, 66, Anm. 2; Mango, Développement, 47; Berger, Patria, 622. - Preger, Tor, 276, zweifelte daran, daß das Tor seinen Namen von einem Friedhof erhalten hatte und führte ihn gemäß den Patria auf die große Ansammlung der Menschen (Demen) zurück.

463 Vgl. Anm. 195. 
1453 und in Verbindung mit dem Mesoteichion. Aus dem Bericht des Kritobulos geht hervor: ${ }^{464}$

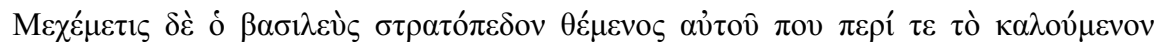

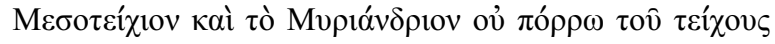

Nachdem Sultan Mehmet aber sein Lager eben dort in der Gegend des sogenannten Mesoteichion und des Myriandrion aufgeschlagen hatte, nicht weit von der Mauer

Der Autor erwähnt das Mesoteichion weiterhin in seinem Bericht über die Aufstellung der osmanischen Armee: ${ }^{465}$

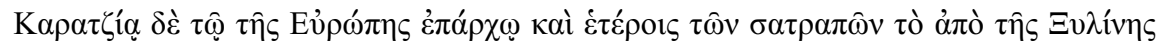

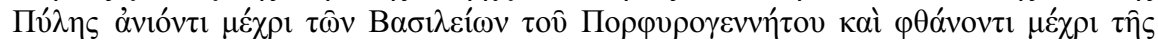

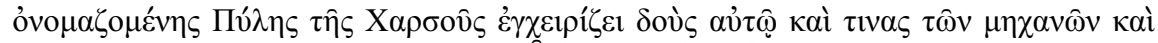

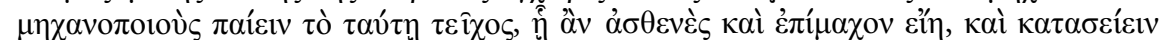

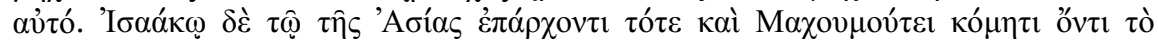

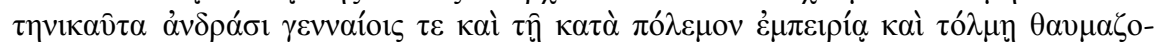

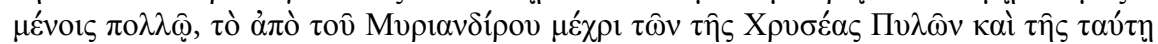

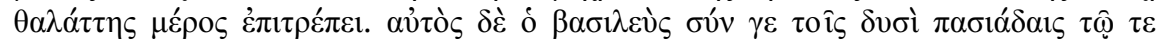

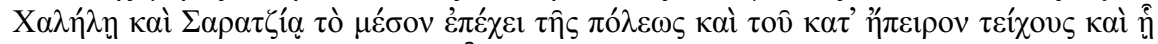

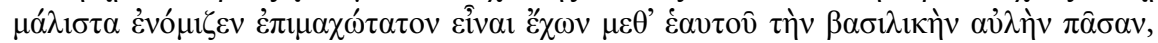

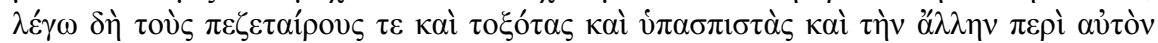

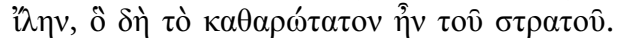

Karaca aber, dem Statthalter von Europa, und noch einigen Satrapen übertrug er [Mehmet] den Abschnitt vom Hölzernen Tor [Xyloporta] landeinwärts bis zum Palast des Porphyrogennetos [Tekfur Saray1] und bis hin zum sogenannten CharisoTor und gab ihm auch einige Geschütze und Geschützmeister, um die Mauer dort, wo sie schwach und verwundbar war, zu beschießen und sie zu zertrümmern. Ishak aber, der damals Statthalter von Asien war, und Mahmut, zu jener Zeit Komes, tapferen Männern, die wegen ihrer Kriegserfahrung und Kühnheit viel bewundert wurden, übergab er den vom Myriandrion bis zum Goldenen Tor und zum dortigen Meer reichenden Abschnitt. Der Sultan selbst aber stand mit den beiden Paschas Halil und Saruca dem mittleren Teil [Mesoteichion] der Stadt und der Landmauer gegenüber und zwar dort, wo er meinte, daß sie am schwächsten sei.

Während also Karaca Paşa und sein Armeeteil zwischen Xyloporta und Charisios-Tor die Stadt angreifen sollten und Mahmut sowie İshak Paşas die Mauerabschnitte zwischen Goldenem Tor bzw. Marmarameer und dem Myriandrion zugewiesen erhielten, nahm der Sultan selbst vor dem Mesoteichion Aufstellung. Demnach muß sich das Mesoteichion zwischen dem Charisios-Tor und dem Myriandrion erstreckt haben. Über die Ansetzung des Mesoteichion und über die Lage der Myriandrion/Polyandrion genannten Örtlichkeit herrscht seit dem 19. Jahrhundert noch Uneinigkeit, obwohl an der Identifizierung von Mevlevihanekapı mit dem Myriandrion- bzw. Polyandrion-Tor heute kein Zweifel

464 Kritobulos, 41/26-30; deutsche Übersetzung: Reinsch, Mehmet, 79.

465 Kritobulos, 42/19-33; deutsche Übersetzung: Reinsch, Mehmet, 81. 
mehr besteht (Abb. 36, 37). ${ }^{466} \mathrm{Da}$ das Charisios-Tor in der älteren Literatur mit dem Myriandrion bzw. Polyandrion gleichgesetzt und mit Edirnekapı in Verbindung gebracht wurde, galt die Strecke zwischen Edirnekapı und Topkapı als Mesoteichion. ${ }^{467}$ Erst Preger interpretierte die Aussagen der Schriftquellen dahingehend, daß sich das Mesoteichion in der Mitte der Mauern befunden haben müsse, und setzte es an der Stelle an, wo sich Mevlevihanekapı befindet, ${ }^{468}$ was später die Zustimmung von Schneider und Janin fand. ${ }^{469}$ Doch scheint die Diskussion noch immer nicht abgeschlossen zu sein. Kleis verfolgte die Mauerbreschen der Verteidigungsanlage und hielt im Begleittext zu seinem Plan die Strecke zwischen Mevlevihanekapı und Edirnekapı für die Bestimmung des Mesoteichion als am besten geeignet. ${ }^{470}$ Setton ${ }^{471}$ und Tsangadas ${ }^{472}$ sprechen von einem „middle wall.“ Tsangadas zufolge müsse das Mesoteichion bzw. Myriandrion nicht in der Nähe von Mevlevihanekapı, sondern um das sog. 4. Nebentor (das eigentliche Romanos-Tor) gesucht werden. Die letzte mir bekannte Arbeit stammt von Hanak, der das Mesoteichion wiederum zwischen Topkapı und Edirnekapı lokalisiert (Abb. 36). ${ }^{473}$

Aus dem Text des Kritobulos geht klar hervor, daß das Mesoteichion sich genau in der Mitte der Landmauer befand. Wir wissen nur nicht, was Krito-

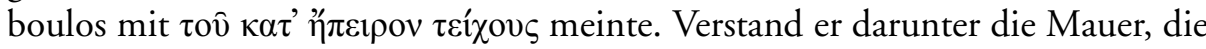
sich vom Marmarameer bis Tekfur Sarayı erstreckt, oder meinte er den gesamten Mauergürtel einschließlich der Blachernen-Mauer, also vom Ufer des Marmarameeres bis zum Goldenen Horn? Das Romanos-Tor, wo Sultan Mehmet während der Belagerung sein Zelt aufgeschlagen hatte, befindet sich einschließlich der Blachernen-Mauer genau in der Mitte der Verteidigungslinie (Abb. 37). Demnach meinte Kritobulos mit "Landmauer" den gesamten Mauergürtel. Da die Inschrift auf dem Sturz des Romanos-Tors dieses als $\pi$ óp $\tau \alpha$ $\mu \varepsilon ́ \sigma \eta$ definiert (Abb. 85), können wir sicher sein, daß nicht erst Kritobulos, sondern schon immer die Byzantiner unter dem Begriff „Landmauer" den geschlossene Mauergürtel vom Marmarameer bis zum Goldenen Horn bzw. zuerst bis zur Demetrios-Kirche ó Kaváßn verstanden haben (vgl. Ab-

466 Vgl. Anm. 352.

467 Mordtmann, Esquisse, 27-28; Van Millingen, Walls, 85; Pears, Destruction, 240; auf der MISN-Karte I ist das Mesoteichion zwischen Mevlevihanekapı und Lykos plaziert.

468 Vgl. Anm. 352.

469 Schneider, Byzanz, 84; Meyer-Plath/Schneider, Landmauer, 12 (Schneider); Janin, Constantinople, 278.

470 Kleis, Plan, 6; im Plan wurde das Mesoteichion bis zum Lykos angezeigt.

471 Setton, Papacy, 113: „The ,Mesoteichion' was apparently well to the south of the Gate of Charisios [the modern Adrianople Gate, Edirne Kap1]; at its northern end it descended into the Lycus valley at the Pempton, to which the name of S. Romanus seems to have been given by the time of the siege."

472 Tsangadas, Fortifications, 90.

473 Hanak, Mesoteikhion, 69-98, bes. 90, fig. 1. 
schnitt 2.1.1.). ${ }^{474}$ Zweifelsfrei lag der Mittelpunkt des Mesoteichion genannten Mauerabschnitts dann beim Romanos-Tor.

Um klären zu können, wie weit das Mesoteichion nach Norden und nach Süden reichte, muß der Bericht des Kritobulos noch einmal herangezogen werden: Karaca Paşa griff zwischen Xyloporta und Charisios-Tor an. Die Xyloporta lag dort, wo die Blachernen-Mauer mit der Seemauer des Goldenen Horns zusammentrifft. ${ }^{475}$ Wie oben dargelegt, muß das Charisios-Tor mit Sulukulekapı identifiziert werden. Aus der Verteilung der osmanischen Armee gewinnen wir nicht nur ein zusätzliches Indiz für diese Bestimmung, sondern auch für eine genauere Lokalisierung des nördlichen Endpunkts des Mesoteichion. Wenn das Charisios-Tor mit Edirnekapı identisch wäre und die von Karaca Paşa befehligte Einheit vom Goldenen Horn nur bis Edirnekapı Aufstellung genommen hätte, würde das bedeuten, daß der Sultan einen sehr langen Mauerabschnitt übernommen haben müßte, wobei seine Armee zudem durch den Taleinschnitt des Lykos geteilt worden wäre. Diese Möglichkeit scheidet m.E. aus zwei Gründen aus: Erstens wäre die Teilung einer Truppeneinheit in strategischer Hinsicht nicht sinnvoll gewesen, zweitens würde das Mesoteichion so weit nach Norden geschoben, daß dies mit dem Namen „Mitteltrakt“ nicht mehr zu vereinbaren wäre (Abb. 36). Wenn aber der Sultan an der Südseite des Lykos vor dem Romanos-Tor stand und das Charisios-Tor das heutige Edirnekap1 gewesen wäre, müßte man fragen, welcher Armeeteil dann in dem ca. $700 \mathrm{~m}$ langen Abschnitt zwischen Edirnekapı und Lykos gekämpft haben soll?

Das Mesoteichion lag aber genau in der Mitte der gesamten Verteidigungslinie mit dem Romanos-Tor im Zentrum (Abb. 37). Wenn meine bisherigen Überlegungen zutreffen, wonach Sulukulekapı das eigentliche CharisiosTor war, das während der Belagerung von Karaca Paşa angegriffen wurde, kann das Mesoteichion nach Norden nur bis an den Lykos (Turm 75) herangereicht haben. Zwischen Lykos und Romanos-Tor beträgt die Entfernung ca. $800 \mathrm{~m}$, nach Süden zum Mevlevihanekapı bzw. Rhesion-Tor nur ca. $600 \mathrm{~m}$. Es wäre daher zu vermuten, daß der Myriandrion genannte Abschnitt im Süden zwischen Mevlevihanekapı und Silivrikapı endete - aber näher zum Mevlevihanekapı hin. ${ }^{476}$ Karaca Paşa hatte demnach in einem Abschnitt von ca. $1800 \mathrm{~m}$ Länge anzugreifen, während İshak und Mahmut Paşas sich die mit ca. $2500 \mathrm{~m}$ längste Strecke zu teilen hatten und auf Mehmet selbst ein ebenfalls ca. $1800 \mathrm{~m}$ langer Abschnitt entfiel.

4741453 hatte man den gesamten und heute noch bestehenden Mauergürtel im Blick.

475 Siehe dazu Schneider, Mauern und Tore, 68; Effenberger, Buondelmonti, 40, Tabelle III, Nr. 1.

476 Siehe Meyer-Plath/Schneider, Landmauer, Faltpläne 1-3. 
Der Name Myriandrion kommt, wie bereits oben erwähnt, auch in weiteren Formen wie Polyandrion bzw. Koliandrion vom 7. bis zum 15. Jahrhunderts vor, im 15. Jahrhundert freilich nicht mehr in Verbindung mit einem Tor. ${ }^{477}$ Es ist daraus zu ersehen, daß der offizielle byzantinische Name des Tors „Rhesion“ lautete, wobei im Volksmund wegen der benachbarten Nekropolen die sich darauf beziehenden Namen üblicher waren. ${ }^{478}$ Dies erklärt, weshalb der Name Myriandrion in den späteren Quellen ohne Bezug auf ein Tor vorkommt.

Der Mesoteichion genannte Abschnitt der Mauer erstreckte sich also zwischen dem Lykos und dem Rhesion-Tor (Mevlevihanekapi) und hatte seinen Mittelpunkt am Romanos-Tor.

\subsubsection{Mermerkule - Das Polichnion von Ioannes V. Palaiologos}

Mermerkule befindet sich an der Südwestecke der Stadt (Abb. 36), wo die Theodosianische Landmauer und die Marmara-Seemauer zusammentreffen (Abb. 133). ${ }^{479}$ Die Anlage besteht aus einem großen Turm, einem nordöstlich davor gelegenen bastionenartigen Turm sowie einer Kurtine zwischen beiden (Abb. 43). Der auf alten Fotos noch erkennbare, mehrfach getreppte Sockel des großen Turms liegt heute unter der modernen Aufschüttung. ${ }^{480}$ Wahrscheinlich erstreckte sich dieses Areal stadteinwärts und bildete eine geschlossene Zitadelle. Während die Wehrgänge und Schießscharten auf eine militärische Funktion hinweisen, verdeutlichen besonders die architektonischen Akzentuierungen im Inneren eine Nutzung als Residenz, wobei diese einige spätere Veränderungen durch die Hinzufügung der Zisterne und die Anbringung zusätzlicher Schießscharten erfahren hatte. ${ }^{481}$

Aufgrund des in einer Nische wiederverwendeten Gesimsfragments mit dem Palaiologen-Monogramm und einem Doppelhastenmotiv (Abb. 134) sowie unter Heranziehung eines Gedichts des Ioannes Chortasmenos über den Palast des Theodoros Palaiologos Kantakuzenos identifizierte Peschlow die Anlage mit

477 Vgl. Anm. 464, 465.

478 Vgl. Mango, Développement, 47.

479 Siehe zuletzt Peschlow, Mermerkule I, 93-97; ders., Mermerkule II, 385-403; Asutay, Mermer-Kule, 270-274.

480 Dirimtekin, Marmara, Abb. 109. - Für ein aus dem 19. Jahrhundert stammendes Bild der Anlage siehe Van Millingen, Walls, gegenüber 266; Historische Fotografien, 44 (vom Meer aus aufgenommen); ein in den zwanziger Jahren des 20. Jahrhunderts aufgenommenes Foto bei Ousterhout/Başgelen, Postcards, 98, Abb. 65.

481 Der Turm wurde in der Literatur mit unterschiedlichen Funktionen in Verbindung gebracht, siehe Peschlow, Mermerkule I, 93; ders., Mermerkule II, 385-403, hat die Besonderheiten der Architektur gründlich besprochen und auf ihre nur bedingte Verteidigungsfunktion hingewiesen. 
der in diesem Gedicht erwähnten Residenz und datierte sie zwischen 1402 und 1410. ${ }^{482}$ Die ganze Erscheinung der Baugruppe, besonders das Mauerwerk und die polychrome Ausbildung der Bögen (Abb. 133), lassen keinen Zweifel daran, daß es sich um ein palaiologisches Ensemble handelt. Das genannte Gedicht des Ioannes Chortasmenos ${ }^{483}$ wurde kürzlich von der Verfasserin behandelt, mit dem Ergebnis, daß die darin erwähnte Residenz des Theodoros Palaiologos Kantakuzenos sich eindeutig auf einem hohen Hügel befand und daher mit dem unmittelbar am Meer gelegenen Mermerkule nicht gleichgesetzt werden kann. ${ }^{484}$ Bei dem erwähnten Gesimsstück mit dem Monogramm und dem Doppelhastenmotiv handelt es sich eindeutig um eine Spolie. Das Doppelhastenmotiv, das als Palaiologen-Wappen angesehen wird, ist vom 13. bis zum späten 15. Jahrhundert nachweisbar. ${ }^{485}$ Es stellt sich daher die Frage, mit welchem Auftraggeber Mermerkule in Verbindung gebracht werden kann und woher die Baumaterialien stammten.

Aus den Quellen erfahren wir, daß Kaiser Ioannes V. Palaiologos sich während der Auseinandersetzungen mit seinem Enkel Ioannes (VII.) Palaiologos

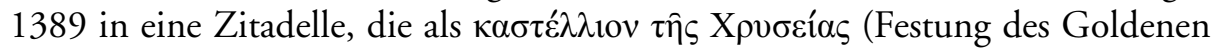
Tors) bezeichnet wurde, verschanzt hatte. ${ }^{486}$ Diese Zitadelle mußte im Jahre 1391 auf Befehl des osmanischen Sultans Yildırım Bayezıt (1389-1402) ge-

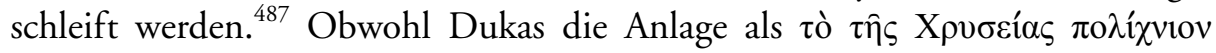
bezeichnet und als Grund für die Errichtung die ständige Bedrohung durch den osmanischen Sultan angibt, ${ }^{488}$ ist eindeutig zu erkennen, daß alle Quellen von

482 Peschlow, Mermerkule I, 94-95, zufolge war das Doppelhastenmotiv möglicherweise ein Signet der Kantakuzenenfamilie, weshalb er annahm, daß Mermerkule die Residenz eines Mitglieds aus beiden Familien gewesen sein könnte. Zum Doppelhastenmotiv siehe auch Mango/Hawkins, Additional Finds, 181; Ousterhout, Byzantine Heart, 43, Anm. 23; zum Kantakuzenen-Monogramm vgl. Franz Tinnefeld, Stammte Kaiser Johannes VI. Kantakuzenos von einer Tarchaneiotes-Linie ab?, in: Byzantinoslavica 56,1 (1995) $201-$ 208, mit Abb. - Vgl. Anm. 485.

483 Zum Gedicht siehe Hunger, Chortasmenos, 190-191.

484 Asutay, Mermer-Kule, 270-274.

485 Das Doppelhastenmotiv begegnet bereits auf Münzen Andronikos' II. Palaiologos; siehe dazu Antigoni Tzitzibassi, Palaeologan monogramms on sculptures from Thessaloniki, in: Museum of Byzantine Culture Thessaloniki 12 (2005) 92-97; weitere Beispiele für die Verbindung von Palaiologenmonogramm und Doppelhastenmotiv, ebd. Abb. 2, 3, 6, $7-10$.

486 Schreiner, Kleinchroniken, I, 68-69, Nr.7, \$21-23; II, 340-341; III, 24-25, Nr.7, \$ 21-23. - Zu den historischen Ereignissen siehe Barker, Manuel II, 2-83; Majeska, Travelers, 408-415; Reinert, Palaiologoi, 289-365; vgl. Mango, The Date, 383.

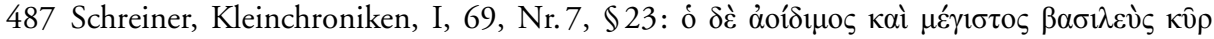

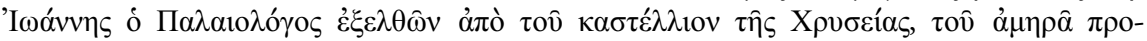

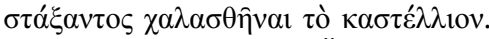

488 Dukas, 77/5; englische Übersetzung: Magoulias, Doukas, 82. 
der gleichen Anlage sprechen. Dukas gibt weiterhin Informationen über die Herkunft des Baumaterials und über die Lage der Zitadelle: ${ }^{489}$

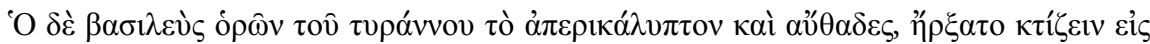

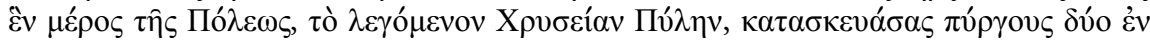

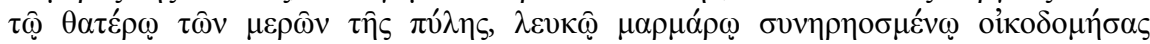

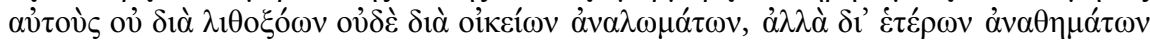

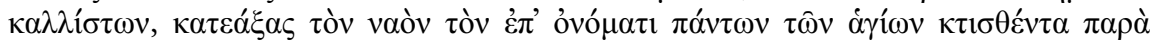

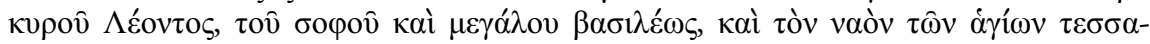

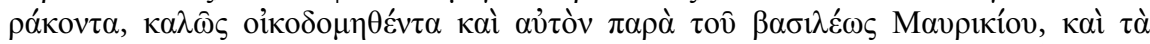

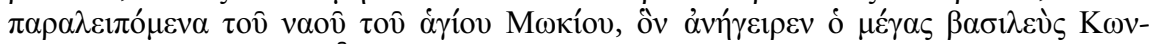

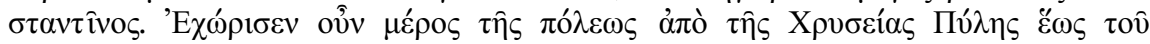

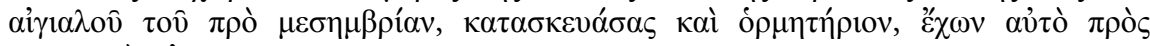

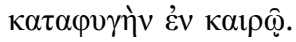

Als der Kaiser die Frechheit und Anmaßung des Tyrannen [Yıldırım Bayezıt] sah, ließ er an der einen Seite der Stadt, am sogenannten Goldenen Tor, zwei Türme an den beiden Seiten des Tors (oder an einer von den beiden Seiten) errichten, aus weißem Marmor künstlich gefertigt. Er erbaute diese aber weder durch Steinmetze noch mit eigenem Geld, sondern aus verschiedenen schönen geweihten Gebäuden. Er riß die Allerheiligenkirche ab, die von Kyr Leon, dem weisen und großen Kaiser errichtet worden war, und die Kirche der Vierzig Märtyrer, die durch Kaiser Maurikios auch diesen schön erbaut worden war, und die Reste der Kirche des Heiligen Mokios, die der große Kaiser Konstantin aufgeführt hatte. Abgesondert von der Stadt errichtete er vom Goldenen Tor bis zum Strand nach Süden hin einen befestigten Stützpunkt als gelegentlichen Fluchtort für sich.

Yıldırım Bayezıt, in dessen Geiselhaft sich Manuel zu dieser Zeit befand, drohte Ioannes mit der Blendung seines Sohnes, wenn er das Polichnion am Goldenen Tor nicht sofort abreißen lasse, weshalb Ioannes die Festung oder wenigstens Teile davon schleifen mußte. ${ }^{490}$ Dukas zufolge erstreckte sich dieses Polichnion also vom Goldenen Tor bis zum Marmarameer. Ignatij von Smolensk bestätigt die Aussage von Dukas: ${ }^{491}$

Then Manuel came to Constantinople for the third time, [this time] with Romans whose emblem was a white cross seen of their chests; they contended bravely with their enemies. He penetrated the limen, that is to say, the harbor, and entered the castle where his father was. (A stone wall with high towers extended to the water's edge so that the enemy was unable to reach him [the old emperor] either by sea or by land).

Aus den Kleinchroniken erfahren wir ebenfalls - wenn nur auch indirekt -, daß dieses Kastellion unmittelbar am Meer lag und Manuel, der während der

489 Dukas, 75/21-31; englische Übersetzung: Magoulias, Doukas, 81-82. - Vgl. Mango,

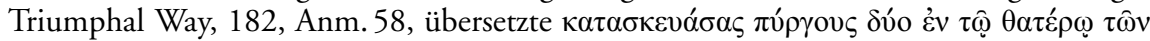
$\mu \varepsilon \rho \hat{\omega} v \tau \eta \hat{\varsigma} \varsigma u^{\prime} \lambda \eta \varsigma$, : "To that end he built two towers on either side [or on one of the two sides]."

490 Dukas, 77/4-13; englische Übersetzung: Magoulias, Doukas, 82.

491 Majeska, Travelers, 102. - Sämtliche Klammern stammen von Majeska. 
Auseinandersetzungen mit Ioannes VII. seinem belagerten Vater zu Hilfe kam, die Stadt bzw. das Kastellion/Polichnion über den hier integrierten Hafen erreichte und wieder verließ. Aus allen Berichten geht darüber hinaus hervor, daß das Kastellion bzw. Polichnion in unmittelbarer Nachbarschaft zum Goldenen Tor lag. So berichtet der anonyme russische Pilger (1389/91): ${ }^{492}$

You go far from there [von den Gerechten Richtern] toward the imperial castle of Kalojan. There are gates before [you come to] the imperial castle; on one side of these gates the Crucifixion is painted, while on the other side is the Last Judgement. Going through these gates you come to the Great Sea and the Peribleptos Monastery.

Daraus ist wiederum zu ersehen, daß die Anlage sich südwestlich der Peribleptos-Kirche befand. Über die genauere Lage des Polichnion Ioannes' V. Palaiologos wurden bisher verschiedene Meinungen geäußert. Es wurde teils zwischen Haupt- und Vormauer der Landmauer oder zwischen Marmaraufer und Goldenem Tor gesucht, ${ }^{493}$ teils mit dem Goldenen Tor bzw. mit dem Vorwerk des Goldenen Tors in Verbindung gebracht. ${ }^{494}$ Erstaunlicherweise wurde Mermerkule, das sowohl von seiner Lage her als auch auf Grund seiner Architektur und der Baumaterialien ein Kandidat für das Polichnion sein könnte, in dieser Hinsicht fast nie berücksichtigt. ${ }^{495}$ Im folgenden sollen zunächst die aus den Quellen gewonnenen Daten aufgelistet werden:

1. Das Polichnion befand sich in unmittelbarer Nachbarschaft zum Goldenen Tor und erstreckte sich bis zum Ufer des Marmarameers.

2. Ein Hafen war dem Polichnion angeschlossen.

3. Es wurde im Jahre 1391 auf das Befehl Bayezits I. abgerissen.

4. Es war aus Spolien der Allerheiligen-Kirche, ${ }^{496}$ der Vierzig-Märtyrer-Kirche $^{497}$ und der Mokios-Kirche ${ }^{498}$ errichtet.

Der nördliche Abschluß vom Mermerkule ist nicht bekannt. Auf Grund eines von Kurtine 2/3 der Landmauer an der Stadtseite ausgehenden Mauerrests nahm Peschlow an, daß diese Mauer mit der von der kleinen Bastion der

492 Majeska, Travelers, 144-145 (erste Eckklammer von Majeska, zweite von Verfn.); zur Datierung des Berichts in das Jahr 1389/91 siehe Mango, The Date, 380-385.

493 Reinert, Palaiologi, 303: „This complex evidently bounded and fortified the area between the inner and outer land walls, extending from the Golden Gate harbor up to the towers of the Golden Gate."

494 Vgl. Anm. 263.

495 Lediglich Berger, Mermer Kule, 400, notierte in seinem auf Türkisch verfaßten Enzyklopädiebeitrag, daß Mermerkule vielleicht mit dem Polichnion Ioannes' V. Palaiologos in Verbindung gebracht werden könnte.

496 Janin, Eglises, 389-390.

$497 \mathrm{Zu}$ allen Kirchen mit diesem Namen siehe Janin, Eglises, 482-486.

498 Janin, Eglises, 354-358. 
Mermerkule-Anlage sich nach Westen erstreckenden Mauer zusammentraf und diese gemeinsam die nördliche Grenze der Zitadelle markiert haben könnten (Abb. 43). ${ }^{499}$ Der heute größtenteils verschüttete Mauerrest an der Kurtine wurde von Ahunbay/Ahunbay in die palaiologische Zeit datiert, womit Peschlows Ansicht eine zusätzliche Unterstützung fand. ${ }^{500}$ Ganz gleich nun, ob dieser Mauerrest palaiologisch ist oder nicht: Ein Blick auf die Pläne zeigt, daß er keineswegs auf die von der Nordwestseite der Bastion ausgehende Mauer zuläuft, was auch Peschlow zugibt. ${ }^{501}$ Die von Kurtine 2/3 ausgehende Mauer kann durchaus eine andere Funktion gehabt haben, womit sich eine pauschale Rekonstruktion des Nordabschlusses der Anlage verbietet. Peschlow will mit seiner Rekonstruktion eine Zitadelle in der Art gewinnen, wie sie mehrfach auf dem Balkangebiet vorkommen. Diese Anlagen bilden öfter ein Dreieck, dessen Spitze, wo sich der Wohnturm befindet, zusätzlich befestigt war. ${ }^{502}$

Für die Frage nach Lage und Ausdehnung des Polichnion wurden bisher niemals die Bildquellen berücksichtigt. Besonders zwei Kopien der İstanbulKarte von Piri Reis im Kitâb-i Bahriye (Buch der Seefahrt) scheinen in dieser Hinsicht von Bedeutung zu sein. Auf der Londoner (Abb. 47) und der Berliner Kopie (Abb. 48) erscheint jeweils an der Südwestecke der Stadt ein befestigtes Areal, an dessen äußerster Ecke Mermerkule steht, wobei der ummauerte Bezirk auf der Londoner Karte als „Bucakbağ ${ }_{1}$ “ (Eckgarten) beschriftet ist (siehe Exkurs II). Dieses befestigte Areal reicht nach Norden bis zum Goldenen Tor und nach Osten fast bis zur Studios-Kirche bzw. bis zu Narlıkapı. Diese Lage entspricht der Aussage des anonymen russischen Pilgers, der die Zitadelle indirekt südwestlich der Peribleptos-Kirche lokalisierte. Ob die noch auf dem Plan von Ayverdi eingezeichneten Turmreste etwas damit zu tun hatten, kann nicht mehr beantwortet werden. ${ }^{503}$

Die beiden Karten von Piri Reis zeigen das Areal noch in einem intakten Zustand. Wir wissen aber nicht, ob der Zeichner die Anlage nur vollständig wiedergeben wollte, oder ob sie bereits in byzantinischer Zeit, d.h. nach dem Abzug von Yıldırım Bayezıt bzw. erst in osmanischer Zeit wiederhergestellt worden war. Ohnehin ist unklar, in welchem Umfang das Polichnion abgerissen

499 Peschlow, Mermerkule II, 393.

500 Ahunbay/Ahunbay, Land Walls, 233: „The regular alternation of brick and squared block courses suggest Palaiologan style. A similar fabric was used in the upper level of Mermer Kule (the Marble Tower), which has been tentatively identified with a Palaiologan princely residence."

501 Peschlow, Mermerkule II, 393: „Selbst wenn diese Mauerung [Kurtine 2/3] und der von dem kleinen SO-Turm abknickende Maueransatz nicht aufeinander zulaufen und sich daher keine geradlinige Verbindung rekonstruieren läßt, wäre es möglich, daß beide Reste zu dem ursprünglichen nördlichen Abschluß der Residenz gehörten.“

502 Vgl. die Beispiele bei Nešković, Smederevo, 208-211.

503 Ayverdi, İstanbul Haritası, Blatt E 1. 
wurde. Auf mehreren Buondelmonti-Ansichten von Konstantinopel erscheint an der Stelle, wo Mermerkule liegt, ein Hafen mit einer Beischrift, wonach diese Anlage auf Befehl „der Türken“ - gemeint ist Yıldırım Bayezıt - abgerissen werden mußte (Abb. 44) ${ }^{504}$ Die dargestellte Hafenanlage kann keinen anderen Hafen meinen als den Hafen des Polichnion, den Manuel II. während der Auseinandersetzungen zwischen seinem Vater und seinem Neffen öfter benutzt hatte. Seine Lage weist wiederum eindeutig in die Nachbarschaft von Mermerkule.

Bertrandon de la Brocquière berichtet für die Jahre 1432/33 über zwei Palastruinen folgenderweise: ${ }^{505}$

Traditionsgemäß baute man an beiden Enden der Stadt [Stadtmauern] je eine starke und schöne Palastanlage. Diese Palastanlagen sind mit ihren Umfassungsmauern und Resten heute immer noch zu erkennen. Soweit ich gehört habe, sind diese [beiden] Paläste vom byzantinischen Kaiser abgerissen worden, da ihm die Gefahr drohte, vom türkischen Sultan festgenommen zu werden. ... Der Sultan hat [beim Abriß der Bauten] gedacht, daß er dadurch die Stadt einfacher erobern könnte. Der Kaiser akzeptierte seine Forderung und ließ diese Paläste abreisen, wie man heute noch anhand der Ruinen erkennen kann.

Bertrandon de la Brocquière kann mit den Palästen „an beiden Enden der Stadt“ nur Mermerkule im Süden und den Blachernen-Palast im Norden gemeint haben, für deren ruinösen Zustand er - wenn auch indirekt - Yıldırım Bayezıt verantwortlich machte. Damit wird nicht nur erwiesen, daß das Polichnion 1432/33 immer noch als Ruine dastand, sondern es wird ein weiteres Argument gewonnen, daß nur Mermerkule mit dem Polichnion identisch sein kann.

Nach Dukas wurde das Polichnion aus Spolien der Allerheiligen-Kirche, der Vierzig-Märtyrer-Kirche und der Mokios-Kirche erbaut. Die Mokios-Kirche wurde im 4. Jahrhundert errichtet und durch Justin I. (518-527), Justinian I. (527-565) und Basileios I. (867-886) repariert. Nach 1200 wird die Kirche in den Quellen nicht mehr erwähnt. Aufgrund ihrer Bau- und Reparaturdaten ist zu erwarten, daß sich in der Kirche sowohl früh- als auch mittelbyzantinische Bauskulpturen befanden. Ein an der Marmara-Seemauer in der Nähe von Samatya (Turm 82) wiederverwendeter Gesimsrest (Abb. 211) gibt eine Vorstellung von der Bauskulptur dieser Kirche und zugleich von der Reparaturtätigkeit Ioannes' V. Palaiologos. Dieses in das 6. Jahrhundert datierbare Stück mit Birnen- und Rankenmotiv findet seine einzige Parallele in einem in der Nähe der Mokios-Zisterne (in der Ali Şir Nevai Sokak) im Jahre 1993 von Ferudun Özgümüş entdecktes und als Bauteil der Mokios-Kirche identifiziertes Kapi-

504 Zuerst von Müller-Wiener, Häfen, 10, Anm.35, erkannt, wenn auch mit Fragezeichen versehen. - Die vor dem ersten Turm der Theodosianischen Landmauer liegende Mole gehörte sicher zu diesem Hafen, vgl. Meyer-Plath/Schneider, Landmauer, 37-39, Taf. 25a.

505 Broquière, Voyage, 97; ich gebe hier nur die Übersetzung. 
tell. ${ }^{506}$ Es zeigt uns zum einen, daß die Bautätigkeit des Kaisers Ioannes V. Palaiologos sich bis zur Seemauer erstreckte und die aus der Mokios-Kirche genommenen Materialien nicht nur zum Bau des Polichnion wiederverwendet wurden. Es vermittelt ferner, daß die Aussage des Dukas den Tatsachen entspricht. Die Allerheiligen-Kirche wurde zur Zeit Leons VI. (886-912) mit Spolien aus der Stephanos-Kirche am Sigma ${ }^{507}$ erbaut und stürzte infolge des schweren Erdbebens vom Jahre 1296 ein. ${ }^{508}$ Hier ist also ebenfalls früh- und mittelbyzantinische Bauplastik zu erwarten. Die von Dukas erwähnte Kirche der Vierzig Märtyrer ist, wie Guberti Bassett betont hat, ${ }^{509}$ nicht sicher zu bestimmen, da es in Konstantinopel mehrere Kirchen mit diesem Patrozinium gab. ${ }^{510}$

Peschlow hat darauf hingewiesen, daß in der Anlage von Mermerkule mehrere Gesimse als Spolien verwendet wurden, auf denen Lotus-PalmettenReihen bzw. Lotus-Wellenranken-Palmetten angebracht sind (Abb. 135). ${ }^{511} \mathrm{Ihm}$ zufolge stammen diese Stücke wahrscheinlich aus einer mittelbyzantinischen Kreuzkuppelkirche. ${ }^{512}$ Er datierte die Gesimse zwar in das 11./12. Jahrhundert, vermerkte dazu aber einschränkend: ${ }^{513}$

Vorarbeiten zur mittel- und spätbyzantinischen Bauornamentik Konstantinopels fehlen, daher kann unsere Datierung auch nur vage sein. Schon der Vergleich mit der Ausbildung und dem Schnitt der Palmetten führt hier zu keinem brauchbaren Ergebnis. Zu betrachten wären dafür z. B. Gesimse in der Nordkirche des Konstantinos Lips Klosters.

Die Nordkirche des Konstantinos-Lips-Klosters stammt wie die AllerheiligenKirche aus der Regierungszeit des Kaisers Leon VI. ${ }^{514}$ weshalb die Frage berechtigt ist, ob die Gesimse aus der zerstörten Allerheiligen-Kirche hierher verbracht worden sein könnten. Neben diesen mittelbyzantinischen Bauskulpturen im Inneren wurde der gesamte untere Turm bis zur Höhe des ersten

506 Der Autor hat dieses Kapitell bereits 1994 in seiner Dissertation (Özgümüş, Tapınaklar, 275 und 279) erwähnt und im Rahmen eines 1995 publizierten Artikels im Zusammenhang mit der Mokios-Kirche behandelt; siehe Özgümüş, Mokios, 46-49. Das Stück findet hin und wieder Erwähnung, ohne jedoch Özgümüş zu zitieren.

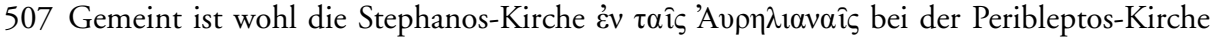
bzw. bei dem dort lokalisierten Sigma; vgl. Berger, Patria, 361-363; ders., Tauros, $17-$ 28. - Vgl. Anm. 104.

508 Janin, Églises, 389-390; Downey, All Saints, 301-305; Kidonopoulos, Bauten, 116 118. - Zum Erdbeben von 1296 siehe Evangelatu-Notara, Seismoi, 36-40.

509 Guberti Bassett, Golden Gate, 120.

510 Vgl. Anm. 497.

511 Peschlow, Mermerkule II, 390-392.

512 Peschlow, Mermerkule II, 392.

513 Peschlow, Mermerkule II, 392, Anm. 13. - Zur Datierungsproblematik der Gesimse mit Lotus-Palmetten-Fries siehe auch Hjort, Sculpture, 232-234.

514 Janin, Eglises, 307-310. 
Gesimsbandes aus wiederverwendeten kannelierten Marmorpfeilern errichtet, für die Parallelen mehrfach aus dem 5. Jahrhundert bekannt sind (Abb. 132). ${ }^{515}$ Daneben wurden undefinierbare und zum Teil noch nicht fertiggestellte Werkstücke verbaut.

Wenn man alle Indizien zusammennimmt, ergibt sich folgendes Bild: Mermerkule ist die einzige Festungsanlage, die mit dem Polichnion des Kaisers Ioannes V. Palaiologos in Verbindung gebracht werden kann. Der von der nördlichen Bastion ausgehende Mauerrest markiert vermutlich nur die Grenze des Wohnorts der kaiserlichen Familie. Die Funktion der von Kurtine 2/3 in Richtung Osten abzweigende Mauer bleibt vorerst im Dunkeln. Das gesamte Areal muß jedoch sehr groß gewesen sein und bis zum Goldenen Tor gereicht haben, da es außer dem Wohnbereich des Kaisers die Unterkünfte der Soldaten und Tiere sowie die notwendigen Versorgungseinrichtungen und einen Hafen aufzunehmen hatte.

Obwohl Dukas die Errichtung des Polichnion mit der Auseinandersetzung zwischen Ioannes V. Palaiologos und Yildırım Bayezıt in Verbindung bringt, muß die Anlage schon früher als Zufluchtsort erbaut worden sein. Fast alle Quellen reden davon, daß die Festung auf Befehl des Sultans geschleift werden mußte. Es scheint, daß nicht die Existenz des Polichnion, sondern der militärische Ausbau besonders von Mermerkule (Zisterne, zusätzliche Schießscharten) erst den Zorn des Sultans hervorgerufen hatte.

515 Für vergleichbare Beispiele siehe Naumann/Belting, Euphemia, 43, und Frratlı, Sculpture, 62, Nr. 104, Taf.40, Abb. 104. 